\title{
Regulatory Impact Assessment and EU Law Transposition in the Western Balkans
}

A comparative analysis of the practice of ex ante assessment of regulatory proposals and EU law transposition

\section{SIGMA Paper No. 61}

\author{
Authorised for publication by Ms. Elsa Pilichowski, Director, \\ Public Governance Directorate, OECD
}

This document has been produced with the financial assistance of the European Union (EU). It should not be reported as representing the official views of the EU, the OECD or its member countries, or of partners participating in the SIGMA Programme. The opinions expressed and arguments employed are those of the authors.

This document, as well as any data and any map included herein, are without prejudice to the status of or sovereignty over any territory, to the delimitation of international frontiers and boundaries and to the name of any territory, city or area.

(c) OECD 2021 - The use of this material, whether digital or print, is governed by the Terms and Conditions to be found on the OECD website page http://www.oecd.org/termsandconditions. 


\section{Table of contents}

Executive summary and key findings

\section{Chapter 1. Principles and tools for evidence-based policy making and EU law} transposition

1.1. Government intervention and RIA as a tool for ex ante analysis $\quad 10$

1.1.1. Why do governments have to intervene? 10

1.1.2. Regulatory impact assessment (RIA) as a tool to support evidence-based policy making 13

1.1.3. RIA as a process supporting the policy cycle 15

1.2. Using analysis and evidence to inform EU accession planning and legal harmonisation $\quad 18$

1.2.1. EU accession process and the main phases of legal harmonisation 18

1.2.2. Use of RIA and analysis in EU accession planning, negotiations and transposition in the

Western Balkans

Chapter 2. A comparative review of the institutional and regulatory frameworks of RIA and EU law harmonisation in the Western Balkans

2.1. Comparative analysis of the RIA systems in the WB administrations 28

2.1.1. Regulatory and methodological framework enabling RIA 28

2.1.2. Scope and type of RIA applied 32

2.1.3. Quality requirements for RIA analysis 36

2.1.4. Organisation of the RIA process in ministries 40

2.1.5. Central management, support and capacity building for RIA 43

2.1.6. Oversight and quality control of RIA 46

2.1.7. Openness and transparency of the RIA process 49

2.1.8. Monitoring, evaluation and continuous development of the RIA system 52

2.2. Use of RIA and analysis in the planning and implementation of EU legal harmonisation in the Western Balkans

2.2.1. Use of costing and RIA in planning EU legal harmonisation 55

2.2.2. Methodological requirements for use of RIA during EU law transposition 58

\section{Chapter 3. Practice and quality of RIA implementation and EU law transposition 62}

3.1. Use of RIA in legislative planning and EU law transposition in the WB administrations, 2017-2019

3.2. Quality of RIA: review of the process and analysis 68

3.2.1. Quality of preparatory process of individual RIA samples 68

3.2.2. Quality of analysis in RIA samples 
Annex A. List of individual RIA reports analysed 87

The SIGMA Programme 90

\section{Tables}

Table 2.1. Regulatory framework enabling RIA in the WB administrations 30

Table 2.2. Main methodological and guidance documents for RIA

Table 2.3. Formal requirements for conducting ex ante impact assessment on different types of regulatory instruments

Table 2 4. Examples of exceptions of certain legislative measures from RIA requirement

Table 2.5. Requirements for options identification and use of options appraisal techniques 38

Table 2.6. Selected impact and specific tests expected to be considered in RIA, based on existing

methodologies

Table 2.8. Specialised training on RIA $\quad 45$

Table 2.9. RIA oversight and quality control 48

Table 2.10. Transparency and openness of the RIA system 51

Table 2.11. Strategic planning of RIA reforms in the Western Balkans 53

Table 2.12. Methodological and procedural requirements for using costing and RIA during preparation of the national plans of EU legal harmonisation

Table 2.13. Procedural requirements and tools used for preparing regulatory measures transposing EU law 59

Table 3.1. Legislative planning and RIA activities from 2017-2019 64

Table 3.2. Staff resources allocated for quality check of draft RIA reports $\quad 65$

Table 3.3. Quality of government planning for EU law transposition $\quad 65$

Table 3.4. Implementation of EU legislative commitment arising from El in 2017-2019 67

Table 3.5. Consistency in following the requirements and standards of the RIA process and methodology 69

Table 3.6. Quality of analysis and discussion of selected sections of RIA (all administrations) 75

\section{Figures}

Figure 1.1. Main categories of government intervention 11

Figure 1.2. Mapping the choice of instruments to achieve policy goals $\quad 12$

Figure 1.3. A typical policy cycle and RIA development phases 16

Figure 1.4. Use of RIA and analysis at different stages of the EU accession planning, negotiation and

transposition process

\section{Boxes}

Box 1.1. The 2012 OECD Recommendation on Regulatory and Policy Governance - Principle 4

Box 1.2. EU 'Better Regulation' and impact assessments 15

Box 1.3. The OECD Best Practice Principles on Regulatory Impact Assessment 17

Box 1.4. The SIGMA Principles of Public Administration - Reinforcing key requirements and standards for EU integration and evidence-based policy making 18

Box 1.5. EU acquis and the main type of EU legal instruments for transposition 19

Box 1.6. Preparation and implementation of EU law transposition in the Netherlands 20

Box 1.7. Use of impact analysis to inform EU law transposition: Latvia 21

Box 1.8. Transposition practices to be avoided $\quad 25$

Box 1.9. Legal methods for transposing EU law 26 


\section{Executive summary and key findings}

\section{Executive summary}

The COVID-19 pandemic and the ensuing debate about the effectiveness of the policy response clearly demonstrates the importance of the role that governments play in our lives. Whether it is protecting public health, providing essential public services or controlling the spread of the virus through temporary restrictions and rules, governments have to act quickly to ensure the security, safety and prosperity of their citizens. The experience illustrates how regulation is a critical instrument to help governments achieve their policies and goals.

At the same time, if they are not prepared and designed well, regulatory measures and policies can create unnecessary burdens and costs for the economy, businesses and citizens, and undercut efficiency in achieving policy goals. Countries that have effective systems and tools of regulatory policy management, such as ex ante regulatory impact assessment (RIA), are likely to be in a better position to manage risks and achieve better regulatory policy outcomes.

RIA is an internationally recognised tool and a process that can help improve the quality of policy making. International experience suggests that, if applied consistently and fully, it can improve the quality of policies and give more legitimacy to government policy intervention, through increased transparency and a strong evidence base. If applied early in the process, RIA systems can also help provide essential methodology and an analytical framework for better prioritisation and planning of government legislative activities, including those arising from EU integration commitments.

Today, an increasing proportion of the national regulations of EU Member States originates at EU level. The same is true for candidate and potential candidate countries, including six administrations ${ }^{1}$ of the Western Balkans (WB) region, which aspire to closer integration and eventually, full EU membership. Understanding the full potential impacts, risks and consequences of EU-originating regulations can help these administrations achieve better policy outcomes in the longer term and advance in the EU integration process.

The potential benefits of ex ante RIA in legislative drafting and the EU transposition process have not yet been fully realised in the accession countries of the WB region, for which this is especially relevant. All WB administrations have ambitious EU integration programmes, and tight deadlines are often set for the development and adoption of a large number of new regulatory proposals to transpose the EU acquis. A

\footnotetext{
${ }^{1}$ Albania, Bosnia and Herzegovina, Kosovo*, Montenegro, Republic of North Macedonia and Serbia.

* This designation is without prejudice to positions on status and is in line with United Nations Security Council Resolution 1244/99 and the Advisory Opinion of the International Court of Justice on Kosovo's declaration of independence.
} 
mistaken view seems to prevail among officials that ex ante analysis of impacts of new regulations stemming from the EU accession process is not necessary, given the strong political-level commitment to move forward with EU integration processes. This creates the risk that countries fail to carry out systematic analysis supporting the implementation of EU transposition cases. As a result, too many sub-optimal regulations may be introduced, reducing the effectiveness and impact of new policies.

Systems for ex ante RIA have been formally established in all WB administrations, but they are not fully functioning in several administrations, and the benefits, in terms of better regulatory quality outcomes, have yet to be realised. RIA is not yet fully recognised within the WB administrations as an essential tool that can help improve the quality of legislation, minimise risks and costs and help achieve greater benefits. Instead, it is often seen as an administrative task that must be completed to secure government approval of legislative or regulatory packages. The RIA systems are almost exclusively focused on the analysis of regulations introduced through primary legislation, which means that secondary legislation is not covered and there is a lack of overall control of the flow of new regulations, including those arising from the EU.

The average quality of individual RIA studies produced in the region is not high and often lacks strong analysis and evidence to support policy recommendations. Alternatives to regulation are considered, but they appear to be the result of formal requirements set by national regulations rather than a genuine attempt by officials to search for and apply non-regulatory solutions to policy problems.

Overall, most countries lack a systematic approach to better regulation and regulatory policy management. RIA systems also lack openness and transparency in most administrations.

Strengthening RIA implementation in the region requires regular review and monitoring of the functioning of the system and its results, to address shortcomings and inefficiencies. Monitoring of the national RIA systems in the region is primarily carried out within the existing frameworks of public administration reform strategies. The OECD RIA Best Practice Principles', particularly those related to ensuring political commitment and buy-in, if they have the right system design, capacity development and accountability, can serve as guiding benchmarks for future reforms in this area.

\section{Key findings}

Formal rules and methodologies to enable the use of RIA in lawmaking, including in EU law transposition, are generally established in all WB administrations, but their implementation is inconsistent and, the overall quality of RIAs produced in the region is still too weak. As a result, the full benefits of RIA, as an ex ante tool to achieve evidence-based decision making and successful and effective EU transposition, have not been realised. Weaknesses and gaps exist in RIA systems in all administrations, and the regulatory framework is incomplete in Bosnia and Herzegovina (BiH), which have yet to establish the necessary processes for enabling full RIA implementation. Serbia, Republic of North Macedonia (hereafter, 'North Macedonia'), Montenegro and Kosovo have integrated RIA in their systems and have the longest experience in the region in conducting ex ante analysis of policies. But even these administrations face challenges, in terms of both methodology and process and the analytical quality of RIAs. Albania started RIA implementation relatively late, only in 2019. It has so far, however, demonstrated good initial results in ensuring consistency of analysis across RIAs produced by different ministries.

A significant proportion of regulations introduced through secondary legislation does not undergo systematic regulatory oversight or assessment of impact and risks in most of the WB administrations. RIA models applied in several WB administrations primarily focus on assessing and analysing regulatory proposals introduced through primary legislation. Only Serbia and Montenegro implement RIA for secondary legislation. While a similar requirement formally exists in $\mathrm{BiH}$ and Kosovo, they have not yet fully operationalised and implemented ex ante assessment of secondary legislation. Systematic, full scrutiny of secondary legislation in $\mathrm{BiH}$ administrations is also in question, because the RIA system is not yet fully established. A significant proportion of new regulations introduced through 
secondary legislation in the region does not undergo adequate preparation or oversight before approval. Often, it is the secondary legislation that creates the most significant regulatory impacts. It is also during the development of secondary legislation that the full impact, on society, businesses and the state budget, become evident. Not having a systematic process for ex ante assessment of all regulations generated through sub-legislative acts thus creates further risks for the WB administrations.

RIA rules and methodologies of the WB administrations apply equally to regulatory measures arising from EU accession commitments. However, a large number of EU accession-related regulatory proposals do not undergo systematic ex ante oversight, and the level of analysis is in general weaker than those conducted for measures originating domestically. This was also confirmed by a review of several sample RIA reports. One contributing factor could be the additional pressure to adopt EU transposition measures on a priority basis, often within tight and unrealistic deadlines, to demonstrate a high-level national commitment to and readiness for full EU integration. Additionally, since the scope of RIA mainly covers primary legislation, as noted earlier, a significant proportion of EU-originating regulations introduced through secondary legislation is not being systematically analysed in most administrations. This raises further risks for the implementation and enforcement of a large body of EU-originating regulations that have to be achieved through the adoption of numerous bylaws and statutory guidelines. Systematic and consistent analysis of all regulatory proposals arising from the EU integration commitments can illuminate the impacts and risks involved and help to reduce unnecessary administrative burdens and costs.

RIA process and methodologies are not being systematically used to inform the preparation and planning of work at all stages of the EU legal harmonisation process, including transposition planning and the preparation of negotiation positions. The EU accession process is thus not benefiting from systematic assessment of regulatory impacts of EU-originating measures at early stages to achieve better prioritisation, sequencing and realistic planning. Moreover, the quality of EU transposition plans of all WB administrations, particularly costing, can in general be considered weak. Overall, a weak analysis of impacts of EU-originating legislation during legal transposition and legal drafting phases can be expected to lead to problems with implementation and enforcement.

RIA is prepared and completed relatively late in the policy-making process in almost all administrations, limiting its possible impact and benefits. This usually happens only after the government makes a firm political decision to intervene through regulations and after including and approving the measures in the annual government legislative plans. While there are no legal constraints on starting RIA work earlier, the ministries' limited resources and overall weak capacity for planning and preparatory work do not allow for initiating RIA in the early stages of the policy-making process, even for major regulatory proposals which are likely to have significant impact. RIA is not seen as a continuing process that needs to follow all steps of the policy planning and policy-making cycle and be updated regularly as new evidence emerges. The OECD RIA Best Practice Principles" state that "it is only if RIA is commenced at an early stage of policy development that there is any real possibility of it being adopted as an integral part of the policy process, rather than as a separate, procedurally-based requirement which takes on the character of an ex post rationalisation of the policy choice already made" (OECD, 2020).

Alternatives to regulation are not systematically considered by WB administrations contemplating government intervention to address policy problems. This is largely because RIA in the WB administrations is directly linked with the governments' legislative plans. There is a pervasive lack of appreciation of the advantages of considering alternative options, such as reduced costs and benefits for businesses. The full benefits of RIA and the analytical and appraisal techniques applied in the analysis cannot be realised if administrations do not genuinely consider alternative and non-regulatory options.

RIA requirements and methodologies adopted in the region set very high formal standards and requirements for analysis and regulatory oversight, which are not applied consistently and fully in practice. The quality of analysis of RIAs, as confirmed by the review of a sample of 50 RIAs, is weak, in particular with respect to cost-benefit analysis and the quantification and monetisation of the impact on 
business, the economy and society. The influence of RIA on the quality of policy making and EU transposition work thus remains below its potential. None of the 50 RIA samples analysed used cost-benefit analysis or cost-effectiveness analysis to analyse impacts, even though this is recommended in the relevant methodology. This may point to a lack of analytical capacity in WB administrations, given that regular training in applying these methodologies is limited.

RIA methodologies applied in the WB region acknowledge the need to be proportionate in analysing regulatory proposals, but the systems do not have the effective processes, criteria and filtering mechanisms to enforce this rule fully and consistently. Both primary and secondary legislation should pass through effective filtering and triage mechanisms to ensure that the level of analysis is proportionate to the anticipated benefits. The lack of effective systems and processes to identify and focus on the most significant regulatory proposals, to allow for in-depth analysis of such proposals, is one of the bottlenecks of successful implementation of RIA in all administrations.

While qualitative discussion of various impacts does take place in practice in RIAs produced by most administrations, quantification and monetisation of impacts of regulatory proposals is weak. Analysis in most RIAs is primarily based on a qualitative discussion of policy impacts. Only limited effort is devoted to quantifying and monetising impacts. Most RIAs produced in the region fail to identify clearly even the key groups affected or the numbers involved. Where some quantification and monetisation of impacts are provided, that analysis is primarily focused on the additional costs to the state budget.

Internal processes for planning, preparing and conducting RIA within ministries are not fully established in most administrations. There are designated RIA contacts and officials in ministries in some of the WB administrations, but they do not provide guidance and proactive support to officials responsible for individual RIAs. The result is a vacuum of information/knowledge in the RIA process, which often causes misunderstanding and delays that ultimately impact the quality of RIA. Only Montenegro, North Macedonia and BiH RS have a formal ministerial or senior management sign-off process for draft RIA reports. Such requirements can help raise the importance and role of RIA and improve the quality of data and analysis and strengthen ministerial and institutional accountability for evidence-based policy making. However, to be successful, sign-off should not simply be a formalistic requirement. Some administrative consequences should follow when major issues are identified with the draft RIA report in the later stages (for example, if many negative opinions are issued by the RIA oversight body).

Lack of adequate capacity and expertise in line ministries for producing high-quality RIAs is a major challenge in all administrations. Limited resources and lack of timely and adequate training on RIA and other relevant topics are major problems in the region. Analytical capacities and skills, which are essential for conducting successful RIAs, are not systematically available for the development of RIA reports. This is critical particularly for the systems that do not have good practices for inter-ministerial co-operation and support, which increases the risks of having gaps in analysis and evidence.

Some form of quality check of draft RIA studies is used by all administrations, but the implementation of the quality check and impact on the final outcome are not always effective; final checks and scrutiny of RIAs are primarily focused on procedural and compliance aspects. The procedures and rules in place do not always ensure that the opinions of the quality-control body are systematically considered by the lead ministry when finalising RIAs. This is particularly true in the case of those that raise major questions about the reliability and robustness of the analysis or evidence. Except in Serbia, the existing rules and procedures do not ensure that negative opinions issued by the RIA scrutiny body are flagged up at the final stage, when the package is submitted to the government for final approval. The mandates of the RIA oversight bodies in most administrations need to be strengthened, and their role in the system enhanced. At the same time, the oversight bodies do not have clear methodologies and approaches to ensure consistent scrutiny of all RIAs, with a focus on the quality of analysis and evidence. Opinions often do not provide useful, practical advice and recommendations on specific issues that need to be addressed. 
Capacity of the RIA oversight bodies involved in quality check and scrutiny of RIAs can be considered weak in most WB administrations. The RIA oversight bodies of the WB administrations are generally not adequately staffed, and frequent staff turnover often creates major issues and gaps in the expert knowledge and skills needed to conduct effective final oversight. This is an issue in Albania, Montenegro and North Macedonia who have recently experienced changes of staff of the RIA oversight bodies. In general, the staff involved in the scrutiny of draft RIA reports should have in-depth knowledge of the RIA methodology and process, and strong analytical skills and capacity, to be able to review and provide meaningful conclusions on a significant number of regulatory proposals.

Openness and transparency of the RIA systems is a major issue in many WB administrations. Final RIA reports are expected to be published online in most administrations, but this is not consistently achieved in the region. North Macedonia is the only administration with a dedicated central website that gives comprehensive information on regulatory policy and better regulation, including RIA. Only half the administrations provide parliaments the final package of legislation with the final RIA reports.

National strategies of public administration reform (PAR) in all the administrations make reforms in policy making and RIA systems a priority. PAR strategies provide the main framework for further development and improvement of the RIA systems. RIA-specific reform objectives and activities are part of the relevant PAR strategy action plans. The ambition and scope of the reforms in different administrations varies, however, reflecting the level of commitment to RIA reforms. Several administrations do have separate strategic documents to advance better regulation and regulatory policy management.

Regular monitoring and evaluation of RIA systems, to identify areas for continuous development and improvement, has not been set up. Several countries in the region have been using RIA for over five to seven years. However, they lack a regular and systematic review of the functioning of their national RIA system, to assess its effectiveness and impact and to identify areas for continuous development. Most of the monitoring and evaluation of reforms in the national RIA systems are carried out within the strategic frameworks that exist for implementation of the national PAR strategies. However, they often focus only on selected elements, such as initiating training and capacity building. 


\section{Introduction}

This study reviews how the practice and use of Regulatory Impact Assessment (RIA) in the Western Balkans (WB) is steadily being adopted, but still falls short of its full potential. Better regulation principles can help both to improve the inherited stock of regulation and to ensure that new legislation, including laws originating from the European Union as part of transposition of the EU acquis, is evidence-based and appropriate. Further improvement and embedding of RIA would be an important step for promoting greater integration with EU practice and performance. It could help reduce the risks related to implementation and enforcement of a large number of new regulations of the WB region that originate from transposing the acquis.

Regulation is an important instrument for governments to achieve certain policy goals. However, if they are not well designed and prepared, regulations can create unnecessary burdens and costs on the economy and people. RIA is an internationally recognised tool and a process for the systematic assessment of the impact and risks of new regulatory proposals, and can help governments make informed decisions and reduce risks during implementation. When it is conducted fully and consistently, RIA can help increase the quality of new regulations and policies, ultimately helping government to deliver better policy outcomes. Together with public consultation and stakeholder engagement, RIA is an essential ex ante tool for regulatory quality management. An effective RIA process thus can help improve and streamline various internal processes and tools used to inform government decision making and to ensure policies are evidence-based and inclusive.

EU integration and eventual EU membership is a top national priority in all WB administrations that are at different stages of the EU accession process. Decisions to open formal EU membership negotiations have already been made for four of the WB countries (Serbia, Montenegro, North Macedonia and Albania), while the integration process for the other two administrations ( $\mathrm{BiH}$ and Kosovo) is making progress. Regardless of the stage of EU accession, all WB administrations have committed to adapting their national legal frameworks to the requirements and standards set by the acquis. Ambitious plans are in place to transpose a large body of EU law into domestic legislation. It is important to ensure that the quality, standards and scrutiny of the new regulations based on the EU integration commitments are fully adhered to and also to minimise the risks of creating a large number of sub-standard regulations. The RIA process can help achieve more informed planning of EU transposition activities.

In the past decade, all six WB administrations (Albania, Bosnia and Herzegovina, Kosovo, Montenegro, North Macedonia and Serbia) have introduced systems of ex ante impact assessment of new regulatory proposals. However, the functioning of the national RIA systems and their impact on the quality of regulatory policy making and EU transposition has not yet been studied comprehensively.

This study provides a comparative analysis of the RIA systems in place in each WB administration, showing how they have been used for the EU legal harmonisation and transposition. The regulatory and methodological frameworks, institutional set-ups and arrangements for RIA and EU law harmonisation, including government planning, accession negotiations and transposition, have been systematically analysed to identify the strengths and weaknesses of national systems and practice and to share knowledge and good practices. 
The first chapter discusses the main concepts and principles of evidence-based policy making, briefly noting the significance of regulation in the government policy-making toolkit. Key steps of RIA in a typical policy cycle are presented, as well as the current state of play and challenges of the EU accession process, its key requirements and steps.

The second chapter discusses in detail the methodological and regulatory frameworks that enable the functioning of the national RIA systems, government legislative and EU legal harmonisation. Different components of the RIA system are systematically analysed.

The third chapter discusses some of the key challenges and issues in the practice of RIA, government legislation and EU transposition planning. It also offers some comparative statistics on government planning and RIA, and presents the findings of a qualitative analysis of a sample of 50 individual RIA reports from WB administrations.

Key policy recommendations are provided in Chapter 4.

\section{Acknowledgements}

The study was conducted by a team of SIGMA experts and advisers of the Strategic Planning, Policy Development and Co-ordination team led by Bagrat Tunyan, who is also the lead author of the report. Significant analytical input and drafting was provided by Erik Akse (analysis of the national RIA systems, Chapters 1, 2 and 3), Vladimir Medjak (EU accession/transposition, Chapters 1, 2 and 3) and Dragana Aleksić (qualitative analysis of sample RIA reports, Chapter 3). Ken Warwick contributed valuable input on the drafting of Chapter 1, as well as external peer review for the whole report. Ivo Rollis provided input for drafting the sections in Chapter 1 concerning EU accession and transposition. Internal SIGMA peer review was led by Timo Ligi, who also gave valuable input on different parts of the report. A team of local experts from the Western Balkan administrations offered crucial assistance during data collection, analysis, drafting and verification of the final draft. The team included: Nevila Çomo (Albania), Amir Ćesić (Bosnia and Herzegovina), Filloreta Bytyçi (Kosovo), Stevo Muk (Montenegro), Magdalena Shaldeva (North Macedonia) and Dragana Aleksić (Serbia). The team is grateful for the helpful feedback, comments and suggestions of many other colleagues and experts, including Gregor Virant, the head of the SIGMA Programme, Annika Uudelepp, Lech Marcinkowski of OECD/SIGMA; Daniel Trnka and Richard Alcorn of OECD/GOV/REG; and Peter Vági (independent expert). The team would also like to thank colleagues from the European Commission for their review and comments on the final draft. Elena Mitrovski provided invaluable support throughout the study and prepared the report for publication. The team would like to express its sincere gratitude to all the officials from the WB administrations for their co-operation and support, and for their comments and suggestions during the final stages of the report. 


\section{Chapter 1. Principles and tools for evidence-based policy making and EU law transposition}

This chapter briefly outlines the main principles of evidence-based policy making, as well as the role of RIA as a regulatory management tool in improving the quality of policy making and the EU transposition process. It also discusses the main steps and processes of EU accession and the legal harmonisation challenges facing EU candidate and potential candidate countries in the Western Balkans.

\subsection{Government intervention and RIA as a tool for ex ante analysis}

\subsubsection{Why do governments have to intervene?}

The COVID-19 pandemic and the ongoing debate over the effectiveness of the policy response demonstrate clearly the important role governments play in our lives. Whether protecting public health, providing essential public services or controlling the spread of the virus through temporary restrictions and rules, governments have to act quickly to ensure stability, safety and prosperity.

In general, governments intervene in markets and other aspects of our lives to achieve certain policy goals. These may include, for example, disease control, financial stability, protection of the environment, rights of workers or consumers, prevention of monopoly power, provision of key services and infrastructure or help for the vulnerable. In general, these interventions address what governments perceive to be "market failures" or an unacceptable degree of inequality in the distribution of income and wealth.

Governments must decide which policy instrument best achieves the goal at hand. Typically, they have three main categories of instruments at their disposal: public expenditure, taxation and regulation (Figure 1.1). Complex policies may require co-ordinated, parallel interventions, using a combination of several of these instruments - ideally co-ordinated through strategic government planning to achieve maximum results. Communication, information campaigns and knowledge sharing are also used to achieve better results. 


\section{Figure 1.1. Main categories of government intervention}

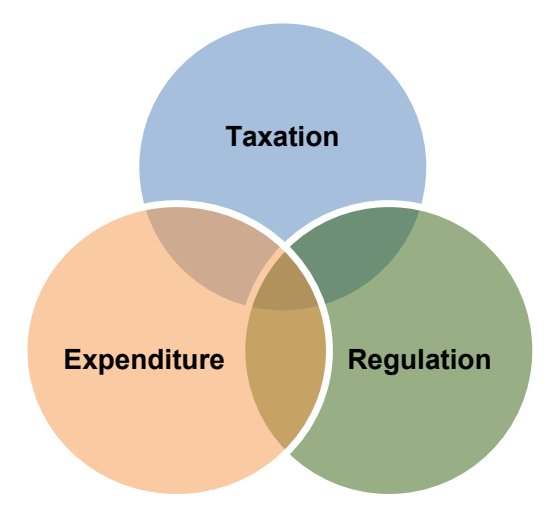

Within the three broad groupings, intervention can take various forms:

- Taxation: This may include revenue raising, redistributive taxation, or taxation designed to address an externality, for example pollution. Tax policy may include tax subsidies, for example investment allowances or research and development (R\&D) tax credits to support activities that may have positive spill-overs.

- Expenditure: Programmes may include providing public goods (e.g. defence, street lighting), merit goods (e.g. education and health care in some countries) and key infrastructure; grants and subsidies to encourage activities with positive externalities; transfer payments to address inequalities; or education and information campaigns.

- Regulation: This may be used to establish and maintain property rights; to provide the basic legal and commercial framework for the economy and society; to address information problems; to control monopoly power; or to shape and influence the behaviour of businesses and citizens ${ }^{2}$.

Regulatory interventions can be seen as one approach in a spectrum of possible government policy interventions in the economy, ranging from free markets to full state control (Figure 1.2).

Reliance purely on market forces is often held up as the ideal but is rarely, if ever, seen in practice. In any market economy, some regulation or government intervention is necessary to underpin a fair and competitive market, facilitate economic growth and protect consumers, society and the environment. Beyond that, however, there is often some degree of choice as to how these goals can be achieved. Governments can sometimes achieve their objectives through education and information campaigns or through market incentives, which allow the economy to adapt in a more flexible way than regulation. Similarly, by allowing greater discretion, interventions based on self-regulation, regulatory reform or lighter-touch, performance-based regulation impose fewer burdens on the economy than command-and-control regulation or even more direct forms of state control.

The 2008 global financial and economic crisis and its underlying failings in governance and regulation demonstrated the importance of good regulatory policy as an instrument for sound policy making. This also applies to the response to the 2020 COVID-19 pandemic. However, even market-enabling or socially desirable regulation imposes costs on businesses, which must demonstrate their compliance with the regulatory requirements of government. Unchecked, regulation can become complex and cumbersome,

2 OECD (2018), OECD Regulatory Policy Outlook 2018, OECD Publishing, Paris, https://doi.org/10.1787/9789264303072-en defines regulations as "The diverse set of instruments by which governments set requirements on enterprises and citizens. Regulation[s] include all laws, formal and informal orders, subordinate rules, administrative formalities and rules issued by non-governmental or self-regulatory bodies to whom governments have delegated regulatory powers." 
with adverse effects on the economy. If it becomes excessive, regulation can impede innovation and create unnecessary barriers to trade, investment and economic efficiency. Moreover, the tendency for policy makers to reach for the regulatory toolbox rather than a public spending solution may be increased when public finances are under pressure.

Figure 1.2. Mapping the choice of instruments to achieve policy goals

\section{Competition and the free market}

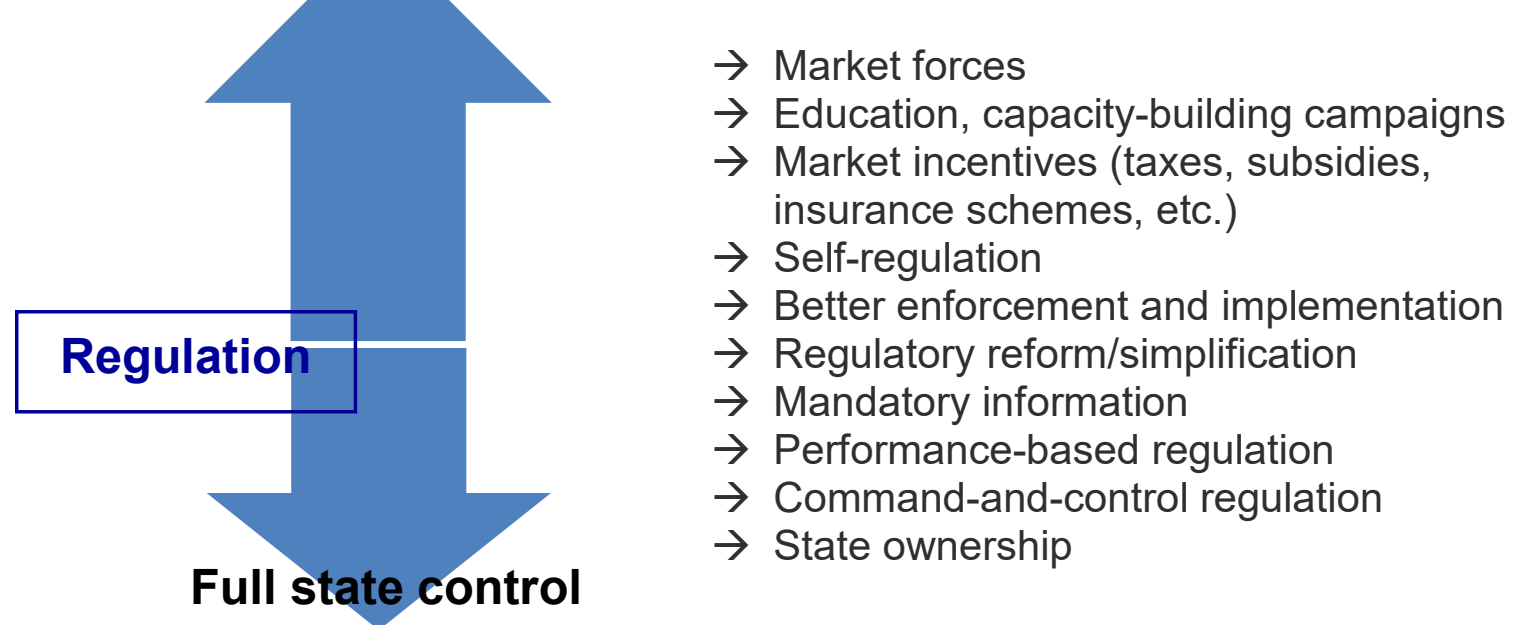

Source: SIGMA analysis, adapted from a diagram originally developed by Lorenzo Allio.

Higher taxes or other burdens on business are the most obvious cost of intervention, with the potential for adverse impacts on competitiveness and incentives. Costs can also, however, arise in less obvious forms, for example through reduced choice, inefficiency or red tape in the public sector, and the risks of inconsistency or "short termism" as a result of political change. Even with a strong rationale for intervention, the case must still be made that government action will lead to a better outcome for society and the economy.

Governments constantly face decisions on whether and how to intervene. The need for intervention can arise from domestic policy priorities, as well as commitments arising from international co-operation and EU integration. Weighing the costs and benefits of different options requires a strong base of evidence and systematic analysis.

Evidence-based policy making is now a well understood and accepted tenet of good governance throughout the EU and OECD. Implemented consistently, evidence-based policy making, and the use of regulatory management tools, such as RIA and public consultation on public policies, should ensure that policies and/or regulations are based on the best available data, analysis and expertise, and take into account the costs and benefits of alternative solutions to a problem. This will ultimately help to obtain the maximum net benefits and minimise the risks for society.

The COVID-19 pandemic has highlighted the challenges governments face in deciding which tools to use in a crisis. Responding is difficult with so much uncertainty and so little time for planning and analysis, given the limited data and evidence. Countries with effective policy-making systems and tools are arguably better equipped to confront a crisis. Those with functioning systems of ex post implementation reviews and evaluation of policies can minimise the risks and burdens of emergency regulations in the long run, by ensuring that the regulations are systematically reviewed and revised if necessary. These and many other challenges related to effective regulatory policy management are discussed by the OECDiii. 


\subsubsection{Regulatory impact assessment (RIA) as a tool to support evidence-based policy making}

When regulation is one of the options under consideration, Regulatory Impact Assessment (RIA) is the internationally recognised tool and process used to ensure greater quality of government intervention. Different types and models of RIA help government carry out systematic ex ante analysis of new proposals to inform government decision making. OECD experience has shown that conducting ex ante RIA improves governments' capacity to regulate efficiently and enables policy makers to identify the most suitable policy solution. It encourages policy makers to think about the impact of their interventions, helps avoid unintended consequences, and provides a framework for balancing the benefits of regulation against its costs and choosing between different options.

RIA also establishes important requirements, working procedures and processes that improve the overall policy-making system and practice in ministries. This can help make policy development more inclusive and evidence-based. Using RIA as an integral part of stakeholder consultation enhances accountability and transparency in formulating policy.

Policy makers can use RIA analysis to defend decisions not to intervene in markets where the costs of doing so outweigh the benefits. When governments do regulate, RIA can draw attention to the benefits that the regulation is designed to achieve, something often overlooked by those shouldering the costs. A functioning RIA framework is thus a tool for securing not only deregulation but also more systematic "better regulation".

\section{Box 1.1. The 2012 OECD Recommendation on Regulatory and Policy Governance - Principle 4}

Integrate Regulatory Impact Assessment (RIA) into the early stages of the policy process for the formulation of new regulatory proposals. Clearly identify policy goals, and evaluate if regulation is necessary and how it can be most effective and efficient in achieving those goals. Consider means other than regulation and identify the trade-offs of the different approaches analysed to identify the best approach.

4.1. Adopt ex ante impact assessment practices that are proportional to the significance of the regulation, and include benefit cost analyses that consider the welfare impacts of regulation taking into account economic, social and environmental impacts including the distributional effects over time, identifying who is likely to benefit and who is likely to bear costs.

4.2. Ex ante assessment policies should require the identification of a specific policy need, and the objective of the regulation such as the correction of a market failure, or the need to protect citizens' rights that justifies the use of regulation.

4.3. Ex ante assessment policies should include a consideration of alternative ways of addressing the public policy objectives, including regulatory and non-regulatory alternatives to identify and select the most appropriate instrument, or mix of instruments to achieve policy goals. The no action option or baseline scenario should always be considered. Ex ante assessment should in most cases identify approaches likely to deliver the greatest net benefit to society, including complementary approaches such as through a combination of regulation, education and voluntary standards.

4.4. When regulatory proposals would have significant impacts, ex ante assessment of costs, benefits and risks should be quantitative whenever possible. Regulatory costs include direct costs (administrative, financial and capital costs) as well as indirect costs (opportunity costs) whether borne by businesses, citizens or government. Ex ante assessments should, where relevant, provide 
qualitative descriptions of those impacts that are difficult or impossible to quantify, such as equity, fairness, and distributional effects.

4.5 Regulatory Impact Analysis should as far as possible be made publicly available along with regulatory proposals. The analysis should be prepared in a suitable form and within adequate time to gain input from stakeholders and assist political decision making. Good practice would involve using the Regulatory Impact Analysis as part of the consultation process.

4.6. Ex ante assessment policies should indicate that regulation should seek to enhance, not deter, competition and consumer welfare, and that to the extent that regulations dictated by public interest benefits may affect the competitive process, authorities should explore ways to limit adverse effects and carefully evaluate them against the claimed benefits of the regulation. This includes exploring whether the objectives of the regulation cannot be achieved by other less restrictive means.

4.7. When carrying out an assessment, officials should: assess economic, social and environmental impacts (where possible in quantitative and monetised terms), taking into account possible long term and spatial effects; evaluate if the adoption of common international instruments will efficiently address the identified policy issues and foster coherence at a global level with minimal disruption to national and international markets; evaluate the impact on small to medium-sized enterprises and demonstrate how administrative and compliance costs are minimised.

4.8. RIA should be supported with clear policies, training programmes, guidance and quality control mechanisms for data collection and use. It should be integrated early in the processes for the development of policy and supported within agencies and at the centre of government.

Source: OECD (2012).

The 2012 Recommendation on Regulatory and Policy Governance (Box 1.1) clearly recommends that all OECD countries introduce RIA in the early stages of the policy-making process for new regulations. In addition, the OECD has also developed a set of RIA Best Practice Principles to provide policy makers and civil servants with practical instruments to better design and operationalise their RIA systems (OECD, 2020). RIA and better regulation principles have also been fully integrated into the policy-making and regulatory system of EU institutions (Box 1.2). 


\section{Box 1.2. EU 'Better Regulation' and impact assessments}

The European Commission (EC) has a comprehensive approach for better regulation that is underpinned by detailed guidelines, procedures and a toolbox. The aim is to make better EU policies and laws that achieve policy objectives at minimal cost. This is achieved by making sure that political decisions are prepared in an open, transparent manner, informed by the best available evidence and backed by strong and regular engagement with stakeholders. Any proposal to revise existing legislation must consider whether there is potential to simplify and reduce regulatory costs without undermining the aims or benefits of the legislation.

Better regulation covers the whole policy cycle - policy design and preparation, adoption, implementation, enforcement, monitoring, evaluation and revision. For each phase of the policy cycle, there are a number of "better regulation" principles, methodologies, tools and procedures to make sure that the EU has the best policy possible. They involve transparency, planning, impact assessment, stakeholder consultation and evaluation.

The EU impact assessments (IA) are tools for achieving better regulation objectives. They collect evidence to assess whether the proposed initiatives are justified and how they can best be designed to achieve desired policy objectives. In the EU system, an IA must identify and describe the problem to be tackled, establish objectives, formulate policy options, assess the impacts of these options and describe how the expected results will be monitored and evaluated. IA for substantial proposals is carried out during the early preparatory phase, as part of the development of policy and (non)legislative initiatives and when drafting implementing and delegated acts.

Source: EC, Better Regulation Guidelines, Commission Staff Working Document from 7 July, SWD (2017) 350, Brussels.

\subsubsection{RIA as a process supporting the policy cycle}

Analysis of policies and impacts is a continuous process that can inform decisions at various stages of the policy-making process. Use of analysis and evidence is important at various stages in the policy cycle. While policy development is rarely a simple linear or cyclical process, it may be helpful to divide the policy process into stages, to show how RIA should be a continuous process that follows and informs decision making at various key stages of policy making - initial, options, consultation, final and post-implementation. Analysis of policy through preliminary or initial RIA undertaken at the early stages may help understand and define the ultimate policy objective. It can be useful in examining the rationale for intervention and the alternative courses of action available.

The identification of problems is often described as the initial stage of the policy cycle. But this phase is rarely as clear-cut as textbooks would suggest. Political priorities, such as the manifesto commitments of incoming governments, changing public expectations or external commitments, for example arising from international treaties or the EU integration process, also play a part. These may be just as important in setting the agenda and shaping the response as the technical identification of a market failure or learning from past interventions. But even in cases when a policy proposal has been initiated to meet certain EU or international commitments, RIA can help policy makers understand the underlying problem and formulate the national policy objectives that the externally driven proposals aim to achieve. RIA can also assist policy makers in transposing international commitments into national law in the least burdensome way possible, through examining different means of implementation. 
Figure 1.3. A typical policy cycle and RIA development phases

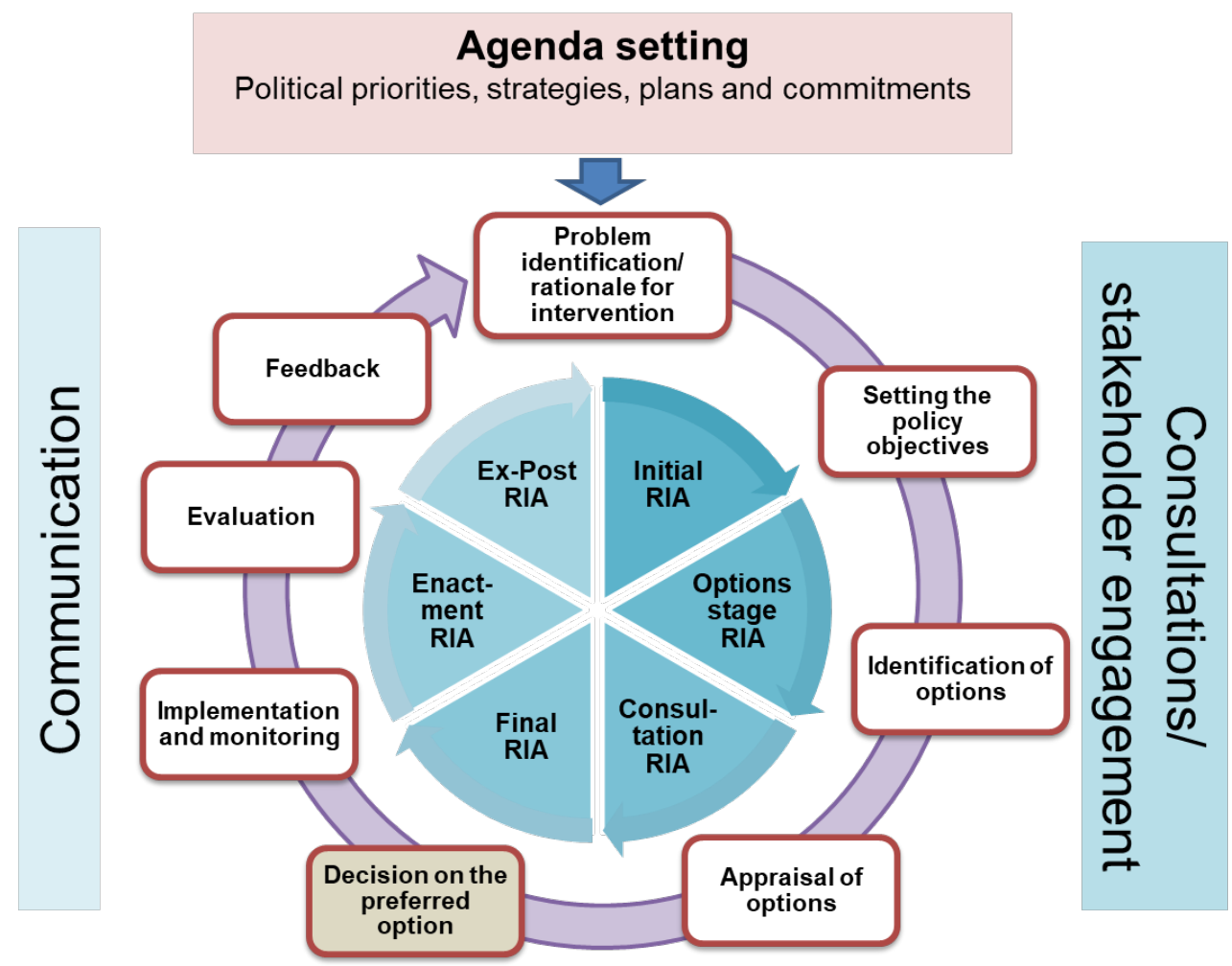

Note: The RIA process is divided into key stages, corresponding to phases of the policy cycle. The terms used to describe RIAs undertaken at each stage are indicative and can vary depending on the model applied in the country concerned.

Source: Developed by SIGMA, based on various models of policy cycles and the RIA process used by OECD, SIGMA, the EU and the UK Government.

Analysis at the next stage can help narrow the list of options to a shortlist for further detailed appraisal and be used as the basis for consultation on the options selected. Consultation-stage RIAs help inform public discussion during consultation and provide a structure for identifying missing evidence to gather. A good RIA enhances public consultation by helping stakeholders and citizens understand more clearly the objectives of the policy and its likely impact.

After consultation and further analysis, the final RIA supporting the decision on the preferred option helps inform discussions among officials and lawmakers across government and in the legislature. Clarity at this stage can enhance good decision making. If the policy proposal is changed significantly during these discussions, it is good practice to prepare and publish a final (updated) enactment RIA for full transparency and accountability.

Finally, plans for implementation, monitoring and evaluation should be built into RIAs from the outset. Weak RIAs give too little consideration to implementation issues, which can yield policies that do not achieve their intended goals. Careful planning and monitoring at the implementation stage can help identify when policies are going off track and point to the need for corrective action. Once the policy has been in place for a sufficient period of time, evaluation evidence and analysis in the shape of a post-implementation review or ex post RIA will help demonstrate accountability and promote lesson learning. The feedback from the policy evaluation can then be used to inform the next round of decision making, including whether a regulation should be renewed, amended, replaced or removed. 
At every stage, engagement with internal and external stakeholders and good communications are important. Ideally, RIA should be fully integrated with the policy development process and not considered as an add-on or tick-box exercise. This requires securing commitment and buy-in for RIA right across government, ensuring training and support is provided and applying RIA tools in a targeted and proportional manner.

Proportionality is a key principle, essential for a well-functioning RIA system. Not all policies will need to be subject to a full RIA analysis. Resources should be focused on policy areas most likely to have a significant impact and where RIA can add most value.

The principle of proportional analysis and several other important principles are laid out in the recently published OECD guidance on best practice in RIA (Box 1.3). The principles can help develop and enhance RIA systems.

\section{Box 1.3. The OECD Best Practice Principles on Regulatory Impact Assessment}

Establishing an effective and functioning RIA system is a challenging task. The Best Practice Principles on Regulatory Impact Assessment, developed by the OECD, aim to provide general guidance about key requirements for a well-functioning RIA system.

1. Political commitment and buy-in for RIA

2. Governance of RIA - having the right set-up or system design

3. Embedding RIA through strengthening capacity and accountability of the administration

4. Targeted and appropriate RIA methodology

5. Continuous monitoring, evaluation and improvement of RIA.

Source: OECD (2020).

Experience in OECD and EU member states demonstrates the value of using evidence and analysis to support policy making. RIA is a tool used throughout the world and is widely practised in the EU. Over time, RIA and other regulatory management tools are becoming more embedded in EU Member States as the "Better Regulation" agenda is promoted and adopted across Europe.

Many EU Member States have incorporated RIA and analysis in the EU transposition process, as integral parts of their national law-making systems ${ }^{\text {iv }}$. EU candidate countries and potential candidates should also aim to integrate RIA more fully into policy making. This is all the more important given the current economic and health crisis, and in a regional economic environment already demonstrating sluggish growth, high unemployment and fiscal problems.

The Principles of Public Administration (OECD/SIGMA, 2017), jointly developed by the EU and OECD/SIGMA, sets out guidelines for a system of policy planning and policy development, including specific requirements and expectations for planning and implementation of measures associated with EU integration (Box 1.4). 


\section{Box 1.4. The SIGMA Principles of Public Administration - Reinforcing key requirements and standards for EU integration and evidence-based policy making}

The Principles of Public Administration were developed by OECD/SIGMA in close co-operation with the EC, to define detailed requirements for a well-functioning public administration in policy development and co-ordination and in five other key areas. They reinforce the EC's approach to public administration reform and establish the key requirements for EU integration process. Several of the Principles relate to the need for adequate planning and monitoring of EU integration and evidence-based and inclusive policy making.

Principle 2: Clear horizontal procedures for governing the national European integration process are established and enforced under the co-ordination of the responsible body.

Principle 4: A harmonised medium-term planning system is in place for all processes relevant to European integration and is integrated into domestic policy planning.

Principle 9: The European integration procedures and institutional set-up form an integral part of the policy-development process and ensure systematic and timely transposition of the European Union acquis.

Principle 10: The policy-making and legal-drafting process is evidence-based, and impact assessment is consistently used across ministries.

Principle 11: Policies and legislation are designed in an inclusive manner that enables the active participation of society and allows for co-ordination of different perspectives within the government.

Source: SIGMA, The Principles of Public Administration (2017).

\subsection{Using analysis and evidence to inform EU accession planning and legal harmonisation}

\subsubsection{EU accession process and the main phases of legal harmonisation}

Many national regulations of the EU Member States originate from the EU. The same is true for candidate and potential candidate countries that aspire to closer integration and eventually, full EU membership. Understanding the potential impacts, risks and consequences of these new regulations can help countries achieve better policy outcomes in the longer term while advancing the EU integration process.

Under Article 4(3) of the Treaty on European Unionv, EU Member States are expected to take any appropriate measures to ensure fulfilment of the obligations arising from the Treaties or resulting from the acts of the EU institutions. EU candidate countries should ensure that their existing laws and future legislation are fully harmonised with the EU acquis before their membership to the EU can formally begin.

The process of accession to the EU and the expectations of candidate and potential candidate countries have become more stringent in recent decades. EU Member States defined the accession criteria for the first time at the Copenhagen European Summit in $1993^{\mathrm{vi}}$, and these were expanded at the Madrid European Council meeting in $1995^{\text {vii. }}$. Before the accession negotiations are finalised, candidate countries are required to demonstrate their readiness and ability to apply the acquis effectively. It is not enough simply to adopt national legislation technically harmonised with EU legislation; countries are expected to demonstrate full preparedness and an ability to apply and fully enforce the new rules as a prerequisite for advancing EU accession. Accession countries must plan and manage the whole process carefully and use 
evidence and analysis at various stages of the EU accession process to deliver the best results for their countries and citizens.

The EU accession process can be lengthy. It involves difficult negotiations in all areas and chapters of the acquis. During the accession negotiations, a candidate country is not negotiating the substance of the acquis, but discussing and agreeing to the modalities, time frames and financial framework for instituting the new rules and standards.

The body of EU law for approximation is large, which requires careful planning and prioritisation. Accession countries need first to transpose the EU regulations expected to deliver best results for their economies and citizens, at minimal cost (Box 1.5). To achieve this, countries should adhere to clear principles and adopt a systematic approach for analysing the impact of the new regulations. Subject to negotiations, exceptional transitional arrangements can be negotiated for full application of the acquis after the accession date, with possible derogations - based on evidence - from the EU rules.

\section{Box 1.5. EU acquis and the main type of EU legal instruments for transposition}

The EU acquis, organised into 35 policy areas ("chapters"), is the body of common rights and obligations binding on all Members of the European Union. It is constantly evolving and comprises:

- the content, principles and political objectives of the Treaties;

- legislation adopted in application of the treaties and the case law of the Court of Justice of the EU;

- declarations and resolutions adopted by the EU;

- measures relating to the common foreign and security policy;

- measures relating to justice and home affairs;

- international agreements concluded by the EU and those concluded by the EU countries between themselves in the field of the EU's activities.

Regulations and directives are the primary sources of EU law. A regulation has a general application. It is binding in its entirety and directly applicable in all Member States. A directive is binding, as to the result to be achieved, upon each Member State to which it is addressed, but the national authorities have to decide on the choice of form and method. Additionally, EU institutions issue decisions as well as opinions and recommendations that also form an important part of the body of EU law.

Source: Article 288 of the Treaty on the Functioning of the European Union (TFEU); Summary of EU Legislation, EU-Lex Access to European Union Law, https://eur-lex.europa.eu/summary/glossary/acquis.html.

For existing EU Member States, EU regulations and decisions have direct application and become binding throughout the EU on the date they enter into force, but EU directives need to be transposed. As far as the EU directives are concerned, a candidate or potential candidate country should be able to transpose a directive into a national law to achieve the objectives of the EU policy, in accordance with the national objectives of EU accession.

Establishing clear procedures and principles for planning and transposition of EU law is also an important task for existing EU Member States (see Box 1.6). 


\section{Box 1.6. Preparation and implementation of EU law transposition in the Netherlands}

Analysis of impacts of new EU law is fully integrated into the policy-making system of the Netherlands. An explanatory document is initially prepared that, among other issues, analyses the objective and impact of new draft EU law and presents the first opinion of the Dutch government on the draft law. This document is discussed by the Government and is sent to Parliament for discussion. The final document serves as the basis for the government's negotiation on the new EU law. Civil servants use the analysis in negotiations with EU institutions. An implementation plan for transposition of the EU directive is also prepared within two months of the adoption of the common negotiating position.

In terms of the legal instrument of transposition of an EU directive, the preferred method in the Dutch system is to incorporate the EU law into the corpus of existing legislation. Standard legislative procedures and requirements, including the requirement to prepare RIA, are applicable for legal acts transposing the EU law, but drafts for implementation of EU legislation can be directly sent to the Council of Ministers to implement the laws in a timely fashion. RIA rules equally apply for those measures that transpose EU law. RIA plays an important role in understanding the full impact of the EU law and helps the Dutch government to decide on the best way to implement transposition.

An electronic database, i-Timer, helps manage the transposition process and steps. It provides information about the EU directives that needs to be transposed and, depending on the legal instruments that will be used for transposition, it also presents the necessary steps and requirements to be followed. Deadlines for each step are established based on previous average practice/time. The system also allows monitoring and reporting of the overall process. Reports are regularly provided to the Parliament.

Source: SIGMA analysis, based on information provided by the Ministry of Justice and Security of the Netherlands.

\subsubsection{Use of RIA and analysis in EU accession planning, negotiations and transposition in the Western Balkans}

EU offers the Western Balkans (WB) administrations a credible perspective for full EU membership, provided that substantive reforms being carried out in key areas, such as the rule of law and democratic governance. Many of these reforms require introducing complex changes in the regulatory frameworks and practices of candidate and potential candidate countries of the WB region.

By signing the Stabilisation and Association Agreements (SAA), six countries of the WB administrations have committed to harmonise their domestic legislation (their existing and future laws) with the acquis. Overall, the SAA covers the entire acquis, as well as the process and approach for full legal harmonisation. However, the depth and pace of integration processes and legal harmonisation can vary significantly, depending on the area of the acquis, as well as each country's national priorities and interests. There is some room for negotiation and discussion. This can help countries plan the overall process, to ensure effective and balanced allocation of administrative and financial resources for EU integration and manage internal risks and pressures.

\section{Strategic planning and priority setting}

The SAAs are the main strategic documents defining the priorities and objectives of the EU integration process. They set out the roles and responsibilities of the EU and partner countries in this process. The SAAs stipulate that legal approximation with the acquis be carried out according to the National Plan for Adoption of the Acquis (NPAA), a programme agreed on by the EC and WB administrations. De jure, the NPAA is only intended to cover the obligations arising from the SAA. In reality, however, the obligations 
are much broader, covering the entire acquis and linking SAA obligations with future accession negotiations.

The NPAA is an important government planning document that defines the vision of a candidate country and sets out the priorities and path for full approximation of the acquis. As a central planning document, the NPAA should be fully aligned with other government planning documents, such as the Government Programmes, the Government Annual Work Plan (GAWP), sectoral strategies and related action plans.

In preparing the NPAA, a country typically analyses several aspects of the acquis. First, the acquis to be transposed is separated from the acquis that has no bearing on the accession process (e.g. decisions directed to EU Member States or individual companies not relevant for the candidate country). Second, a country identifies the elements of the acquis relevant to its future membership but which do not require transposition, since they would intrinsically be directly applicable after the accession (e.g. procedural aspects applicable within EU, or any duty of annual reporting to the EC). What is left represents the acquis that a country is required to transpose during accession negotiations (the majority would consist of regulations and directives, but also decisions, recommendations, opinions and non-legislative acts like EC notices, etc.).

Regular review and analysis of the NPAA, particularly its costing and potential impact on the state budget, are crucial for understanding the scope of impact of various regulations that originate from the EU. This can also help assess the administrative capacity necessary for full implementation and enforcement of the new standards and rules.

\section{Screening process}

The NPAA serves as the basis for a screening process during which a country presents its detailed plan for achieving full approximation with the acquis. At this stage, countries are also expected to indicate any challenges or risks they anticipate during the legal approximation process. Later, during the negotiations, the NPAAs are updated on the basis of the screening reports, agreements made during negotiations and the plans made by the candidate countries to reach the opening, interim and closing benchmarking.

The screening process is a unique opportunity for a candidate country to understand fully the real gap between the EU and national regulatory regimes and raise questions to the EC directly on practical issues of implementation of the acquis, as well as on the impacts it has had on EU Member States. Being well prepared, able to raise useful and relevant questions, and having a basic analysis of the impact of various chapters and major regulations covered in each chapter can be critical for the candidate country. At this early stage, the impact assessment (IA) prepared by the EU or a Member State can be a useful source of information on the scope of the regulatory change and its potential impact. Information and data contained in the EU IA report can be invaluable for preparing the national RIA. It can then be elaborated upon later, during the design and drafting of the new national regulation.

\section{Box 1.7. Use of impact analysis to inform EU law transposition: Latvia}

In 1998, Latvia introduced a system of Initial Legislative Impact Assessment Statement ("Annotation"), as its main regulatory management tool for ex ante analysis of the impacts of new policy proposals. Annotations became mandatory in 2001, and were used in the EU pre-accession period before 2004 to assess the impact of regulatory changes resulting from EU membership. The Annotations system allowed the government to review and collect information about the potential social, economic and fiscal impacts of new draft legal acts systematically, including those arising from the EU membership commitments. Additionally, they provided compliance assessment of the draft legislation with the new EU requirements. Lead ministries were responsible for preparing Annotations, using a standard 
template. The final Annotation reports were included in the final package of documentation submitted to the government for final approval. Various ministries and institutions were required to review and assess the parts of the Annotation directly relevant to their competencies. For example, the Ministry of Finance had to review and confirm the assessment of the impact on the state and municipal budget.

All EU transposition cases considered during the pre-accession period were required to have Annotation statements before they were considered and approved by the Government. In particular, the responsible line ministry had to conduct various tests and assessments, such as: $i$ ) justification for initiating a new legislative change; ii) assessment of what it would mean for Latvia's social, economic and administrative burden; iii) assessment of the impact the draft legal act would have on both state and municipal budgets; iv) assessment of possible impact of the legislative initiative on the existing system of legal norms; $v$ ) compliance with Latvia's international commitments. Additionally, legal acts transposing EU law had to go through additional checks and assessments, such as: $i$ ) assessment of the purpose of the particular legal act of the EU and the justification for its implementation in the Latvian legal system through the proposed legal methods; ii) a review of the timeline and deadlines for introducing the respective EU legal acts, adoption of the elaborated draft legal act, and substantiation of these deadlines with reference to various documents; iii) preparation of the table of conformity of the national legal act with the acquis; iv) report on any external consultations and communication activities held during the preparatory phase, and v) discussion about the implementation and enforcement approach.

After becoming an EU Member State, the Latvian administration further expanded the system of Annotations as its main ex ante regulatory management tool, to ensure effective transposition of the new EU law and for other purposes. The template of the Annotation report was revised to require additional assessments to be carried out when transposing an EU law. In particular, additional checks were introduced to assess : $i$ ) whether the draft national legal act is more stringent than the requirements in the EU legislation (effectively checking against the risk of "gold plating"); a statement on the reasons and consideration of possible alternatives (including non-regulatory options); ii) how the Member State's freedom of action as envisaged in the EU law is exercised to transpose or implement certain provisions of EU law; and iv) information on the obligations associated with observance of EU institutions and regulatory enactments that regulate the provision of information on draft technical regulations, granting of state aid and financial regulations.

Source: SIGMA summary based on Guidance issued by Latvia's Cabinet of Ministers $(2009,2001)$.

\section{Preparing for accession negotiations}

Use of analysis and evidence to inform decisions during accession negotiations can help the EU and candidate countries achieve conclusions that are beneficial for both parties. After the EU screening report is prepared, and gaps in the existing legislation have been identified by the EC, a country is expected to start preparing its own negotiation position. This is also the time for countries to request any transitional arrangements/periods as well as any derogations, if necessary. It may be in the best interest of the candidate country to request specific adaptations to the acquis, and exceptionally, also require transitional arrangements and measures to minimise any negative consequences of implementing EU laws within the anticipated timeline. Some negotiation positions, and particularly requests for transitional arrangements and derogations, have a better chance of being accepted by the EU if they are supported and substantiated by robust analysis and evidence, demonstrating why it is not possible or desirable to achieve full approximation by the date of accession.

RIA or similar tools and methodologies can help countries systematically assess major impacts and risks of new regulations that arise from the transposition of the EU law, and inform decisions during the 
accession negotiations. Without analysis of this kind, it will be impossible for the government to make optimal, evidence-based decisions. Having a strong analysis and evidence base is indispensable for the negotiation team to refine its strategy and prioritise and sequence the reform measures. Typically, it is up to the national chief negotiator (and ultimately the EU co-ordination and decision-making structures of the government) to make strategic decisions about requests for derogation or transitional arrangements. They should thus have established processes and criteria for initiating detailed analysis of impacts of new regulations, to guide the requests that have a better chance of EU approval, so that they can prepare and plan accordingly. 
Figure 1.4. Use of RIA and analysis at different stages of the EU accession planning, negotiation and transposition process

An integrated systemic approach for ensuring an evidence-based EU accession process.

Strategic priorities and planning of EU accession, based on the Stabilisation and Association Agreement (SAA)

- Developing a programme for legal approximation or a National Plan for the Adoption of the Acquis (NPAA) based on the Stabilisation and Association Agreement and national priorities and goals, and on the available administrative capacity

- Initial costing of the NPAA; initiation of analysis of the most significant regulations in each acquis chapter, to prioritise and plan transposition work. Consulting the relevant EC and Member States' Interim Agreements (if available) to inform the initial analysis and planning.

\section{Screening and negotiations (for candidate countries)}

- Initial screening and analysis of all EU acquis chapters, followed by negotiations. Initial preassessment of all draft laws.

- Initiation of a preliminary analysis of impacts (preferably using RIA methodology) of the most significant regulations to inform the preparation of negotiating positions and to support any requests for transition arrangements/derogations.

\section{Transposition: Planning, drafting and approval of the national} legal instrument

- Annual planning/update of EU transposition work, aligned with other government plans

- EU transposition cases must follow the same processes, rules and standards as those required for domestic policies.

- Initiation of RIA, as required by the national rules, as early as possible

- Revising the negotiation positions based on updated RIA/new evidence (if needed).

\section{Implementation and enforcement}

- Discuss implementation and enforcement risks in ex ante RIA.

- Ensure full implementation of new regulations through enforcement, and initiate monitoring to review implementation.

- Plan and implement ex post RIA and/or other forms of evaluation (following domestic policies and rules).

Note: The process is simplified to include key stages and milestones of the EU legal harmonisation and transposition process and potential stages for using RIA and other analytical tools.

Source: Developed by SIGMA, based on various guidance and external frameworks on EU accession and legal harmonisation.

At the same time, it should be noted that initiating analysis of impacts of new EU regulations through RIA early in the process requires additional administrative resources, which national administrations may find challenging to obtain. Following the principle of proportionality, it is important to focus only on the most complex and potentially controversial new regulatory proposals in conducting RIA analysis at this stage in the process. It is not realistic, or justified, to perform RIA for the entire acquis during accession negotiations. Triaging and filtering mechanisms can help single out the most important regulations to focus on. Initiating 
RIA early in the process makes it easier to secure approval of the relevant regulatory proposal than when it is undertaken in the later stages of policy development.

\section{Transposition-stage planning, drafting and approval of domestic legal instruments}

Accession countries should plan EU transposition work carefully, considering many factors. These may include: the impact and alignment of the measures with national priorities; the timeline of implementation; the availability of administrative capacity for development; implementation and enforcement of new rules; and so on. National transposition plans should indicate the ministries and institutions responsible, as well as the method of transposition for each individual EU legal act. The quality of the plan can be measured by its comprehensiveness and the depth of the planned transposition cases. The effectiveness of the plan can be measured based on implementation of the planned commitments within the deadlines originally agreed upon and on the quality of transposition.

Transposition of EU law involves certain risks and challenges. Some of the risks involve the nature of the accession process and the country's individual circumstances. At the same time, certain generic risks and undesirable practices are relevant not only for accession countries, but for many existing EU Member States. This particularly relates to so-called "gold-plating", when countries go beyond the minimum EU requirements. Such practices can create unnecessary additional burdens and costs for domestic businesses and organisations, making them less competitive in the EU and internationally. It is thus important for candidate countries to be aware of these risks and minimise them as part of impact analysis of new regulations during the drafting phase (Box 1.8).

\section{Box 1.8. Transposition practices to be avoided}

Going beyond the minimum requirements of the EU law is often referred to as "gold-plating". It is defined by the EC as "an excess of norms, guidelines and procedures accumulated at the national, regional and local levels, which interfere with the expected policy goals to be achieved by such regulation". "Gold-plating" unnecessarily and unjustifiably raises the regulatory bar for domestic businesses and individuals, creating additional costs and burdens, and making them less competitive within the EU market.

The other major risk, double-banking, occurs when EU legislation covers the same legal area as the existing national legislation, possibly in different ways and to varying degrees. National administrations should aim to streamline both the new and existing legal regimes, and to use the transposition process as an opportunity to repeal and simplify existing national rules and regulations. Countries should aim to achieve as much consolidation as possible through transposition, by merging all the relevant regulations into one.

Systematic consideration of risks, as part of the analysis of implementation and drafting options when drafting the domestic legal act, can significantly help to reduce both of these risks. To avoid double-banking, all related existing national legislation should be examined fully to note potential areas of overlap with the acquis. The best way to avoid double-banking is not to treat EU legislation as an add-on to existing national rules, but to have an underlying objective to create a coherent regulatory regime through transposition, either by amending the existing legislation or repealing or revoking it and starting afresh with a new regime.

Source: HM Government (2018), Transposition guidance: How to implement European Directives into UK law effectively. 
All new laws originating from the transposition process are required to conform with the same standards and processes as domestic laws. The transposition plan should thus consider the additional time and work required for completing the necessary preparatory work, such as RIA and external and internal consultations. Draft individual legal acts transposing EU law are assessed individually by the EC. Initiating a RIA report on these individual legal measures early in the process, and sharing those reports with the EC together with draft laws, can facilitate discussions and improve policy dialogue between the EC and candidate countries. Once a country begins accession negotiations, all draft laws (and most important secondary legislation) relevant for EU accession are subject to prior assessment by the EC. Similarly, RIA on these draft regulations can ensure a more effective policy dialogue with the EU.

The preparatory and adoption process of legal transposition involves several steps, similar to those required for adopting regulations that originate domestically. Additional documents, such as Tables of Concordances and legal compliance statements, are also prepared for transposition cases. Countries also need to ensure translation of the original EU law should be planned and conducted early in the process, so that the related preparatory analysis and work can be conducted.

Selecting the right legal instrument and the right method and technique for transposition is equally important for successful legal harmonisation. Choosing the right method can help minimise potential risks and unnecessary burdens of transposition (Box 1.9).

\section{Box 1.9. Legal methods for transposing EU law}

Selecting and applying the most appropriate legal method of transposition is important for minimising unnecessary costs and burdens and ensuring effective implementation. These methods and related risks can be systematically analysed when developing alternative options of policy implementation, monitoring and enforcement.

1. Logical transposition with reformulations. This method suggests using legal terminology different from that of the EU act, to achieve the same policy goals and outcomes. This may involve adoption of several national legal instruments for transposing one EU act. This technique can be used for both regulations and directives before accession, but solely for directives afterwards. Reformulation of the EU regulation can create risks of exceeding the minimum requirement, resulting in "gold-plating". It is thus important to analyse options and impacts as part of a full RIA if this method of legal drafting is selected.

2. Copy-out (word-for-word) transposition. This is the technique used for transposing EU acts or elements of EU acts whose wording, definition, numerical values and characteristics must be the same in all EU Member States. In accession countries, it is primarily used for transposing regulations, since they are intended to be used in the same way in all EU Member States. It is also applied for transposition of directives that aim to define product standards and technical specifications that can ensure the smooth functioning of the EU internal market and the legal system. One of the advantages of the copying-out method of transposition is that it eliminates risks of "gold-plating" (the domestic law will not exceed the minimum requirements of the EU law).

3. Transposition through reference to the EU act. This technique is rarely used even by EU Member States, and in candidate countries, it is not legally permissible, because EU law is considered foreign law.

Source: OECD/SIGMA, Policy Paper prepared for the Republic of North Macedonia on legal harmonisation with the EU acquis: Overview and recommendations. 
There are some differences in the process of transposition, depending on the type of EU law. As EU regulations are not directly applicable in candidate countries, their legal systems must be harmonised with the material norms of the regulations, so that the administrative practices, harmonised with EU practices, can be developed and prepared throughout the country. To avoid duplication, candidate countries must eliminate all the legislation previously used to transpose EU regulations, ensuring that implementation and enforcement of those regulations continues unhindered. Essentially, the date of accession should only bring the change of the source of the legislation, switching from national to the $\mathrm{EU}$, while implementation and enforcement continues.

\section{Implementation and enforcement}

Enacting a new domestic legal act is the start of implementation of new regulation. Implementation involves making new legislation general practice. For this, public administrations need to develop the necessary administrative capacity, through adequate resource and staff management, training and the introduction of new procedures and tools, as well as investment in infrastructure (according to the 1995 Madrid criterion ${ }^{\text {viii). }}$.

The legal harmonisation process is considered complete after adequate enforcement of the new rules and regulations is ensured at the national level and across the entire country. This means that the country must apply all measures available within the jurisdiction to promote and/or enforce adequate behaviour and compliance, in line with the national legislation in force. This can involve regular monitoring, promoting, informing, inspecting, controlling, licensing, prosecuting, fines and any other measures that could lead to proper and full enforcement.

Enforcement is closely dependent on judiciary overview of the legislation in force. The capacity of the judiciary to enforce an increasing number of new rules and regulations arising from the EU should thus also be considered in planning the transposition, so that it can keep pace with legal harmonisation and keep track of all changes incurred.

Any RIA prepared on a transposition case should fully consider the potential risks and impacts associated with the implementation and enforcement of the new regulations. This should be an integral part of the analysis and appraisal of options within an RIA. For example, the additional costs and burdens of enforcement should be carefully considered in RIA reports when comparing options and calculating potential costs, to ensure that the optimal route for implementation is selected.

The EU candidate countries cannot influence the development and approval of new EU legislation, in the same way as the EU Member States do. This situation will change when they become full EU Member States. Accession will provide them the opportunity to provide input for and influence the EU legislative development process more effectively and much earlier in the process. For that, countries will need to make further changes in their internal, national rules and methodologies on lawmaking, to align their policy-making processes with those of the EU. 


\section{Chapter 2. A comparative review of the institutional and regulatory frameworks of RIA and EU law harmonisation in the Western Balkans}

This chapter provides a comparative analysis of the regulatory and methodological frameworks of the Regulatory Impact Assessment (RIA) systems and the planning and preparation of EU legal harmonisation in the six Western Balkans (WB) administrations. The analysis first explores several components and elements of a well-functioning RIA system, focusing on the following key aspects ${ }^{3}$ : i) regulatory and methodological frameworks of RIA; ii) the scope and type of RIA applied; iii) the quality requirements for RIA analysis; iv) organisation of the RIA process in ministries; v) central management, support and capacity building for RIA; vi) oversight and quality control; vii) openness and transparency of the RIA process; and viii) monitoring, evaluation and continuous development of the RIA system. The second part analyses the methodologies and procedures enabling the use of RIA and costing tools during planning and implementation of the acquis transposition work in the WB administrations.

The comparative analysis is based on a review of the formal regulations and methodologies, as well as information and data provided by the WB administrations in March-April 2020. The RIA systems of the following administrations are analysed: Albania, Bosnia and Herzegovina (BiH), Kosovo, Montenegro, North Macedonia and Serbia. Because of its complex constitutional and administrative set-up, BiH does not have a unified, countrywide approach to policy making. Each of the four levels of the $\mathrm{BiH}$ administration is analysed separately in this study: the State level, the Federation of $\mathrm{BiH}(\mathrm{FBiH})$, Republika Srpska (BiH RS) and Brčko District (BiH BD).

\subsection{Comparative analysis of the RIA systems in the WB administrations}

\subsubsection{Regulatory and methodological framework enabling RIA}

Is there a complete regulatory and methodological framework to enable and ensure effective and consistent implementation of RIA, as an integral part of the government policy-making system?

\section{Introduction}

The experience of international and EU Member States suggests there are different models for the institutional and regulatory framework of RIA. It is important that the framework ensures full integration of

\footnotetext{
3 The specific aspects of RIA system analysed in this chapter build on earlier SIGMA reports and publications, including SIGMA's Principles of Public Administration (Policy development and co-ordination), and the OECD publications on RIA and regulatory policy.
} 
RIA in the internal government systems and processes of strategic planning and policy development, and that all RIA-related procedures and rules are aligned with government decision making. Mandates and responsibilities for RIA preparation, management and quality control; internal consultations and approval within ministries; and submission for final adoption need to be clearly established in internal rules and regulations to avoid confusion, inefficiency and unnecessary delays. The RIA process needs to fit a whole-of government approach to policy development and law making and thus link to the requirements for public consultation and ex post evaluation.

The requirements and methodology for conducting RIA should be laid out in dedicated guidance documents. The challenge with RIA guidance is that it must be comprehensive enough to cover all possible decisions in the different policy areas prepared for government adoption. At the same time, it must provide clear, detailed methodology and instructions on the process and on the minimum standards and requirements for preparing individual proposals, so civil servants can perform their tasks effectively, regardless of the policy area.

Guidance documents can help an RIA system to function efficiently and consistently. Manuals, methodologies, templates, practical case studies and other written materials and online tools provide essential information to those who are expected to apply the RIA analysis. They also establish the processes and standards to be followed by all the parties involved in the process. Sometimes even more detailed than more general regulatory requirements for RIA, they can provide helpful technical and methodological information. They should explain how RIA should be developed; which procedures and kind of analysis should be considered for different types of proposals; and also consider the need to be proportionate and targeted. For efficient, consistent RIA, methodologies for impact analysis and the ways they can be applied should be presented in a clear, easily understandable manner (explaining, for example, the required level of analysis; how specific types of analysis should be performed; and how stakeholders should be consulted, etc.). RIA guidance is also a useful source of information for external stakeholders, to clarify the requirements and standards of policy making they can expect and demand from their administrations when they consider individual proposals.

Since the ultimate goal of RIA is to inform decision makers and external stakeholders about the possible trade-offs and key information of the policy being prepared, the findings of the analysis should be communicated in standardised RIA reports and templates with a summary of key findings and conclusions.

\section{State of play in the Western Balkans administrations}

Regulatory frameworks for enabling RIA, as an ex ante tool for regulatory policy analysis, are established in all administrations of the WB region. Review of the existing systems shows that the WB administrations have generally embedded RIA in the rules of procedure (RoP) of the government (Table 2.1).

The requirement to perform RIA in Albania, Kosovo, Montenegro and North Macedonia is embedded in the RoPs of each government. The regulatory basis for RIA implementation in Serbia is broader and reflected in several legal acts, including a law. In the BiH State level, RIA was formally introduced through an amendment to the Uniform Rules for Legislative Drafting. However, the RoP of the Council of Ministers of $\mathrm{BiH}$ are not updated to reflect that the new RIA requirement is part of the government decision-making process. 
Table 2.1. Regulatory framework enabling RIA in the WB administrations

\begin{tabular}{|c|c|c|c|}
\hline & $\begin{array}{l}\text { Year RIA was formally } \\
\text { introduced through } \\
\text { regulations }\end{array}$ & $\begin{array}{c}\text { Year when implementation of RIA } \\
\text { started }\end{array}$ & Main regulation(s) requiring RIA \\
\hline Albania & 2018 & $\begin{array}{c}2019 \\
\text { (Full implementation) } \\
2018 \text { (piloting phase) }\end{array}$ & RoP of Government ${ }^{\mathrm{ix}}$ \\
\hline $\mathrm{BiH}$ (State) & 2017 & $\begin{array}{l}2019 \\
\text { (Partial implementation, } \\
\text { "initial/basic" RIAs only) }\end{array}$ & Uniform rules for legislative drafting $\mathrm{x}$ \\
\hline BiH (Federation) & 2014 & $\begin{array}{c}2009 \\
\text { (Partial implementation, mainly } \\
\text { "initial/basic" RIAs) }\end{array}$ & Decree on RIA Procedure ${ }^{\mathrm{xi}}$ \\
\hline $\mathrm{BiH}(\mathrm{RS})$ & 2009 & $\begin{array}{c}2009 \\
\text { (Partial implementation, mainly } \\
\text { "initial/basic" RIA) }\end{array}$ & $\begin{array}{c}\text { RoP of Government } \\
\text { Decision on Implementing Regulatory Impact } \\
\text { Assessment in the Legislative Drafting } \\
\text { Procedure }\end{array}$ \\
\hline $\mathrm{BiH}(\mathrm{BD})$ & 2018 & $\begin{array}{l}2018 \text { (Partial implementation, } \\
\text { "preliminary" RIAs only) }\end{array}$ & $\begin{array}{l}\text { Decision of the BD Government on the } \\
\text { Procedure and Methodology for RIA }\end{array}$ \\
\hline Kosovo & 2012 & 2012 & RoP of Government ${ }^{\text {XIII }}$ \\
\hline Montenegro & 2012 & 2012 & RoP of Government ${ }^{x i v}$ \\
\hline North Macedonia & 2009 & 2013 & RoP of Government ${ }^{x v}$ \\
\hline Serbia & 2003 & 2003 & $\begin{array}{l}\text { Law on the Planning System, } \\
\text { RoP of Government } \\
\text { Government Decree }\end{array}$ \\
\hline
\end{tabular}

Note: Information is accurate as of March 2020. In the national regulations of $\mathrm{BiH}$, different terms are used to describe various categories and types of RIA ("shortened", "abbreviated", "preliminary"). They are all referred to as initial/basic RIAs. In October, 2020, Montenegro introduced RIA at local government level. It is not included in the scope of this study.

Source: SIGMA analysis, based on information provided by the WB administrations.

All WB administrations have developed methodologies and guidance documents to support RIA implementation (Table 2.2). These documents clarify and supplement the main regulations enabling RIA, by establishing additional procedural steps and requirements, and providing guidance to help conduct RIA analysis. The comprehensiveness and clarity of these guidance documents and their content vary widely, partly because the systems and type of RIA applied in the region differ.

Guidance documents in almost all WB administrations do not have enough practical advice showing how data collection, analysis and consultation should be organised and applied in practice in the RIA process. For example, the Albanian methodology on RIA acknowledges the need to use public consultations to collect additional information and feedback. However, it is not clear how this is to be accomplished. Public consultation is not being systematically and consistently carried out, and RIAs are not always published on the public consultation website. Some of the guidance documents, like those used in North Macedonia and Serbia $^{4}$, have been in use for seven to ten years or more. While it is good to ensure consistency in the methodological approach, the practical knowledge, insights and good examples since gathered in the administration are likely to enhance materials that have been in use for several years. North Macedonia has a comprehensive set of guidance materials and methodologies, but many provide the same or very similar advice, and it is doubtful whether so many different documents are necessary.

$\mathrm{RIA}$ guidance of $\mathrm{BiH}$ State, $\mathrm{FBiH}$ and $\mathrm{BiH} \mathrm{BD}$, which is provided through the main regulation enabling RIA, appears to be insufficient and is not clear. As a result, civil servants may have difficulty understanding and applying the methodology in practice. The BiH RS guidance document on RIA is more comprehensive but

${ }^{4}$ A new RIA manual was subsequently approved by the Serbian administration in 2020. 
appears to be out of date. The Albanian RIA methodology has not been formally approved. This, however, has not been an obstacle for its acceptance and implementation by ministries.

In general, guidance materials for RIA appear to have been developed and issued by a single authority in the administration, and often with the support of external partners. It appears that these documents were not prepared in active consultation with and with contributions from other institutions that have specialised knowledge and expertise in a particular area in the administration. For example, guidance for analysing environmental impacts should be provided and led by the centre of expertise on that topic within the administration.

While the RIA regulations and methodologies in all WB administrations mention the importance of monitoring and evaluation as key components of a policy cycle, most administrations have not established functioning systems to analyse and manage them, through ex post RIAs or implementation reviews and evaluations. Since ex post evaluation of legislation and policies is generally not conducted in the region, the benefits of RIA cannot be fully realised, and the policy cycle of the WB administrations is missing vital components (Figure 1.3).

Most administrations have introduced a standard template for RIA, but only a few require a summary of key findings at the beginning of the document, presented in a clear and concise manner. Without such summaries, it is much harder to communicate the key findings and conclusions of the analysis, especially to senior political leaders and decision makers. In many administrations, because the RIA report lacks clarity and simplicity, it is harder for decision makers and stakeholders to grasp the findings and make informed decisions. This can reduce the value of the RIA process, leading the anticipated key users to question the value of the exercise. Albania uses an electronic template that standardises and fixes the font and formatting of an RIA report, and limits the size of different sections of the cover pages, to ensure that only the most important information is entered and reported in the executive summary section of the final RIA.

Table 2.2. Main methodological and guidance documents for RIA

\begin{tabular}{|c|c|c|c|c|c|}
\hline & $\begin{array}{l}\text { Main methodological documents on } \\
\text { RIA available for line ministries }\end{array}$ & $\begin{array}{l}\text { Available } \\
\text { guidance } \\
\text { covers all RIA } \\
\text { stages and } \\
\text { analysis }\end{array}$ & $\begin{array}{l}\text { Includes } \\
\text { good } \\
\text { practical } \\
\text { examples }\end{array}$ & $\begin{array}{l}\text { Availability of an } \\
\text { electronic } \\
\text { standardised RIA } \\
\text { template }\end{array}$ & $\begin{array}{c}\text { Provides } \\
\text { methodology on } \\
\text { options } \\
\text { appraisal and } \\
\text { analytical } \\
\text { techniques }\end{array}$ \\
\hline Albania & $\begin{array}{l}\text { Methodology on RIA } \\
(2018)\end{array}$ & Yes & Yes & Yes & Yes \\
\hline $\mathrm{BiH}$ (State) & $\begin{array}{l}\text { Guidance is part of the RIA Regulation } \\
\text { (2017) }\end{array}$ & No & No & No & No \\
\hline $\begin{array}{l}\mathrm{FBiH} \\
\text { (Federation) }\end{array}$ & $\begin{array}{l}\text { Guidance is part of the RIA regulation } \\
\qquad(2014)\end{array}$ & Yes & No & No & Yes \\
\hline $\mathrm{BiH}(\mathrm{RS})$ & $\begin{array}{c}\text { Decision on Implementing RIA in the } \\
\text { Legislative Drafting Procedure } \\
\text { RIA Manual (2013) }\end{array}$ & Yes & No & No & No \\
\hline $\mathrm{BiH}(\mathrm{BD})$ & $\begin{array}{l}\text { Decision on the Procedure and } \\
\text { Methodology of RIA (2018) } \\
\text { Instruction of BD BiH Mayor for the } \\
\text { Conduct of Regulatory Impact } \\
\text { Assessment in Public Administration } \\
\text { Bodies and Institutions in BD BiH (2018) }\end{array}$ & No & No & No & No \\
\hline Kosovo & $\begin{array}{l}\text { Guidelines on Developing Concept } \\
\text { Documents (2018) } \\
\text { Manual on Developing Concept } \\
\text { Documents } \\
\text { Standard Cost Model (SCM) Manual }\end{array}$ & Yes & Yes & Yes & Yes \\
\hline Montenegro & RIA Instructions issued by the Ministry & Yes & Yes & Yes & Yes \\
\hline
\end{tabular}




\begin{tabular}{l|c|c|c|c|c}
\hline & $\begin{array}{c}\text { of Finance (2012) } \\
\text { RIA Manual (2011) } \\
\text { RIA Guidelines (2018) }\end{array}$ & & & \\
\hline North & $\begin{array}{c}\text { IA Methodology (2013) } \\
\text { Decision on the Form and Contents of } \\
\text { the RIA Report (2013) } \\
\text { Guidelines on RIA (2013) } \\
\text { RIA Handbook (2013, MISA) }\end{array}$ & Yes & Yes & Yes & Yes \\
\hline & $\begin{array}{c}\text { Decree on Public Policy Management } \\
\text { Methodology, Impact Assessment of } \\
\text { Public Policies and Legislation and } \\
\text { Contents of Public Policy Documents } \\
\text { (2019) }\end{array}$ & Yes & Yes & No & Yes \\
\hline Serbia & $\begin{array}{c}\text { Manual on IA of Public Policies and } \\
\text { Legislation (2020) }\end{array}$ & & & \\
\hline
\end{tabular}

Source: Information is accurate as of March 2020. SIGMA analysis, based on review of the RIA guidance documents and methodologies, and on information provided by the administrations.

The RIA templates used in Kosovo, Montenegro and North Macedonia provide a clear structure to present different parts of the analysis, but they do not include a separate summary section presenting the key findings and conclusions. Several administrations, for example Serbia and North Macedonia, provide additional online tools to help in other aspects of RIA analysis (such as tools for calculating the administrative burdens through the Standard Cost Model, or SCM). Similarly, Albania has an offline, electronic (Microsoft Excel-based) tool for conducting cost-benefit calculations to report in the RIA template in a clear and consistent manner.

\section{Key conclusions}

All WB administrations have formally established the necessary regulatory requirement to facilitate ex ante analysis of policy proposals. Methodologies and key tools, such as templates, are also developed and available for ministries to use in most administrations. The RIA requirement is embedded in the main regulations establishing the working procedures and policy-making rules of the administrations, thus forming an integral part of the main government-decision-making process. The methodological guidance and materials available in all of the administrations are often found to be too generic and theoretical, with few or no practical examples or case studies to support RIA in different sectors and policy areas. The main guidance documents available in BiH RS and North Macedonia have not been updated for about 7 years, while Serbia issued an updated, comprehensive RIA Manual in 2020, about 10 years after the previous guidance was issued. Guidance documents and available materials could benefit from more regular reviews and updates to include real-life experience, case studies and lessons learned from implementation on the ground.

\subsubsection{Scope and type of RIA applied}

Are clear criteria, processes and rules in place for consistent, targeted use of ex ante RIA in government decision making, allowing for proportionate analysis of the impact of the most significant policy proposals?

\section{Introduction}

RIA is a useful ex ante policy tool for analysing not just regulatory proposals but other policy measures and initiatives. That is one reason why the terminology for RIA in different administrations varies (e.g. impact assessment, impact analysis, impact statements, concept documents, etc.). Some administrations also use other tools, such as policy impact assessments (PIA), or fiscal/budgetary impact 
assessments (FIA/BIA), to evaluate certain types of policies and impacts through different or parallel processes, rather than by RIA. Regardless which model of ex ante policy analysis is applied, it is important to ensure that the impact assessment system is comprehensive, optimally designed and consistently enforced, without unnecessary overlaps between the various tools and processes.

While accepting the need for RIA, one should also be aware of the additional demands any ex ante system of policy analysis can impose on administrative resources and skills. It is essential to establish an optimal scope of RIA that helps the administration perform ex ante analysis of government proposals, given the needs and capacity of the administrations. The actual scope of RIA or, in other words, the number of RIA studies conducted in a system, is typically determined by the relevant RIA regulations, considering two main factors. First, it is determined by the type of legal instrument or government decisions or proposals captured by the main RIA regulation. This can be referred to as the "horizontal scope" of RIA (e.g. primary legislation, secondary legislation, policy programmes and documents).

Secondly, countries often apply exceptions and filtering mechanisms to exclude certain types of proposals from the demands imposed through RIA, given the relatively limited added value of conducting ex ante analysis on such measures. This normally relates to the nature of the policy proposal or area it is covering, not the legal instrument. For example, the state budget laws that establish the political and policy priorities of public finances for a calendar year are generally exempted from RIA (while, of course, being subject to other types of analysis). Similarly, time-sensitive measures adopted during emergency situations, such as COVID-19, are typically excluded from full processes of ex ante regulatory oversight and impact analysis. Having such provisions and filtering mechanisms embedded in the system allows much-needed flexibility to ensure effective and efficient use of available resources and skills. Such decisions should not be stalled due to a generic RIA requirement. However, other regulatory management tools, such as automatic sunset clauses and ex post implementation reviews and evaluations, should be considered for emergency regulations, to minimise the risks and burdens in the long term. Criteria for any exemption from the RIA requirement should be clearly defined and consistently enforced to ensure effective implementation.

A proportionate approach to analysis has to be considered when establishing the actual scope of RIA, and, also when determining the depth of analysis of individual RIA studies. Considerations of value for money may not justify applying and enforcing high standards of analysis for every type of government proposal. This is particularly true for administrations that do not have strong traditions, capacity and expertise for using analysis and evidence in government decision making.

RIA systems should build in a filtering mechanism that allows the administration to identify the most significant proposals, in terms of their anticipated impacts, potential public interest, political sensitivity and other factors. The challenge is, of course, to establish a system that can quickly identify policy proposals with significant impacts or risks that require in-depth analysis and deserve more resources. A functioning and effective filtering system would require some level of initial analysis of the proposal as soon as possible in the policy-planning phase. It would also require a verification and oversight mechanism. This could help ensure that any decision to exclude certain measures from a more demanding RIA analysis is justified and, before formal adoption, to confirm that the anticipated impacts are in fact not substantial.

\section{State of play in the Western Balkans administrations}

Ex ante systems of policy analysis in the WB administrations are mainly focused on regulatory measures introduced through primary legislation. Conducting RIA on draft laws is required in all the administrations. A formal requirement to conduct ex ante analysis of the impact of secondary legislation through RIA or other similar methodology has not been established in Albania or North Macedonia (Table 2.3). Albania has the regulatory basis to expand the scope of the RIA requirement to cover secondary legislation, but this is not yet institutionalised and in operation. RIA is required for "important" secondary legislation in Kosovo, but it is not fully operationalised. The WB administrations have other tools for analysing all regulatory proposals, such as explanatory memorandums. However, not applying full ex ante oversight of regulations introduced in secondary legislation can adversely affect the quality of regulations. 
In the $\mathrm{FBiH}$ administration, the RIA requirement is formally extended to cover policy documents. In Serbia, in addition to RIA, a separate tool and process, the policy impact assessment, is used to assess the impact of policy proposals and documents. But the methodology prescribes that those tools should be closely linked with RIA if a legislative or regulatory instrument is developed later. The Law on Planning System of Serbia acknowledges the proportionality principle while the scope and methods of policy and regulatory analysis are being established.

\section{Table 2.3. Formal requirements for conducting ex ante impact assessment on different types of regulatory instruments}

\begin{tabular}{l|c|c}
\hline & Primary legislation & Secondary legislation \\
\hline Albania & Required & Not required $^{*}$ \\
\hline BiH (State) & Required & Required $^{*}$ \\
\hline BiH (Federation) & Required & Required $^{*}$ \\
\hline BiH (RS) & Required & Required $^{*}$ \\
\hline BiH (BD) & Required & Required $^{*}$ \\
\hline Kosovo & Required & Required $^{*}$ \\
\hline Montenegro & Required & Required \\
\hline North Macedonia & Required & Not required \\
\hline Serbia & Required & Required \\
\hline
\end{tabular}

Note: The information indicates the regulatory requirement for analysis, not the actual practice.

*In Albania, the regulations require extension of the RIA to secondary legislation from January 2020. The implementation of this rule, however, has not started. While RIA is formally required for secondary legislation in $\mathrm{BiH}$ administrations, it has not yet been fully implemented. Similarly, RIA is also required for "important" secondary legislation in Kosovo, but it is not fully operationalised. Additionally, Kosovo regulations require impact assessment of secondary legislation within Explanatory Memorandums, but the implementation has been suspended. In 2020, Montenegro introduced RIA for regulations introduced by local government.

Source: SIGMA analysis, based on the national regulations and information provided by the WB administrations.

All WB administrations also acknowledge various exceptions to the RIA requirement for certain types of proposals, but individual approaches and the lists of exceptions vary. Exceptions typically include measures introduced in emergencies, such as for COVID-19 (Table 2.4). State budget laws are excluded from RIA requirements in most administrations, except in $\mathrm{BiH}$. In several administrations, such as in Albania and Serbia, the RIA oversight body must check and confirm all individual exceptions to the rules. While in most administrations, the approach aligns with international best practice, it could be further tailored and made more specific, to remove any loopholes in the system by establishing clear criteria that can ensure that all major regulatory changes are systematically analysed. 
Table 2.4. Examples of exceptions of certain legislative measures from RIA requirement

\begin{tabular}{l|c|c|c|c}
\hline & $\begin{array}{c}\text { Emergency laws, including } \\
\text { COVID-19 related }\end{array}$ & State budget laws & Tax laws & Ratification of international agreements \\
\hline Albania & Excluded & Excluded & Included & Excluded \\
\hline BiH (State) & Included & Excluded & Included & Excluded \\
\hline $\mathrm{BiH}$ (Federation) & Included & Included & Included & Excluded \\
\hline $\mathrm{BiH}$ (RS) & Included & Included & Included & Excluded \\
\hline BiH (BD) & Excluded & Included & Included & Excluded \\
\hline Kosovo & Excluded & Excluded & Included & Excluded \\
\hline Montenegro & Excluded & Excluded & Included & Included \\
\hline North Macedonia & Excluded & Excluded & Included & Excluded \\
\hline Serbia & Excluded & Excluded & Included & Included \\
\hline
\end{tabular}

Note: * In Serbia, while international agreements are formally included in the scope of RIA, they are exempt in practice.

Source: SIGMA analysis, based on a review of the regulations and information provided by the administrations.

The RIA process and the categories applied in the WB region varies widely. Several administrations, including $\mathrm{BiH}$ at all levels and Serbia, formally recognise two categories or types of RIA studies, depending on the expected magnitude or significance of the impact of proposals. An initial analysis, usually at the legislative planning phase, is first conducted on all proposals, then used to assess and confirm the need for a full-scale, in-depth analysis through a so called "full or comprehensive RIA". Terms such as "preliminary", "shortened" or "abbreviated" RIAs are used in the BiH administrations to indicate the initial or basic-level analysis that is normally conducted at an early stage of policy development ${ }^{5}$. Development of comprehensive RIAs in many $\mathrm{BiH}$ administrations has not yet been fully institutionalised.

There is a risk, however, that these "basic" RIA reports, prepared in the early stages of policy planning, are not updated and strengthened later to provide useful input for the final decisions. Even if a proposal is considered to have a relatively small impact at an early stage, it is important to regularly review, and potentially, update, the initial analysis in the later stages of policy development and legal drafting. Some changes in the draft law can have major consequences that require thorough analysis and consideration.

Serbia formally differentiates two types of RIA: basic and full. Which of the two is required is determined at the planning stage, based on the anticipated impact. The proportionality principle is thus used to manage administrative resources and skills. Clear criteria and thresholds are established in the RIA regulations that are used to determine whether to use basic or full RIA. The Public Policy Secretariat (PPS) has the authority to make the final decision, and actively confirms whether a proposal is exempt from RIA or whether a basic or full-fledged RIA should be conducted.

If implemented fully and consistently, this two-tier approach can serve as an effective filtering mechanism. It allows resources to be allocated and prioritised for analysing the most important proposals that are expected to have the largest regulatory impacts. However, if it is not implemented and enforced fully and consistently, this approach risks complicating the RIA process by establishing different standards and parallel processes, requiring more resources and efforts for overall management and oversight of the process. It also runs the risk that ministries will classify too many measures as having relatively limited impact, to avoid the burden of the requirement to conduct comprehensive RIA analysis. Clear criteria and strong oversight are necessary for a two-tier RIA system to run effectively.

On the other hand, the majority of WB administrations, including Albania, North Macedonia and Montenegro, do not formally differentiate RIA types based on the anticipated impact. Instead, the significance of the impact and importance of proposals is normally considered by ministries, and later by the RIA oversight body, when reviewing the draft RIA proposals. This is another model of filtering and

\footnotetext{
5 The term "basic RIA" is used here to refer to all the different types of basic, shortened or preliminary RIA studies normally conducted at the initial stage of policy development.
} 
triaging to establish standards and requirements of analysis, based on the anticipated size and significance of regulatory proposals. The challenge in this informal approach is to establish clear and objective criteria and rules for a differentiated approach to impact analysis, fully understood and implemented by all parties involved. In addition, such decisions should be made as early as possible in the RIA development process, to leave enough time for planning and implementation of in-depth RIA analysis.

Regardless of the filtering mechanism and approach applied, it is important that the RIA system and requirements allow proportionate analysis of impacts, based on the anticipated benefits of such analysis. The RIA process should be manageable for the administration's available resources, capacity and skills.

In Kosovo, the ex ante analysis is carried out as part of so-called Concept Documents. These are effectively considered ex ante RIA reports by the administration. The Concept Documents, which contain detailed analysis of the proposal, the options, possible impacts and risks, are prepared early in the legislative planning process. They must be approved by the government before the annual legislative plan is approved and legislative drafting can begin. Applying a high standard of analysis and a requirement for formal approval early in the process is a positive feature of Kosovo's RIA system. At the same time, the design of its system and the processes in place do not allow for updating the RIA report, once it is approved. This could provide a more comprehensive and relevant assessment of the potential impacts, considering all the details that can emerge during drafting of legislation.

Additionally, most administrations, such as $\mathrm{BiH}$, Kosovo, Montenegro, North Macedonia and Serbia, have separate fiscal/budget impact assessments (FIA/BIAs). These are required for all proposals likely to have some financial impact (usually mainly cost estimates) on the state budget. These fiscal impact assessment forms or their summaries are to be included in the main RIA report. The methodology and process of FIA/BIAs is often managed directly by ministries of finance. Other administrations, like Albania's, have adopted fiscal impact assessment as part of the main RIA analysis, and no separate form is available to report fiscal impacts only. The Albanian RIA template requires reporting on the summary page the total expected costs for the state budget in the upcoming three years. In addition to RIA, all the WB administrations are required to use explanatory memoranda to present summaries of policy proposals and provide explanations of legal and regulatory provisions contained in the draft. This can help show the relevance of RIA and help analyse impacts better. These documents may include a summary of the analysis and the main conclusions of RIA reports.

\section{Key conclusions}

Ex ante RIA systems of the WB administrations are primarily focused on the analysis of draft initiatives introduced through primary legislation. In Albania, Kosovo and North Macedonia, regulatory proposals initiated through secondary legislation, even those with potentially significant impacts, are not required to undergo systematic oversight using RIA methodologies. This creates gaps and risks in the regulatory management of the WB administrations, especially considering the weaknesses in implementation in other administrations that formally require RIAs on secondary legislation. Exemptions from RIA rules are established in the relevant regulations. All the administrations appear to recognise the importance of prioritising and conducting further in-depth analysis of the most important regulatory proposals. No clear criteria and operational procedures are in place, however, to enforce this rule consistently in every area.

\subsubsection{Quality requirements for RIA analysis}

Are there sufficient methodologies, standards and procedures in place to ensure an adequate level of analysis of policy proposals as part of individual RIA studies?

\section{Introduction}

Conducting RIA is an administrative task involving its own costs and risks. If the outcome of the RIA process is poor and/or inadequate, the quality of decision making will suffer. Poor outcomes may breed disillusionment and cynicism about the effectiveness of RIA as a policy development tool. An RIA process 
and analysis that is based on the best available information and can deliver high-quality recommendations is thus essential to achieving evidence-based and inclusive policy making.

Quality is vital at all phases of the RIA process, whether planning, information and data collection, verification, analysis, consultation, oversight or reporting. In-depth, robust analysis is particularly helpful for objectively assessing and comparing alternative policy options. At the same time, the level of analysis should be proportionate to the anticipated benefits of conducting such analysis, and it should be the most significant regulatory proposals that are subject to in-depth study.

Standards of analysis of policy proposals and their impacts are normally established in the guidance and methodological documents and other relevant tools. The RIA system and methodology should be geared towards an integrated approach in which all types of impacts and risks - economic, social and environmental - can be systematically analysed in a wide range of sectors and types of proposals. Clear standards should be established for data and information collection and analysis.

OECD Best Practice RIA Principles states that it is necessary for RIA to go beyond direct economic impacts and include various types of impacts, such as impacts on the environment, social impacts, impacts on innovation, cross-border impacts and also second-round effects and unintended consequences (OECD, 2020).

Practical methodologies and techniques are critical for RIA systems that function well. They can show how to appraise different policy options, in order to compare and select the one expected to deliver the highest net benefit for the country and society as a whole. Internationally, many different tools and techniques are used for options appraisal. Those most widely used in RIA systems are: cost-benefit analysis (CBA); cost-effectiveness analysis (CEA) and multi-criteria analysis (MCA). While CBA is often considered the standard appraisal technique, since it can produce the best results, it is not easy to apply fully and effectively. It is also challenging to provide full monetisation of impacts. Monetisation of benefits, in particular, can be very challenging. This is particularly an issue for administrations with limited analytical capacity and data.

It is important that the RIA process promote consideration of alternative policy options, including non-regulatory ones. Even if fundamentally different alternative options are not available, applying analytical thinking and tools can help policy makers and stakeholders grasp the likely impacts and risks of the preferred (only) policy option. RIA may help identify less costly policy variations. It can also consider ways to implement and enforce the regulations that can help use public resources more sustainably and efficiently.

In addition, guidance documents can draw attention to methodologies and topics to consider for specific impact tests in areas of priority policies. These might include analyses of impacts on gender and social equality, impacts on business and SMEs, and administrative burdens. Institutions considered to be the centre of expertise in these areas (e.g. departments or agencies responsible for gender equality), should be involved in defining the methodology and setting quality standards in their core expertise.

As a key government document presenting the impacts of policy and legislative proposals, the RIA report should summarise and present clearly the findings of the analysis, describing all types of impact, including impact on the public sector and state budget. The role of ministries of finance in the process is key in this regard. The RIA system should link to the budget process to ensure that additional financial costs, benefits and risks to the state budget on new policy proposals are considered in the review and planning of budgetary allocations in particular sectors. It is important that the relevant methodologies for budget preparation/costing and calculation of impacts of policies be fully aligned, so the estimates of likely impacts provided in RIA, and the financial estimates included in the budget process, remain consistent.

Finally, it is critical that the level of analysis of different types of impact chosen for individual RIAs match the expected level of benefits of the analysis. Resources are limited, and a proportional, targeted approach to analysis must be applied to determine the resources and standards of analysis in each case. 


\section{State of play in the Western Balkans administrations}

The RIA guidance and methodologies of all WB administrations formally set a high standard for analysis and options appraisal. They recognise and encourage the need for systematic analysis of many different types of impact, whether economic, social or environmental. Guidance documents of all the administrations acknowledge the need to explore alternative options when conducting analysis (Table 2.5).

\section{Table 2.5. Requirements for options identification and use of options appraisal techniques}

\begin{tabular}{l|c|c|c|c}
\hline & $\begin{array}{c}\text { Requirement to } \\
\text { consider a "Do } \\
\text { nothing" option }\end{array}$ & $\begin{array}{c}\text { Requirement to consider at } \\
\text { least one alternative option }\end{array}$ & $\begin{array}{c}\text { Recommended } \\
\text { period for appraisal of } \\
\text { options }\end{array}$ & $\begin{array}{c}\text { Common appraisal techniques } \\
\text { recommended for RIA } \\
\text { (CBA, CEA, or MCA) }\end{array}$ \\
\hline Albania & Yes & Yes & $5 / 10$ years & CBA + MCA \\
\hline BiH (State) & Yes & Yes & Not established & CBA \\
\hline BiH (Federation) & Yes & Yes & Not established & CBA \\
\hline BiH (RS) & Yes & Yes & Not established & No \\
\hline BiH (BD) & Yes & Yes & $3-5$ years & All three \\
\hline Kosovo & Yes & Yes & Not established & All three \\
\hline Montenegro & Yes & Yes & Not established & All three \\
\hline North Macedonia & Yes & Yes & Not established & All three \\
\hline Serbia & Yes & Yes & & \\
\hline
\end{tabular}

Source: SIGMA analysis of RIA regulations and methodologies of the WB administrations.

The formal requirement to conduct specific impact analysis, or tests that should be taken into account, should include a diverse field of issues considered to be relevant. These might range from impacts on competition and on small and medium-sized enterprises (SMEs), and to gender impact analysis (Table 2.6). They are not, however, always supported by a detailed practical explanation on how to perform the specific impact analysis, and how the existing specialist knowledge and resources from other relevant institutions could help deliver the best results. At the same time, the formal rules do incorporate some good approaches for special impact tests. The Serbian regulation and guidance on RIA suggest conducting a full gender-impact analysis based on an initial gender-impact test. It also requires other special impact tests to be conducted, including on SMEs and on competition. It is not clear, though, how consistently these rules are applied in practice. A new gender impact test is being prepared and tested in Serbia as part of the new RIA Manual, which was introduced in the summer of 2020.

Table 2.6. Selected impact and specific tests expected to be considered in RIA, based on existing methodologies

\begin{tabular}{l|c|c|c|c|c}
\hline & $\begin{array}{c}\text { Budget/fiscal } \\
\text { impact }\end{array}$ & $\begin{array}{c}\text { Economic, social and } \\
\text { environmental Impacts }\end{array}$ & SME impact test & $\begin{array}{c}\text { Impact on } \\
\text { gender equality }\end{array}$ & $\begin{array}{c}\text { Estimation of administrative } \\
\text { burdens: Standard Cost } \\
\text { Model (SCM) }\end{array}$ \\
\hline Albania & Yes & Yes & Yes & No & Yes \\
\hline BiH (State) & Yes & Yes & No & No & No \\
\hline BiH (Federation) & Yes & Yes & No & No & Yes \\
\hline BiH (RS) & Yes & Yes & No & No & Yes \\
\hline BiH (BD) & Yes & Yes & No & Yonly for full RIA) \\
\hline Kosovo & Yes & Yes & Yes & Yes & Yes \\
\hline Montenegro & Yes & Yes & No & No & Yes \\
\hline
\end{tabular}




\begin{tabular}{l|c|c|c|c|c}
\hline North Macedonia & Yes & Yes & No & No & Yes \\
\hline Serbia & Yes & Yes & Yes & No $^{*}$ & Yes \\
\hline
\end{tabular}

Note: * The new Serbian RIA Manual (2020) requires implementation of a Gender Impact Test, but the relevant guidance is not yet prepared. Source: SIGMA analysis, based on the review of RIA methodologies and guidance.

Administrative burdens are generally expected to be assessed as part of the RIA, but only a few administrations work with detailed, practical guidance that explains how measurements through the Standard Cost Model (SCM), a methodology used to measure such tasks, should be conducted. Kosovo has a separate manual on SCM, while guidance on SCM in Albania, North Macedonia, Montenegro and Serbia is part of the main RIA methodology document. In Albania, North Macedonia and Montenegro, the guidance documents do not include detailed practical advice and examples to help with the implementation of SCM.

Except for BiH BD, RIA methodologies in all the administrations contain guidance on the use of at least some of at least one or more of the three main analytical techniques: cost-benefit analysis (CBA), cost-effectiveness analysis (CEA) and multi-criteria analysis (MCA). The guidance often fails to provide enough insight into the application of these comparison techniques, or appropriate examples of the use of these techniques. CBA is acknowledged as one of the preferred appraisal techniques in most WB administrations, but full technical guidance on how it should be implemented is not available (e.g. the time period, the discount rate to apply and the process for achieving it). Albania recognises CBA as the preferred method of options appraisal and analysis, but the use of other methods, such as MCA, is more often encouraged. Ministries have available a CBA calculation template and separate guidance on the time period and discount rate to be used for appraisal. Implementation of such analytical methods and techniques requires specialist knowledge and skills that the administration cannot yet provide.

Throughout the WB administrations, the centres of expertise in the administration on various thematic aspects of RIA are only exceptionally involved in developing guidance materials and standard setting for RIA. This means that civil servants developing RIA have limited possibilities for tapping into existing expertise in such areas as economic, social and environmental impacts, impacts on gender equality, impacts on employment, etc. This can make it more difficult to develop high-quality RIAs.

Formally, in all WB administrations, the link between RIA and the state budget process is well developed in the RIA methodologies and processes. Most administrations have incorporated the official guidance on determining fiscal impacts in their RIA systems. Several administrations, such as those of $\mathrm{BiH}$ and Serbia, use separate forms and methodology to assess and report the impact of regulatory proposals on the state budget.

Finally, while countries in the region acknowledge the need for applying the principle of proportionate analysis, only Serbia specifies detailed criteria in its RIA methodology that can help identify the most significant regulatory proposals for more detailed analysis. The criteria for determining significant impact thresholds in Serbia include, for example: a level of anticipated fiscal impact greater than $0.1 \%$ of the state budget, or an impact on 200,000 citizens or more. In general, it will be hard to apply the proportionality principle without clearly established criteria and a process including external oversight and checks.

\section{Key conclusions}

Formal standards and requirements for analysis are set quite high across all administrations of the WB region and cover a broad range of impact, including economic, social and budgetary/fiscal impact. The relevant methodologies in several WB administrations recognise and recommend the use of various advanced appraisal techniques, analytical tools and methods, such as CBA, CEA and MCA, as well as $\mathrm{SCM}$, for estimating administrative burdens. Application of these methods and standards require strong analytical skills and expertise in line ministries and the centre of government (CoG). This, and the fact that 
triage and filtering mechanisms for identifying the most significant regulatory proposals for in-depth analysis have not been established, makes it difficult to conform with high standards of analysis. National methodologies on RIA acknowledge the need to be proportionate in the analysis, but only Serbia has a clear set of criteria for determining the threshold of significant impacts.

\title{
2.1.4. Organisation of the RIA process in ministries
}

\author{
Are there clear rules and procedures established in ministries for planning, conducting and \\ completing individual RIA studies?
}

\section{Introduction}

Internal working procedures, organisational structures and co-ordination mechanisms in ministries should facilitate the RIA process. They should ensure that all relevant units of ministries are consulted, and that adequate internal oversight is provided for in order to deliver an effective outcome. To implement RIA effectively, line ministries must be receptive to changes and development of RIAs in their own policy domains. They also need to participate in the development of RIAs of other ministries, if necessary, to ensure policy co-ordination and share essential expert knowledge and information in specialist areas. This can be done by setting up official (inter-ministerial) working groups for complex, cross-cutting regulatory proposals. Experts from various institutions and agencies can be invited to support analysis in specialist areas. Informal exchanges between officials from different institutions can help share key data and information. Administrations can establish central support structures within the CoG to help prepare for RIA and ensure that ministries co-operate. Internal ministerial units, or designated officials to lead on RIA policy in ministries, are also important, to facilitate intra- and inter-ministerial co-operation.

Ultimately, however, it is the lead ministry's responsibility to ensure adequate planning and organisation of policy analysis and RIA work, as part of the activities of legislative drafting and policy development. All phases of the RIA process, and the roles and responsibilities of units and specialists involved in policy development, should be clearly established in the relevant (ministerial) regulations and working procedures.

Internal rules should be clear on the key steps in the RIA development process, such as who leads the RIA work, how and when a draft RIA report can be considered completed and ready for public consultation, and who formally signs off the RIA report for submission to government for approval and eventual publication. As a general rule, completed RIAs should not be shared with the public or stakeholders without an internal quality check and approval. Official sign-off of RIA reports by a responsible minister, deputy minister or general secretary at key stages of policy development (e.g. at the initiation of inter-ministerial or public consultations, or the final submission of the report to the government for approval) can help improve the quality of RIA process, strengthen internal co-operation and deliver better outcomes. This statement, by ministers or senior officials, would confirm that the findings of RIA study are based on the best evidence available, and that the required procedures have been followed. Ultimately, ministers and senior managers are also key beneficiaries of the RIA process, since it provides critical information for decision making. The senior management of line ministries needs to stay informed about the progress made for individual RIAs and be able to intervene when the process is unduly delayed.

The work planning of the government and ministries needs to allow officials the time and information to plan and complete the RIA process, and to consider other important processes, such as planning for public consultation and resources, and the capacity of ministries for other important tasks.

\section{State of play in the Western Balkans administrations}

Working procedures and approaches to the organisation of RIA work in line ministries are comparable among the WB administrations. In general, line ministries lack internal regulations or guidance on organising and co-ordinating work within ministries, to help develop policies in general and RIA in particular. Work on RIA in line ministries is primarily guided by the main regulatory and methodological 
documents provided centrally. Ministries have no clear processes to ensure the smooth initiation, planning, organisation and completion of RIAs. This includes resource planning and allocation of internal analytical resources for RIA work, as well as internal quality checks.

Kosovo, Montenegro, BiH RS and North Macedonia have instituted a practice of a sign-off of the final draft RIA reports by ministers or general secretaries of ministries. They effectively validate the quality of analysis and evidence, before the reports are submitted to the government for approval. This formal sign-off of the RIA report confirms at the highest level that the RIA analysis and findings are based on the best evidence and analysis available, following the established RIA guidance. North Macedonia also has central guidelines for organising the RIA process and work within ministries. It largely repeats the guidance and rules set by the central RIA regulations, however.

In all WB administrations, the RIA preparatory process is linked with the government legislative planning. In every administration but Kosovo's, the work on a legislative proposal, including RIA, starts after approval of the government's legislative plan. In Kosovo, the ex ante RIA system is built on Concept Documents that must be approved before the measure is included in the legislative work plans. This helps, well before the legislative drafting, to develop important evidence on the problem and the objectives, as well as on the potential impact of the proposal.

North Macedonia has been using annual RIA plans to help ministries prepare, plan and prioritise RIA work. RIA plans must be prepared alongside the preparation of the annual work plan of the Government and are later published on the Government's central electronic database of regulations (ENER), 15 days after adoption of the Government's annual work programme. They should include information on the purpose of the legislation and stakeholder consultation plans.

Ministerial consultation plans adopted in Montenegro 15 days after the adoption of the Government Work Plan could serve a similar purpose, but are methodologically not linked to the RIA process. Other administrations do not appear to have procedures for planning the RIA work early in the process, to help with resource allocation and preparatory work, including public consultation.

It is important for ministries to initiate work on RIA early in the process, as soon as an internal decision is made to propose a new regulatory change based on the strategic priorities and plans in their respective areas. This can help reduce additional pressure on ministerial capacities. Analytical resources, for example, can be centralised to serve various departments in a ministry, allowing more time for preparation of RIA and legislative proposals. Formal procedures similar to those used in Kosovo (which require the approval of Concept Documents before the measure is even considered for inclusion in the annual legislative plan) or North Macedonia (which requires preparation of RIA plans) can help ensure that the RIA process itself starts early.

Several administrations, including BiH BD and Kosovo, require RIA working groups to be set up to conduct the analysis. The Secretary Generals of line ministries in Kosovo, for example, establish official working groups that are responsible for the development of RIAs. These working groups regularly involve officials from other government bodies, such as other line ministries or agencies, as well as stakeholders.

Serbia and several other administrations do allow for setting up working groups to develop RIAs. However, it is more standard practice to set up a working group to develop a legislative or policy proposal, covering all tasks, including RIA. The group typically includes experts in the field with specific tasks and responsibilities, including RIA-related tasks. In line ministries, RIA is co-ordinated by civil servants trained in RIA. In Albania, the work on RIA is primarily led by the RIA co-ordinators, who work closely with the officials drafting the law. In North Macedonia, the responsibility for RIA development is assigned to the head of individual sectors (policy units).

In general, in all the administrations, it is not clear how economists and analysts in ministries are used to provide analytical input for the RIA process. This is nevertheless essential, particularly for analysing complex regulatory proposals using CBA or other analytical and policy appraisal techniques.

In most administrations, except for the BiH Federation, BiH RS, Montenegro and Serbia, designated officials in ministries, or "RIA co-ordinators" are tasked to provide internal guidance and support for the 
RIA preparation process (Table 2.7). Some of these RIA networks, like one at the BiH State level, are formally established through central co-ordination structures (the Expert Working Body). Albania established an RIA network that involves officials from line ministries representing legal departments, budget departments and some policy departments. The network plays an important role in helping to prepare RIA reports for their ministries, in line with central guidance. In Kosovo, RIA co-ordinators in line ministries are part of the Department for European Integration and Policy Coordination (DEIPC). Ministries in North Macedonia have established ministerial RIA co-ordinators and deputies who support RIA work and the Government's wider "Better Regulation" agenda.

\section{Table 2.7. Organisation and planning of RIA}

\begin{tabular}{|c|c|c|c|c|}
\hline & $\begin{array}{c}\text { Are there designated } \\
\text { officials co-ordinators } \\
\text { for RIA in line } \\
\text { ministries? }\end{array}$ & $\begin{array}{l}\text { Is RIA required before a } \\
\text { measure is included in } \\
\text { the legislation or } \\
\text { government work plan? }\end{array}$ & $\begin{array}{l}\text { Official sign-off of draft } \\
\text { final RIA reports before } \\
\text { submission to the } \\
\text { Government }\end{array}$ & $\begin{array}{l}\text { RIA report must be included in } \\
\text { the final package submitted for } \\
\text { approval to the Council of } \\
\text { Ministers }\end{array}$ \\
\hline Albania & Yes & No & No & Yes \\
\hline BiH (State) & Yes & $\begin{array}{c}\text { Yes } \\
\text { (basic RIA) }\end{array}$ & No & $\begin{array}{c}\text { Yes } \\
\text { (for full RIA) }\end{array}$ \\
\hline $\begin{array}{l}\mathrm{BiH} \\
\text { (Federation) }\end{array}$ & No & No & No & $\begin{array}{c}\text { Yes } \\
\text { (for full RIA) }\end{array}$ \\
\hline $\mathrm{BiH}(\mathrm{RS})$ & No & No & Yes & Yes \\
\hline $\mathrm{BiH}(\mathrm{BD})$ & Yes & No & No & Yes \\
\hline Kosovo & Yes & Yes & No & Yes $^{*}$ \\
\hline Montenegro & No & No & Yes & Yes \\
\hline $\begin{array}{l}\text { North } \\
\text { Macedonia }\end{array}$ & Yes & $\begin{array}{c}\text { Yes } \\
\text { (basic RIA) }\end{array}$ & Yes & Yes \\
\hline Serbia & No & No & No & Yes \\
\hline
\end{tabular}

Source: SIGMA analysis, based on the review of methodological and regulatory frameworks of RIA and information provided by the Western Balkan administrations.

\section{Key conclusions}

In general, line ministries in the WB administrations do not have clear internal rules to guide and support policy making and RIA preparation within ministries, including for organisation of internal consultations, allocation and use of different experts and final quality checks. Final draft RIA reports are officially signed off by ministers or senior officials only in Montenegro, BiH RS and North Macedonia. Planning and preparation of RIA work is generally linked with the annual legislative plans of the government, but the formalised steps for ensuring that the analytical process is consistently initiated as early as possible in the process are only in place in Kosovo, and to some extent in North Macedonia and BiH State (limited). Internal resources for RIA support and guidance, through professional networks of co-ordinators and analytical expertise, exist in most administrations. Annual planning of RIA work is established only in North Macedonia. 


\title{
2.1.5. Central management, support and capacity building for RIA
}

\author{
Are the functions for central management, support and training on RIA allocated to and \\ implemented by the relevant national institutions?
}

\section{Introduction}

The RIA process affects all institutions and civil servants in the central government who are involved in policy-making work. It also affects the policy dialogues and consultations with external stakeholders and partners. RIA is a key tool for a government's "better regulation" agenda, including administrative simplifications and burden reduction programmes. Strong central management of the government's RIA process is thus important not only to ensure that policy development and lawmaking proceed smoothly, in an inclusive and evidence-based manner, but also for achieving government objectives in better regulation and enhancing the business environment.

Strong central structures and processes are needed to support high-quality analysis through RIA, to facilitate inter-ministerial co-operation, to promote knowledge sharing in the administration and to ensure consistent application of new tools and approaches in all areas and sectors. The central management of the RIA system should include providing practical methodological advice and support to staff in line ministries throughout the RIA process. Support and guidance can take different forms, including in-person discussions, guidance and meetings, providing advice online or electronically, regular communication and holding discussions with ministerial officials on frequently raised questions, promoting co-operation and facilitating a pooling of knowledge and information between the ministries and institutions involved in the process.

The central management of RIA should also cover training and capacity building, with the aim of establishing institutional mechanisms for continuous training and capacity development of staff involved in policy making and RIA work. This should be organised in close partnership with the institutions responsible for training civil servants, such as civil service institutes and academies.

Developing the necessary capacity and skills in an administration is a continuous process and demands time and resources. Regular interventions should be organised, through trainings, workshops and other mechanisms, to develop capacity for RIA and individual analytical methodologies. All officials, particularly those new to policy-making work, need to fully understand RIA requirements and methodology. Training for RIA purposes must be available on an ongoing, regular basis. This can help ensure that the administration can fulfil the requirements it has set for policy making, and that the training needs of different categories of officials are consistently met. A training schedule should thus be provided to combine general training with specialist training for the staff who perform analytical work, such as cost-benefit analysis.

Professional networks of RIA practitioners, such as officials involved in RIA work, analysis and scrutiny and oversight, can be important mechanisms for continuous professional development and capacity building. This can be ensured by establishing (in)formal RIA networks or groups. The central management structure for RIA should help set up and operate these mechanisms.

The important central functions of RIA policy management, guidance and support, as well as training, are often centralised and allocated to institutions based in the CoG or ministries responsible for certain CoG functions. Embedding these functions in the CoG can help establish synergies with other procedures led by the centre for policy planning, decision making and co-ordination. It is the CoG's role to ensure that ex ante RIA aligns with other processes and tools, such as stakeholder consultation and engagement, ex post RIA and evaluation. This can help avoid duplication, minimise confusion and inefficiencies in the government decision-making process, and achieve better policies.

\section{State of play in the Western Balkans administrations}

The responsibility for managing the RIA policy and central support and guidance in the WB administrations is typically attributed to a CoG institution. In some cases, it is assigned to key ministries that perform 
RIA-related CoG functions. In Albania, the Unit of Programming of Regulatory Acts and RIA of the Prime Minister's Office (PMO) is responsible for RIA policy management and other central functions, including oversight and quality control. The PPS in Serbia manages the RIA policy as part of its broader mandate for public policy management. It gives specialist support to ministries during the preparation of RIA, and performs other key functions. In North Macedonia, the function is assigned to the Regulatory Reform Department of the Ministry of Information Society and Administration (MISA) which manages RIA, as a central tool for regulatory decision-making and better regulation agenda. The department is also responsible for managing the central government registry of regulations (ENER), the platform also used for online consultation of the draft proposals with the general public. The Ministry of Finance in Montenegro is tasked with the central management function for RIA policy, as part of its broader mandate on improvement of business environment and regulation. The Government Co-ordination Secretariat (GCS) within the Office of the PM of Kosovo provides guidance and support to line ministries in developing RIAs ${ }^{6}$.

In some administrations, such as the $\mathrm{BiH}$ State level, there are several institutions responsible for different aspects of RIA policy management, without a clear division of roles and responsibilities between them. Key roles are assigned to the Ministry of Justice, the General Secretariat and the Legislative Office, but also the Ministry of Finance and Treasury (fiscal impact). The specific roles and tasks of these institutions in the RIA development process, and in managing RIA policy and support to ministries is not clearly established. This can reduce the effectiveness of implementation.

The central management units of RIA, among other tasks, provide guidance and methodological support to ministries in preparing individual RIA. Practical guidance and support for RIA is generally provided through published methodological documents and materials. The online and electronic tools ministries can consult in preparing individual RIA studies are limited. Best practice RIAs, although limited in number, are available and shared in most systems, but not proactively. No system has a publicly accessible library or database of good RIA examples. Specialist advice to ministries to perform certain aspects of impact analysis, such as gender or environmental impact assessments, using the knowledge and skills of specialist agencies and ministries, is not systematically available or used in any administration.

In all administrations, except Serbia and Kosovo, training on RIA is provided only sporadically, and no systematic RIA training programmes are available to civil servants. The number of officials trained on RIA in the region in 2018 and 2019 highlights the weaknesses in this area (Table 2.8). Some administrations, like North Macedonia and BiH RS and BiH BD, offered no specialised training on RIA in 2019, while training offered in Albania - although substantial in outreach - was ad hoc, organised and delivered with the support of external partners (mainly with the support of OECD/SIGMA). Similarly, the only specialised RIA training offered in Montenegro in 2019 was with the help of OECD/SIGMA.

\footnotetext{
${ }^{6}$ The structure and organisation of the CoG institutions in Kosovo were changed in late 2020, after this study was completed.
} 
Table 2.8. Specialised training on RIA

\begin{tabular}{l|c|c|c}
\hline & $\begin{array}{c}\text { Availability of regular training on } \\
\text { RIA for ministries }\end{array}$ & \multicolumn{2}{|c}{$\begin{array}{c}\text { Number of officials trained } \\
\text { (regular and ad hoc training on RIA) }\end{array}$} \\
\hline Albania & No & 2018 & 2019 \\
\hline BiH (State) & Yes & 174 & 190 \\
\hline BiH (Federation) & No & 203 & 292 \\
\hline BiH (RS) & No & 63 & Not provided \\
\hline BiH (BD) & No & 25 & 0 \\
\hline Kosovo & Yes & 87 & 278 \\
\hline Montenegro & No & 234 & 12 \\
\hline North Macedonia & No & 0 & 0 \\
\hline Serbia & Yes & 148 & $118^{*}$ \\
\hline
\end{tabular}

Note: Figures for Albania include the number of ministry officials who attended various workshops and events organised and supported by SIGMA, in co-operation with the PMO. BiH State figures include numbers of officials with training in RIA, policy impact assessment and administrative simplification. Figures for training in Montenegro include the number of officials who attended a workshop on fiscal impact analysis organised by SIGMA.

* The figures for Serbia would be higher if all related training were also considered (including training on policy impact assessment and administrative simplification): 236 in 2018 and 233 officials in 2019. Data on BiH (BiH Federation, BiH RS and BiH BD) are taken from the final report of the PAR-funded Project: "Establishment and/or strengthening of capacity of the institution/s for control of regulations and establishment of the system of reduction of administrative barriers".

Source: SIGMA analysis and estimates based on the information collected from the WB administrations and RIA units, as well as external reports.

In Serbia, by comparison with the other administrations of the region, the organisation and resource allocation for RIA management and training is better established. The PPS is responsible for setting the direction and managing overall policy development. As the RIA management and oversight body, it is a well-resourced example for the WB. It also supports capacity building in every aspect of the policy development process.

Sustainable capacity development can only be achieved when training is fully institutionalised and integrated into the civil service training curriculum. Most national training institutes for civil servants do not appear to offer any RIA-related training. When they do, the number of training sessions offered is too low. RIA training in Serbia is usually organised by the National Academy for Public Administration and instructed by PPS staff. One or two RIA training sessions a year are standard, with more offered if external support is available. At the BiH State level, training of officials is managed in collaboration with the Civil Service Agency. The Albanian School of Public Administration offers training that includes policy making, but no training on the government-approved RIA methodology is offered.

Albania and Kosovo have established or are in the process of establishing official RIA networks or groups to promote co-operation among practitioners and sharing knowledge and skills through formal or informal platforms. Serbia also has a network of RIA practitioners, but it is not formalised. Even where formal networks of RIA practitioners exist, they are not yet interactive groups in which professionals exchange information, share knowledge and support each other. Central RIA bodies do not use these networks to strengthen capacity and share skills and expertise in their administrations.

\section{Key conclusions}

The institutional responsibility for central management of RIA policy and the provision of advice and support to ministries during RIA preparation is established in all administrations of the region, often as part of the main CoG institutions or ministries performing CoG functions. In the BiH State level, several bodies are expected to be involved in RIA management and capacity building, but the roles and responsibilities of 
various institutions in this process are not clearly established. In recent years, Serbia and Kosovo appear to have devoted relatively more resources and effort to RIA training compared to their neighbours. Regular and in-depth training on RIA through national civil service training institutions has not been set up and is not available in the whole region. RIA training in most administrations is ad hoc and depends on having assistance from external projects. Several administrations have formal and informal networks and groups of RIA practitioners that could contribute more to capacity building and continuous development if they were to share knowledge and expertise with colleagues from other ministries.

\subsubsection{Oversight and quality control of RIA}

\section{Do the institutional set-up, regulations and methodologies ensure systematic oversight and scrutiny of the RIA process and quality?}

\section{Introduction}

Oversight and quality control are essential elements for a well-functioning RIA system. They ensure that the formal processes, quality standards and requirements established in the policy-making system are systematically followed, delivering the anticipated results of good quality policy design and outcomes.

Procedural and analytical quality standards and demands for RIA need to be enforced systematically and consistently. Political interference should be avoided during data gathering, consultations and analysis. Such interference can undermine the credibility and value of the end product, which is meant to provide data-driven, fact-based and unbiased advice so ministers can make informed decisions. The preconditions for the success of RIA must be endorsed by political decision makers and senior management. Such officials should hold their administrations accountable for the way in which decisions are prepared when they are submitted for final review and adoption.

There are different ways to set up the oversight and quality-control function in an RIA system. These are often combined with RIA management and support functions. In many countries, the function is allocated to CoG institutions, which are best positioned to enforce internal rules and standards of quality control, as part of other checks. But the process of quality control and oversight may also include more than one institution, including those dealing with initial quality review, triage and issuing formal opinions on the final draft RIA reports.

Ensuring effective, consistent implementation of this "gatekeeping function" is important for an RIA system if it is to result in the anticipated high-quality input for policy design. The function often involves provision of a formal opinion from the quality-control body on the quality of analysis and evidence presented in the RIA report, as well as compliance with RIA processes and rules. The general approach should be not to submit a proposal to the government for final approval unless the supporting RIA and analysis is considered to be of sufficient quality. Ultimately, it is the ministers' responsibility to make final policy decisions, and they should have full access to background analysis, including the opinion issued by the RIA scrutiny body, in making final decisions.

There are different models and approaches applied internationally for institutionalisation and operationalisation of oversight and quality control for RIA. One such model incorporates all aspects of quality control into one body that also conducts overall management of the RIA system, usually within a centre-of-government institution. This body may engage expertise from other institutions to perform oversight and quality control. In another model, quality oversight is performed by independent organisations or bodies that, based on their mandate, function at arm's length from the decision-making process of the government xvii. This model is followed in Germany and the UK, for example. In variations on these arrangements, the organisation responsible for ensuring quality control usually has the mandate to issue negative opinions on RIAs whose quality is in question, and halt or slow down the decision until the shortcomings have been addressed.

Regardless of the institutional set-up, quality control for RIA is, by default, a process that must be conducted by specialised staff with ample experience in developing and conducting RIA. Enough people 
must be involved in this process to conduct adequate scrutiny of individual RIAs, based on the flow of new proposals sent for adoption per year. If quality control is to work effectively, RIAs for the proposals adopted by the government should ideally be spread evenly throughout the year, as noted in the previous subchapter on planning the work.

Scrutiny of RIAs should be transparent and based on a clear, objective assessment criteria and methodology. It may also involve scoring or assessment of draft RIAs (e.g. Red-Amber-Green ratings). Methodology and internal process for quality scrutiny of RIAs is important if the system is to produce the anticipated results. RIA oversight units must have a clear internal process and rules for individual oversight of RIAs. Formal opinions should be issued clearly indicating the main challenges and gaps in the analysis and including practical recommendations on how the draft RIA should be improved to meet the expected minimum standards.

Draft RIA reports, together with the formal opinion of the quality-control body, other supporting materials and the draft proposal, should be presented to the political leadership before the government officially considers and adopts a proposal. This ensures that the findings and conclusions of the RIA analysis, and any gaps or weaknesses identified by the quality check, are made an integral part of the government's ultimate decision-making process. For better regulatory outcomes, it is good practice to publish both the RIA report and the opinion of the quality control body. These are part of the final package submitted to parliament with the draft law.

\section{State of play in the Western Balkans administrations}

The model predominantly chosen by the Western Balkan administrations for RIA oversight and quality control is full integration of all key oversight and management and support functions in a single department or unit, typically in a CoG institution or a ministry performing central CoG functions (Table 2.9). This allows for more efficient management of available resources for the many important functions needed to support the operation of the RIA system. At the same time, having the same unit responsible for establishing the RIA standards and methodology, providing guidance during preparation, and conducting external quality control and scrutiny in the final stages may not be optimal in the long term, given the potential conflicts of interest in performing these different but related functions. Independent oversight has the advantage of offering objective reviews of the quality of RIAs, which can help improve overall RIA standards.

In most WB administrations, except in Albania and BiH Federation, the scrutiny body is responsible for issuing official opinions on draft RIA reports before the regulatory proposal package is submitted to the government for approval. The Albanian RIA unit issues informal feedback to ministries on draft RIA reports. As it is the same unit that reviews the full package of the draft legislation, the draft law technically cannot be processed if the concerns raised by the RIA scrutiny body are not taken on board in the final RIA report.

Line ministries in North Macedonia are required to request an official opinion from MISA on the quality of RIA as part of the standard inter-ministerial consultation process. Opinions issued by MISA can be negative, but do not necessarily influence the process of final approval or automatically initiate revision of the draft RIA before its submission.

Serbia's PPS is responsible for the quality-control function for RIA and issues formal opinions on all draft RIAs. The PPS has the right to return the RIAs to line ministries and require further revision of RIAs before the package is submitted to the Government for final approval. Furthermore, the regulations require that in the case of substantial changes in the draft law or RIA, a second PPS opinion is requested. However, line ministries can proceed with the decision-making process even when they have received a negative opinion.

The Government Co-operation Secretariat in Kosovo is responsible for quality control of RIAs. Because of the unique RIA model applied in this administration, based on the Concept Documents, full scrutiny of its quality is carried out before the start of the legislative process, when the RIA document is submitted for approval. This leaves room for the risk, however, that the impact of the final legislative proposal is not 
properly analysed. The RIA is not normally updated after its approval, so its content and analysis is not checked by the quality-control body against the final draft legislative proposal.

Table 2.9. RIA oversight and quality control

\begin{tabular}{l|c|c|c|c}
\hline & $\begin{array}{c}\text { Is an institution assigned to } \\
\text { perform the RIA quality } \\
\text { control and oversight } \\
\text { function? }\end{array}$ & $\begin{array}{c}\text { Are formal opinions } \\
\text { issued by the RIA } \\
\text { scrutiny body? }\end{array}$ & $\begin{array}{c}\text { Are opinions on } \\
\text { RIA submitted to } \\
\text { the government? }\end{array}$ & $\begin{array}{c}\text { Is a special assessment } \\
\text { methodology available for an } \\
\text { RIA quality check? }\end{array}$ \\
\hline Albania & PMO & No & No & Yes \\
\hline BiH (State) & $\begin{array}{c}\text { The Legislative Office of the } \\
\text { BiH Council of Ministers }\end{array}$ & Yes & Yes \\
\hline BiH (Federation) & $\begin{array}{c}\text { General Secretariat of the } \\
\text { Government }\end{array}$ & No & No & No \\
\hline BiH (RS) & $\begin{array}{c}\text { Ministry of Economy and } \\
\text { Entrepreneurship }\end{array}$ & Yes & Yes & No \\
\hline LiH (BD) & $\begin{array}{c}\text { Legislative Office of the } \\
\text { Office of the Mayor of BD BiH } \\
\text { Government }\end{array}$ & Yes & Yes & No \\
\hline Kosovo & PMO & Yes & Yes & Yes \\
\hline Montenegro & Ministry of Finance & Yes & Yes & Yes \\
\hline North Macedonia & MISA & Yes & Yes & Yes \\
\hline Serbia & PPS & Yes & Yes & \\
\hline
\end{tabular}

Note: The information is based on formal requirements for RIA process as established in the relevant regulations. In BiH State level, the scrutiny is done only on comprehensive/full RIAs, which are limited in number (only two have so far been conducted). In Kosovo, final scrutiny is conducted at an early stage of policy concept development, not when the draft law is finalised and considered for approval.

Source: SIGMA analysis, based on the regulatory and methodological framework of RIA and information provided by the relevant administrations.

The quality of scrutiny and the opinions issued by any oversight body depends in part on the scope and methodological requirements set out in the main regulations governing the RIA process. The mandate and scope of RIA scrutiny, however, is not always clearly established. In North Macedonia, the oversight body is responsible for reviewing and commenting only on procedural aspects, not on the quality of analysis. Albania has no formal requirement to consult with the quality-control body on the final draft RIA, and the check is done as part of a review of the final package of documents submitted for government approval, which is performed by the same PMO directorate.

Several administrations have special assessment checklists used by the scrutiny bodies to review draft RIA reports. These checks, though, focus chiefly on such procedural aspects as how complete the forms are, and not the substance and content of the analysis.

The PPS of Serbia uses a checklist to assess the quality of RIAs and provide scores for individual elements in it. The PPS scrutinises the quality of RIA with the legislative or policy proposal for which it is drafted. Albania has also developed a weighted, stand-alone indicator to assess parts of the RIA report. This makes it possible to systematically categorise RIAs based on their quality. However, it is not clear if it is being used consistently when reviewing draft RIA reports, especially since the feedback to ministries in Albania is given informally and no formal opinions are issued by the scrutiny body. The review of RIAs in Montenegro involves a simple checklist with yes/no answers for different RIA sections. If needed, additional clarification is sought from other sources to conduct a quality check. Because the oversight body in Montenegro is the Ministry of Finance, checks on the fiscal and business impact receive relatively more attention. 
Official oversight of quality is only one of several tasks of the RIA units. Their appropriate staffing level should thus be carefully monitored to ensure that the oversight function is performed effectively. Information from WB administrations about staff numbers involved in implementation of various RIA functions is not detailed enough to establish and assess the level of the resources allocated to external oversight.

Finally, there is a concern that the opinions and feedback provided by the RIA oversight bodies in all the administrations are not fully considered when the legislative proposals are finalised and submitted for final approval. It is also not clear what happens if a negative opinion is issued, and whether that is considered or checked by the relevant CoG institution in preparing the final package for government approval.

\section{Key conclusions}

Procedural requirements for quality control of final RIA reports have been formally established in all WB administrations. Except in Albania and the BiH Federation, the quality-control bodies of other administrations are required to issue formal opinions on the final RIA reports that are submitted to the Government for final approval, together with the draft law and other supporting documents. However, there is no requirement to publish these opinions, except in Serbia. In Kosovo, the quality-control function is performed early in the process, based on the draft RIA report prepared before the legislative drafting process starts. In general, in all administrations, the quality of final scrutiny is primarily focused on procedural compliance, not on the quality of the analysis and evidence presented in RIAs. External scrutiny of RIA is often performed by the body responsible for the overall management, support and guidance of the RIA system. This can create problems for effective final scrutiny and quality check of RIAs, given the limited number of staff working on these functions in most administrations.

\subsubsection{Openness and transparency of the RIA process}

Is the RIA process transparent and open to participation and scrutiny by Parliament,
external stakeholders and partners, and the general public? Introduction

As a key tool of the government decision-making process, RIA can be used to promote the openness and transparency of public administration, facilitate involvement of stakeholders in the policy-development process and increase accountability. First and foremost, this can be achieved by regular publication of individual RIA reports at different stages of the decision-making process. Making RIAs and the draft legislative proposal available to the public for consultation can help stakeholders better understand the upcoming policy and regulatory changes and enable them to participate more meaningfully in developing policy and legislation. Openness in policy making and publication of RIA reports can show how the policy debate evolves through external engagement, and whether the new insights and data obtained during the analytical and consultative processes are considered by the administration in the final design of policy, increasing accountability and transparency. In addition, openness of RIA to external stakeholders can help obtain important information directly from those who are likely to be affected by the policy, thus helping to fill in data gaps and improve the quality of analysis.

One of the key stakeholders in the RIA process is of course the legislative branch. It is a good practice to ensure that the final RIA report is included in the legislative package a government submits to parliament for approval. Parliaments should actively use the underlying RIA analysis and information as part of their review of the government proposal and its expected benefits, costs and risks.

Developing an RIA should be seen as a continuous process. The RIA report thus needs to be updated regularly, when changes are considered or made in the draft legislative proposal, or when new evidence or information emerges that can affect the analysis and conclusions of the RIA. This is also true when the draft law is deliberated on in the Parliament. It requires strong and effective collaboration between the 
Parliament and the executive branch on various aspects of the policy-making and legislative drafting process $^{7}$. Updates to the RIA report are particularly relevant in the case of changes that have a major impact on business costs or the expected budget implications, since, for example, the original budget allocations and planning may no longer be sufficient for full implementation. Similarly, any major changes in implementation and enforcement that could result in significant changes in the original estimates of impact and risks should be reflected in the final RIA report.

Governments should ensure full transparency of the RIA system by providing key information and statistics on the functioning of the ex ante scrutiny process and its impact on the quality of legislation. Information about RIA regulations and rules should be easily accessible to ministry officials and wider stakeholders. Dedicated government websites describing and explaining relevant requirements, regulations and guidance materials in the RIA system, as well as upcoming regulatory changes, can allow stakeholders to keep up to date with the planned policy and regulatory changes likely to affect them. This should be supplemented by information on the functioning and results of the RIA system: the number of RIAs and evaluations completed, number of responses received through public consultation, how these were addressed and other useful information on how the system operates. For full transparency, all finalised RIA reports should be made easily accessible on a centralised website or online electronic library, together with the final draft law and the opinion issued by the oversight body.

\section{State of play in the Western Balkans administrations}

Final RIA reports are formally required to be published in most WB administrations during the public consultation stage and at the time of final adoption by the Government (Table 2.10). In some administrations (e.g. in the $\mathrm{BiH}$ administrations), this applies only to comprehensive/full RIAs that are generally not yet developed and fully introduced. In Kosovo, the government is expected to publish RIAs both during the consultation and the final stage. However, they are not published with the draft laws. As discussed earlier, the RIA Concept Documents in Kosovo are not updated after they are approved at the early stage, even if they are published with the draft law. They do not necessarily present a full, accurate assessment of the impacts arising from the draft law, and this can differ from the original concept on which the RIA was prepared. In Albania, ministries are expected to publish RIA reports during public consultation, but final RIA reports are published on the parliamentary website. In Montenegro, only the RIAs for draft laws are required to be published for public consultation, and RIAs on secondary legislation do not have to be published. Similarly, Albania, Kosovo and North Macedonia have no formal requirement to publish analysis of impacts of secondary legislation, because that is not a formal RIA requirement.

In North Macedonia, the regulations require that RIAs be made publicly available on the government electronic platform, the National Electronic Registry of Regulations (ENER), a comprehensive database of government regulations. Final RIAs are published in Serbia on several websites, since RIAs are part of the official package submitted by the Government: the website of the RIA oversight body (the PPS), the Government website and the Parliament website. The Serbian RIA oversight body publishes the formal opinions it issues on draft RIA prepared for primary and secondary legislation and PIA reports.

\footnotetext{
7 The Interinstitutional Agreement between the European Parliament, the Council of the European Union and the European Commission on Better Law-Making is a good example of such a collaboration and can be accessed at https:/leur-lex.europa.eu/legal-content/EN/TXT/?uri=CELEX\%3A32016Q0512\%2801\%29.
} 
Table 2.10. Transparency and openness of the RIA system

\begin{tabular}{|c|c|c|c|c|}
\hline & $\begin{array}{l}\text { Requirement to publish draft } \\
\text { RIA on laws during public } \\
\text { consultation }\end{array}$ & $\begin{array}{l}\text { Publication of final RIA } \\
\text { reports on a government } \\
\text { website }\end{array}$ & $\begin{array}{l}\text { Submission of RIA } \\
\text { report to Parliament }\end{array}$ & $\begin{array}{c}\text { Existence of a dedicated } \\
\text { government website for } \\
\text { better regulation/ RIA } \\
\text { guidance }\end{array}$ \\
\hline Albania & Yes & No & Yes & No \\
\hline BiH (State) & $\begin{array}{c}\text { Yes } \\
\text { (but only "full RIAs") }\end{array}$ & $\begin{array}{c}\text { Yes } \\
\text { (but only "full RIAs") }\end{array}$ & $\begin{array}{c}\text { Yes } \\
\text { (but only "full" RIAs) }\end{array}$ & No \\
\hline $\begin{array}{l}\mathrm{BiH} \\
\text { (Federation) }\end{array}$ & No & No & $\begin{array}{c}\text { Yes } \\
\text { (but only "full" RIAs) }\end{array}$ & No \\
\hline $\mathrm{BiH}(\mathrm{RS})$ & $\begin{array}{c}\text { Yes } \\
\text { (but only "full RIA") }\end{array}$ & $\begin{array}{c}\text { Yes } \\
\text { (but only "full" RIA) }\end{array}$ & $\begin{array}{c}\text { Yes } \\
\text { (but only "shortened" } \\
\text { RIAs) }\end{array}$ & No \\
\hline $\mathrm{BiH}(\mathrm{BD})$ & No & No & No & No \\
\hline Kosovo & Yes & Yes & No & No \\
\hline Montenegro & Yes & Yes & Yes & $\begin{array}{c}\text { No } \\
\text { (limited) }\end{array}$ \\
\hline $\begin{array}{l}\text { North } \\
\text { Macedonia }\end{array}$ & Yes & Yes & No & Yes \\
\hline Serbia & Yes & Yes & Yes & Yes \\
\hline
\end{tabular}

Note: The BiH Federation publishes only best practice comprehensive RIAs. BiH BD shares some parts of the RIA draft with the stakeholders who are invited for e-targeted consultations. Only North Macedonia has a dedicated website for regulatory policy and RIA. The official website of the PPS in Serbia gives detailed information on the government's approach to regulatory and policy impact assessment and administrative simplification, and publishes key guidance materials (on various websites). In Montenegro, RIA guidelines and other key documents are available electronically through the website of the Ministry of Finance, but it is not comprehensive.

Source: SIGMA analysis, based on a review of existing RIA regulations and methodology and information provided by the relevant administrations.

Albania, Montenegro and Serbia submit final RIA reports to the parliament with the draft law for which the RIA is conducted. RIAs are also published on Parliament's website, together with the draft law and other supporting materials in all these countries.

None of the WB parliaments have set up rules for preparing full RIA for own-initiative laws (i.e. laws initiated by members of Parliament, rather than laws initiated by the government) or for impact analysis of substantial amendments to government-proposed laws that would cover a similar type of impact and risks as those prepared by the executive branch. WB administrations also do not systematically check and update RIAs after the final version of the related draft law has been adopted in parliament. Such omissions can hamper implementation of the legal provisions at a later stage, and make monitoring and evaluation more difficult.

Only North Macedonia and Serbia have dedicated government websites that give information and guidance on the Government's policy and its approach to better regulation, public policy and regulatory management, including RIA, public consultation and evaluation. North Macedonia's ENER website is a good example of a centralised and systemic approach to openness of government regulatory policy. Most administrations publish RIAs on various websites, and no practice in the region has been established to provide centralised, convenient access to all final RIA reports in an online RIA library or database. This could increase transparency and serve as an important source of sharing knowledge and expertise among RIA practitioners. 


\section{Key conclusions}

Despite various efforts and initiatives, most WB administrations face major challenges in ensuring openness and transparency of their RIA systems. This is partly explained by shortcomings in the functioning and openness of other elements of the policy-making system, for example, public consultation and stakeholder engagement in policy development. North Macedonia has a comprehensive central database for regulations, which also provides key information on RIA and better regulation policy. Several administrations, such as those of Albania, Kosovo and North Macedonia, do not have formal processes for publishing ex ante assessments of impacts of new secondary legislation, largely because RIA applies only on primary legislation. Montenegro has a requirement to conduct RIA on secondary legislation, but these are not required to be published. Many administrations publish RIA reports prepared on draft laws, but not systematically, and not on a central database that would allow information and knowledge sharing and transparency. Finally, RIA reports are not checked and updated after formal approval by the Government and, later by the Parliament, even if substantive changes are made during parliamentary deliberations.

\subsubsection{Monitoring, evaluation and continuous development of the RIA system}

\section{Are there mechanisms and procedures in place for regular monitoring and improvement of the RIA system?}

\section{Introduction}

Once they are in place, RIA and other regulatory and policy management tools and processes need to be regularly reviewed and evaluated to identify inefficiencies and weaknesses and to introduce improvements. International practice and approaches in regulatory policy are evolving, and new external challenges, such as COVID-19, have raised discussion of fundamental aspects of government intervention and regulatory quality management and standards, including RIA. Discussions between RIA practitioners, debates between government and parliament and input from external stakeholders, as well as insights from international regulatory collaborators, can provide essential feedback and new ideas for continuous development of RIA systems and how to deliver better results.

Changes to an RIA system can be initiated in incremental steps, and a number of such changes have been identified in this review, but at times, a full overhaul of the system may be required. Enhancing the RIA system can be part of a strategy that encourages reporting on the progress made and the challenges faced.

Major reforms in RIA systems and in government policy making in general need to be carefully planned and managed, as part of a government-wide reform strategy or programme. It is important that any new requirements or changes in standards and processes related to ex ante policy analysis be fully aligned and synchronised with the administrative reforms that governments introduce. Changes in systems and working procedures can be complex and difficult to implement and can only succeed when they have full and continuous support from the political leadership and senior management. To ensure reforms are sustainable, they also need to be planned and implemented based on the existing resources, administrative capacity, administrative culture and traditions.

However, even when no strategic framework is in place for reforms in policy making or for RIA, monitoring and reporting on the functioning of the system, based on some indicators, can still be conducted to assess the progress and impact of RIA, and initiate corrective measures for improvement.

Successful, smoothly run RIA systems can help advance reforms in many other areas of public administration. New requirements and high demands for better policy analysis can help achieve better outcomes in all policy areas and sectors. 
The way in which updates to the RIA system are made and the frequency at which more fundamental improvements occur is not a predefined or standardised process. However, evaluations of an RIA system could usefully take place every four to five years. Important improvements and redesign of RIA systems (or the "Better Regulation" systems in their entirety) should be conducted based on systematic review and analysis of problems and challenges, as part of evaluations. The process should be carried out in extensive consultations with internal and external stakeholders.

\section{State of play in the Western Balkans administrations}

In recent years, all WB administrations have implemented reform programmes and strategies aiming to improve the quality of the public administration, albeit with substantial variations in their objectives and with very different results. Establishing a strategic policy framework and improving government decision making by introducing RIA, in particular, has been a central pillar of the reform strategies of most administrations. However, the level of ambition and commitment to serious reforms in this area has varied. At a low level of commitment, this might involve organising ad hoc training and awareness-raising events. At a high level of commitment, supported by substantial reform ambitions, this has allowed for a fundamental redesign of the RIA system linked to the development priorities and strategic plans of the government.

In all WB administrations, reforms in RIA and policy making are included in the national strategic frameworks for public administration reforms (PAR). This in some aspects demonstrates high-level priority and commitment to reforms in this area. Monitoring and further development of reforms in the RIA system are primarily based on these PAR strategic frameworks. The actual reform objectives, the number of activities planned for implementation and the desire for change, however, differ, given various factors, such as the maturity of the system, the resources and the stage of reforms (Table 2.11).

\section{Table 2.11. Strategic planning of RIA reforms in the Western Balkans}

Objectives and activities related to RIA reforms, as reflected in their PAR strategies and other strategic documents

\begin{tabular}{l|c|c|c}
\hline & $\begin{array}{c}\text { Inclusion of an RIA-specific } \\
\text { objective in the current PAR } \\
\text { strategy }\end{array}$ & $\begin{array}{c}\text { Number of RIA-related } \\
\text { activities/actions in PAR strategic } \\
\text { documents }\end{array}$ & $\begin{array}{c}\text { Other strategic document or programme for } \\
\text { RIA or better regulation reforms }\end{array}$ \\
\hline Albania & Yes & 6 sub-activities & - \\
\hline BiH (State) & Yes & 3 activities & - \\
\hline $\begin{array}{l}\text { BiH } \\
\text { (Federation) }\end{array}$ & Yes & - & - \\
\hline BiH (RS) & Yes & - & - \\
\hline BiH (BD) & Yes & - & - \\
\hline Kosovo & Yes & 25 activities & Better Regulation Strategy 2.0 (2017-2021) \\
\hline Montenegro & Yes & 5 activities & Programme for strengthening RIA skills \\
\hline $\begin{array}{l}\text { North } \\
\text { Macedonia }\end{array}$ & Yes & 8 activities & - \\
\hline Serbia & Yes & $\begin{array}{c}\text { 8 RIA measures 5 } \\
\text { activities/measures for simplification } \\
\text { objective }\end{array}$ & $\begin{array}{r}\text { Strategy for Regulatory Reform and } \\
\text { Improvement of Public Policy Management } \\
\text { (2016-2020) }\end{array}$ \\
\hline
\end{tabular}

Source: SIGMA analysis, based on the information provided in the existing active PAR strategic planning documents of the WB administrations.

One of the objectives of Albania's cross-cutting PAR Strategy is improving the quality of lawmaking. It has a specific indicator for measuring the quality of RIA and is used to assess progress towards achievement of this objective. Montenegro's PAR Strategy 2016-2020 also has a specific objective and several activities to improve the implementation and quality of RIA. For example, the strategy provides for an evaluation of the RIA system, for the organisation of training and introduction of the Standard Cost Model (SCM) 
methodology. The PAR Strategy 2018-2022 of North Macedonia also has a specific objective to improve the quality of legislation, ensure transparency and increase stakeholder participation. The Action Plan includes measures to improve the methodological framework and guidance for ex ante RIA and ex post evaluation and for integrating the two into one framework, with one comprehensive guidance document.

Serbia's strategic approach to improving RIA is reflected in the Action Plan for implementation of the PAR Strategy 2018-2020, and the Strategy for Regulatory Reform and Improvement of Public Policy Management 2016-2020. Activities are under way to strengthen the RIA system, introduce the SME Test and increase capacity building.

$\mathrm{BiH}$ is finalising its nationwide PAR Strategy, which has been endorsed by the governments of all levels. The draft PAR Strategy includes objectives and measures on strengthening RIA at all levels of $\mathrm{BiH}$ administration. The Action Plan accompanying the PAR Strategy, however, has not been adopted by the governments at all levels.

In Kosovo, the reforms in RIA are guided by the Better Regulation Strategy 2.0 2017-2021, which sets out a multiannual framework. The Strategy helped the administration introduce major changes in the RIA system, including a complete revision of the guidance documents, the introduction of new analytical tools, and comprehensive training and capacity development. Serbia and Montenegro have additional strategies and programmes intended to strengthen policy making and RIA systems.

Since RIA was only recently introduced in several countries in the region, only a limited number of systems could have been expected to go through one or more rounds of major changes and improvements. The situation in administrations that have had systems in place long enough to warrant a fundamental review is mixed. Some evidence suggests that RIA systems have been left in place for too long before evaluating their efficacy, addressing their shortcomings and building on their strong points. Serbia has been evaluating its RIA system, and changes are planned. In Kosovo, the Better Regulation Strategy provides for systemic changes in the model of ex ante RIA, transitioning from Concept Documents to a full Impact Assessment system. In 2018, North Macedonia initiated an analysis of existing systems of ex ante and ex post evaluation of policies, and a new RIA methodology is being prepared. The process has not yet been finalised.

Most of the WB administrations, including BiH Federation, Kosovo, Montenegro, North Macedonia and Serbia, prepare annual reports on the implementation of RIA. This helps review and summarise RIA in different ministries. However, the reports do not appear to use indicators to measure the progress and impact of the RIA system on the quality of policy making.

External assessment and reviews of the national RIA systems were performed mostly by the OECD/SIGMA, as part of the regular monitoring of the WB countries' progress against The Principles of Public Administration and a 2017 study conducted by the Regional School of Public Administration (ReSPA). Many countries in the region, including Albania, Serbia and Montenegro, have recently conducted evaluations of their national PAR strategies. The findings of these evaluations are also an important source of information for future reforms in their policy-making and RIA systems. Overall, some improvements have been made in some of the countries since external evaluations, but it appears that many of the findings and recommendations are still relevant.

\section{Key conclusions}

Although RIA was only recently introduced in several countries in the region, all administrations have made further reforms and improvements of policy making and RIA systems a priority. Many activities and changes have been supported in the government PAR strategic documents that include RIA-related reform activities (and sometimes separate strategies for better regulation). None of the administrations, however, is systematically monitoring and evaluating RIA as a whole, in order to identify areas and directions for improving the system. While some administrations have a practice of preparing and publishing annual 
reports on RIA, they are not based on indicators and assessments that can monitor the overall process, assess its progress, identify weaknesses and make improvements.

\subsection{Use of RIA and analysis in the planning and implementation of EU legal harmonisation in the Western Balkans}

As noted in Chapter 1, EU law harmonisation is a demanding, complex process requiring proper planning, co-ordination, organisation and division of tasks among key institutions and players. European integration can only be successful when adequate resources (staff, budget, time) and administrative capacity are available for policy development, lawmaking and implementation, so the increased workload can be managed effectively.

EU legal harmonisation, which involves planning, analysis and drafting of transposition cases, as well as implementation and enforcement, should be fully embedded in national strategic government planning, policy development and lawmaking. It is important that the same standards and principles of policy making, including those for RIA, are applied both for domestic proposals and those based on European integration commitments.

This section discusses the methodological and procedural requirements for systematic use of RIA and other analytical tools and methodologies, to inform the preparation and implementation of the national plans for legal harmonisation with the EU.

\subsubsection{Use of costing and RIA in planning EU legal harmonisation}

\section{Introduction}

Countries of the region are at different stages of EU accession. Montenegro and Serbia have been involved in accession negotiations since 2012 and 2014 respectively. North Macedonia and Albania received the green light to open EU accession negotiations in 2020. Bosnia and Herzegovina has applied for EU membership and needs to fulfil several benchmarks in order to receive candidate status. Since 2016, Kosovo's EU integration (EI) process has been covered under the stabilisation and association agreement (SAA) with the EU, and it has not yet submitted an application for EU membership.

All WB administrations but Bosnia and Herzegovina have multi-annual programmes of EU integration that include measures for legal harmonisation of domestic legislation with the acquis. Preparing and using the national programme for the adoption of the acquis (NPAA) early in the process, even before the start of accession negotiations with the EU, is highly beneficial for countries, since it allows them to conduct initial review and mapping of the whole body of existing national legislation with the acquis in a single document. It also provides a good opportunity for prioritisation and planning over the medium to long term, to ensure optimum results for the country.

The NPAA, as a planning document, forms an integral part of the overall government strategic planning system. Ensuring full alignment between the NPAA and other government strategic documents, including annual legislative plans, sector strategies, the state budget and the multi-annual budget programme, is essential for successful El planning and smooth and effective implementation and results.

Adequate procedures and methodologies and systematic use of various costing and analytical tools, such as RIA, to inform the preparation of El planning documents can help increase the overall quality of plans and ensure successful implementation and results. While overall, the El process is expected to yield substantial benefits, individual El activities are likely to require additional budget resources and have an impact on the state budget and economy. Systematic use of analytical tools and processes to assess the likely impacts and risks of individual EU transposition cases can help to prioritise better and develop effective and realistic plans, reducing risks for implementation. 


\section{State of play in the Western Balkans administrations}

WB administrations have been using government planning documents to plan and implement activities aimed at EU integration and legal harmonisation. While the structure, content and process of preparation of the NPAAs vary between administrations, they all reflect the strategic goals and obligations arising from the relevant SAAs and specific requirements resulting from accession negotiations.

The methodological frameworks and approaches for preparing the NPAAs vary across the region (Table 2.12), particularly the analytical and costing tools used to estimate the impact and costs of the transposition measures. The methodologies and guidance available are often too generic and do not explain clearly which costs should be included in the financial estimates. More importantly, little guidance is provided on how those costs should be calculated and reported. Similarly, no clear procedures appear to be in place for reviewing and verifying estimates provided by ministries to ensure a consistency of approach across different chapters and areas.

For example, Albania's methodology on preparation of its National Plan for European Integration (NPEI), which was adopted in October 2020, stipulates that all measures included in the plan should have financing estimates. Costing of the NPEI is expected to provide insight into the cost of preparation of the legal act, as well as it's implementation. However, limited methodology is offered on how to prepare the costing estimates, what kind of costs ministries should expect to report and how they should be verified, especially costs related to implementation.

\section{Table 2.12. Methodological and procedural requirements for using costing and RIA during preparation of the national plans of EU legal harmonisation}

Based on requirements in the regulations and methodologies for preparing NPAA/EU integration plans

\begin{tabular}{l|c|c|c}
\hline & $\begin{array}{c}\text { A requirement to provide cost } \\
\text { estimates of measures } \\
\text { included in the NPAA }\end{array}$ & $\begin{array}{c}\text { Availability of guidance on how } \\
\text { to estimate costs of NPAA } \\
\text { measures }\end{array}$ & $\begin{array}{c}\text { RIA or other form of analysis of } \\
\text { regulatory measures is required } \\
\text { during NPAA preparation }\end{array}$ \\
\hline Albania & Yes & Yes & No \\
\hline BiH (State) & No & No & No \\
\hline BiH (Federation) & NA & No & - \\
\hline BiH (RS) & NA & No & - \\
\hline BiH (BD) & NA & No & No \\
\hline Kosovo & Yes & Yes & No \\
\hline Montenegro & No & No & No \\
\hline North Macedonia & Yes & Yes & No \\
\hline Serbia & Yes & Yes & \\
\hline
\end{tabular}

Note: Based on the review of national methodologies and regulations on the preparation of the NPAAs and related documents. In North Macedonia, ministries are required to submit a plan for preparing RIA at the time of preparation of the NPAA, which contains some analysis. In Albania, the new 2020 methodology on preparation of the NPEl includes limited guidance on costing.

Source: SIGMA analysis, based on the relevant methodologies, regulations and information provided by the WB administrations.

All levels of $\mathrm{BiH}$ have their own separate plans for transposition, except the $\mathrm{FBiH}$, which uses the EU action plan adopted by the $\mathrm{BiH}$ Council of Ministers. All BiH administrations lack a clear methodology and guidance for costing of measures and the use of RIA in the planning and transposition process. In October 2019, the Council of Ministers of $\mathrm{BiH}$, in close co-operation with all levels of $\mathrm{BiH}$ administration, adopted a new EU Action Plan for 2019-2020, as a single El planning document covering the entire country. The action plan does not provide clear information on the legislative commitments that are required for EU legal 
harmonisation, and no costing is provided ${ }^{8}$. In April 2020, the Directorate for European Integration of BiH published updated guidelines for harmonisation of legislation with the acquis ${ }^{\text {xviii }}$. This provides detailed guidance on the preparation, drafting and adoption of acts in the process of transposition of acquis, at the State level, but no guidance is available on costing.

The requirements and procedures for preparing Kosovo's National Programme for Implementation of the Stabilisation and Association Agreement (NPISAA) are stipulated in a Government decision ${ }^{9}$. Its methodology requires that cost estimates be provided for all measures planned. The cost of measures must be kept within the limits defined by the budget and Mid-term Expenditure Framework. A general manual for conducting budget impact assessment of all the measures submitted to the Government is also available for ministries, to prepare cost estimates of the NPISAA measures ${ }^{\text {xix }}$.

In North Macedonia, the NPAA includes national strategies, plans for harmonisation of national legislation with the acquis, implementation and enforcement activities. There are separate guidelines for planning of the legislative procedures for transposition of the acquis, a methodology and a handbook for legal transposition. Ministries are required to provide estimates of costs of transposition and implementation and identify the source of funding (state budget, Instrument of Pre-Accession or other bilateral support). For each NPAA chapter/subchapter, North Macedonia line ministries are required to submit to the Secretariat for European Affairs (SEA) a budgetary template indicating the estimated costs of activities, organised into different categories. The plan also indicates the sources of funding for planned measures. Costing of the NPAA activities (including legislative activities) is conducted with a standard calculation tool prepared by the SEA and the Ministry of Finance. SEA is planning to update the tool to serve as a basis for calculation of activities arising from bilateral screening outcomes, and preparation of negotiation positions in each chapter of the acquis.

Montenegro also has a methodology for preparation of the NPAA, but it does not include guidance on costing of individual measures. Instead, the NPAA provides information about the administrative needs for preparation and implementation of measures, such as the number of additional staff and infrastructure (mainly IT systems) needed, but the costs are not monetised.

WB administrations generally do not use RIA or a similar methodology to prioritise and prepare the national transposition plans early in the process, by providing a systematic assessment of all impacts of the planned transposition. The guidance documents for preparation of the NPAAs do not explain that RIA can be used early in the planning phase to help prepare a more effective plan. Only North Macedonia's methodology for preparation of the NPAA ${ }^{\mathrm{xx}}$ requires ministries to submit a plan for RIA in preparing the update for the NPAA, which appears to be a good practice. Analysis of these measures by RIA is apparently conducted only after the approval of the annual government legislative plan. RIA is acknowledged in Albania's NPEI methodology, but no guidance is given on how and when it should be initiated to benefit the transposition planning.

Serbia has a strong regulatory and methodological basis for preparation of its NPAA, based on several documents. The preparation of the El plan uses budgetary impact assessment, which is required by the regulation/methodology on NPAA. Both Serbia and Montenegro use fiscal/budgetary impact assessments (FIA/BIA) to assess impacts of the measures for which transitional arrangements are being requested. In Serbia, this is done particularly for the action plans and documents required for fulfilling opening

\footnotetext{
8 There is no link between planned legislative measures and the relevant acquis to be transposed.

9 Decision 02/136 of 10 March 2017 is the legal basis for the preparation of the NPISAA. "Guide to reviewing the National Programme for Implementation of the Stabilisation and Association Agreement (NPISAA): The cycle for 2020".
} 
benchmarks ${ }^{10}$. Montenegro also conducted fiscal impact assessment of some measures, particularly those related to acquis Chapters 23 and 24 and the related action plans.

None of the administrations has a systematic approach to using the findings of available policy and regulatory impact analysis prepared at the EU level, in particular, impact assessments and evaluations developed by the EC to inform prioritisation and planning of the EU legal harmonisation work.

\section{Key conclusions}

Most of the WB administrations have established the necessary regulatory and methodological frameworks for developing of their national plans for El, including transposition plans. The methodologies for preparation of NPAA in most countries require provision of estimates of state budget costs of the planned measures. However, it is not clear how those costs estimates are checked and verified. The benefits of the RIA methodology and process in place in each of the administrations are not utilised fully to inform the prioritisation and planning of EU legal transposition work. Similarly, policy analysis conducted on EU level, in particular by the EC, is not systematically used in the process of El planning to understand fully the scale of regulatory change and magnitude of impact of transposition of individual EU directives or regulations.

\subsubsection{Methodological requirements for use of RIA during EU law transposition}

\section{Introduction}

As noted in the previous chapter, RIA can provide valuable input in regulatory policy making at various stages of the EU accession process, including planning, negotiation and drafting and adoption of individual legal instruments transposing EU law. Methodological requirements for RIA, internal and external consultations and oversight of regulatory proposals originating from the EU integration commitments should be subject to the same procedures and oversight as those originating domestically.

At the same time, certain aspects and factors related to the EU law harmonisation should be considered carefully in preparing, adopting and implementing new regulatory measures. Other tools, such as Tables of Concordance and legal compliance statements, are used with RIA to ensure inclusive, evidence-based transpositions, in compliance with the procedures and rules agreed upon with the EU. Similarly, it is important to establish mechanisms to organise and co-ordinate preparatory and support activities, such as translations of the original EU law into local languages in time to help the process. If the text of the EU directive or regulation is not available in the local language, it can limit the participation of internal and external stakeholders (such as businesses, parliamentarians and the general public) during the transposition work. This will make it harder for the officials leading the transposition case to carry out analysis of the planned changes and to ensure evidence-based transposition.

National guidance documents and methodologies should fully acknowledge the need to use robust evidence and analysis at all stages of EU transposition, from planning to drafting, adoption and implementation. Similarly, the national methodologies on RIA and other ex ante tools should provide

\footnotetext{
${ }^{10}$ Assessment made on opening benchmarks and screening reports in Chapter 2, Free movement of workers (where Serbia needs to carry out a feasibility study on the impact of introduction of European Health Insurance Card (EHIC) on public finances; Chapter 11, Agriculture and rural development (where Serbia needs to present to the Commission an action plan that will serve as a basis for the transposition, implementation and enforcement of the acquis in agriculture and rural development). This action plan will, among other issues, include the development of the relevant administrative capacity, the estimation of the resources required, and the development of the Integrated Administrative and Control System to prepare for the management and controls of agricultural payments; Chapter 23, Judiciary and fundamental rights and Chapter 24, Justice, liberty and security where, in both chapters, Serbia needed to present action plans with adequate cost evaluations and financial allocations; and on the Post screening document developed in Chapter 27.
} 
additional guidance on the use of those tools and approaches during EU transposition, highlighting any special considerations and risks.

\section{State of play in the Western Balkans administrations}

The process and standards of preparation, consultation and approval of domestic and EU-originated regulatory measures are largely identical in all WB administrations, as confirmed (OECD/SIGMA, 2017 Monitoring Assessments ${ }^{11}$ ). Most administrations apply the same requirements and standards for analysis and assessment of impacts for EU transposition cases as for domestic proposals. Tables of Concordance are integrated into the systems of all administrations, except that of the $\mathrm{BiH}$ (Table 2.13).

\section{Table 2.13. Procedural requirements and tools used for preparing regulatory measures transposing EU law}

\begin{tabular}{|c|c|c|c|c|c|}
\hline & $\begin{array}{l}\text { RIA required for } \\
\text { EU } \\
\text { transposition } \\
\text { cases }\end{array}$ & $\begin{array}{l}\text { EU transposition cases } \\
\text { following the same } \\
\text { requirements as domestic } \\
\text { proposals } \\
\text { (2017) }\end{array}$ & $\begin{array}{l}\text { Availability of special } \\
\text { guidance on } \\
\text { conducting RIA on } \\
\text { EU transposition } \\
\text { cases }\end{array}$ & $\begin{array}{l}\text { Use of Table of } \\
\text { Concordance } \\
(2017)\end{array}$ & $\begin{array}{c}\text { Timely translation } \\
\text { of EU directives } \\
(2017)\end{array}$ \\
\hline Albania & Yes & Yes & No/minimal & Required & Yes \\
\hline $\mathrm{BiH}$ (State) & Yes & Yes & $Y_{e s}{ }^{x i}$ & - & Yes \\
\hline BiH (Federation) & Yes & Yes & No & - & Yes \\
\hline $\mathrm{BiH}(\mathrm{RS})$ & Yes & Yes & $Y_{e s}{ }^{x i i}$ & - & Yes \\
\hline $\mathrm{BiH}(\mathrm{BD})$ & Yes & Yes & No & - & Yes \\
\hline Kosovo & Yes & Yes & Yes ${ }^{x x i i i}$ & Required & No \\
\hline Montenegro & Yes & Yes & No & Required & No \\
\hline North Macedonia & Yes & Yes & No/minimal ${ }^{x x i v}$ & Required & Yes \\
\hline Serbia & Yes & Yes & No/minimal ${ }^{\mathrm{XXV}}$ & Required & Yes \\
\hline
\end{tabular}

Source: SIGMA analysis, based on country responses and the findings of the 2017 SIGMA Monitoring Assessment reports of the WB administrations.

Demand for an adequate level of analysis of policy impact through RIA increases during the El process, as the country advances to eventual membership. This is particularly important during the negotiation phase and for the preparation and adoption of the national legislation that harmonises the legislation with the acquis. This is largely driven by the EU's own request for additional assessment of impact and risks to support any transitional arrangements requested by national administrations.

The full RIA process starts late, and it is not yet fully operational in most administrations, which often results in fragmented activities and efforts for policy analysis. The administration often conducts analysis twice: first, for the purposes of preparation for the negotiation, and then for the purpose of policy and/or legislative development at a later stage, when the government drafts and adopts the relevant national legislation. The problem is that these two processes are not always clearly linked with each other, resulting in inefficiencies and potential confusion. It is important to ensure that this is seen as part of the same policy development process. Furthermore, the focus of analysis at an early stage is often only on certain aspects of planned transposition measures.

The national RIA methodologies of several administrations have limited guidance on how to deal with the EU transposition cases. But those are not detailed enough, and the processes of analysis and legislative drafting and EU negotiation and transposition cases are not clearly described and linked as a single

11 Policy Development and Co-ordination section of country monitoring reports, available at: http://sigmaweb.org/publications/monitoring-reports.htm. 
policy-making process. For example, the Albanian RIA methodology acknowledges the need for doing RIA on EU transposition cases. Similarly, the methodology for preparation of the NPEI refers to the RIA process. No clear guidance is given as to when and how RIA should be initiated to provide useful input at each stage.

Additional guidance on the use of RIA is available at the BiH State and RS levels, for conducting RIA on EU transposition cases. For example, RIA guidance used in the BiH RS explains the differences between transposing EU directives and regulations, and explains how the development of RIAs is linked with future work on establishing the negotiation position and EU accession negotiations.

In Kosovo, the guidelines for drafting concept documents/RIAs do provide additional guidance for specific aspects of analysis of EU transposition cases ${ }^{x \times v i}$. In particular, Tool 15 of the methodological document provides guidance on the required analytical steps to be carried out during EU transposition cases. The Rules of Procedure of the Government of Kosovo establishes the main requirements for the process of aligning the legislative framework with the acquis ${ }^{\mathrm{x} v \mathrm{ii}}$. A separate practical guide to approximate the legislation with the EU legislation was prepared in 2014xxviii. It provides comprehensive guidance on the transposition planning and implementation. Little reference and information are available, however, on using analysis and information at the different stages of the legal harmonisation processes, including during formal negotiations.

In Montenegro, the RIA manual suggests that draft legislation to transpose the acquis may be exempt from the RIA requirement in cases when it does not allow consideration of options on how the legislation will be implemented. But the exception rule is applied very rarely, and requires approval of the RIA oversight body ${ }^{12}$. The RIA manual gives information on the impact assessment process at the EU level, but no guidance on how RIA should be conducted on transposition cases in the Montenegrin system. The Government has prepared guidelines for transposition of the acquis that do not provide additional guidance on RIA and analysis ${ }^{x x i x}$. Separate guidelines for preparation of the negotiation position do not explain how RIA should be used to help prepare the negotiation positions.

In North Macedonia, the RIA system, which is quite comprehensive, covers fully and equally both domestic legislation and legislation originating from the EU. RIA methodology emphasises that RIA is important tool for developing future negotiation positions. Methodology for developing NPAA requires a preliminary RIA to be performed for planned legislation before the plan is approved. North Macedonia has established complex negotiation structures for EU accession in 2019. It has yet, however, to develop the required procedural documents for developing negotiation positions that would define the use of RIA in the process of drafting negotiation positions.

Serbia has a comprehensive methodological framework for RIA that gives guidance on analysing proposals originating from the EU. The same preparatory process and analytical requirements are applied for both domestic and EU-originated proposals. Nevertheless, the guidance on how to deal with the EU transposition cases within the RIA methodology is minimal. The Serbian government negotiation team prepared and adopted Guidelines for Preparation of the Negotiation Position in 2016. Every negotiation position was accompanied by a FIA, checked by the Ministry of Finance. These documents are monitored by the Ministry of European Integration.

\section{Key conclusions}

All administrations of the WB region apply the same RIA requirements for both domestic and EU-originated regulatory proposals. The administrations that are at the accession negotiation stage, particularly Serbia and Montenegro, use fiscal impact analysis to assess the impact on state budget and use that information to inform negotiations. Use of RIA, however, is limited and not systematically applied to inform the EU transposition process throughout all stages of EU transposition planning, negotiations, legislative drafting

12 This is confirmed by officials from the Montenegrin administration. 
and approval. Limited guidance is available within RIA methodologies on how to deal with special circumstances and issues related to analysing, preparing and implementing EU transposition cases. Similarly, guidance and methodological documents used during planning and negotiation do not fully acknowledge the presence of RIA. The acquis translation process is not systematically done in advance to help in the preparatory work, such as RIA. 


\section{Chapter 3. Practice and quality of RIA implementation and EU law transposition}

As noted in the previous chapter, all the administrations in the Western Balkans (WB) region have put RIA regulations and methodologies in place. They have also set up mechanisms and institutions for RIA as part of government decision making. Procedures are also set up for preparing and implementing European Union (EU) transposition activities, in line with the national plans for EU integration (EI). While recognising these positive developments in establishing formal procedures and rules, it is important to understand how the RIA systems work in practice and whether the analysis in individual RIA studies is adequate and useful for improving legislative drafting.

This chapter reviews the quality and consistency of RIA implementation in the region by looking into several key results and outcomes, looking first at government legislative planning, EU transposition and RIA implementation results in the WB administrations in 2017-2019. The second part analyses the quality of individual RIA reports, based on a sample of RIA reports provided by the WB administrations. Annex 1 provides the full list of sample RIAs and the methodology and process of the qualitative review.

\subsection{Use of RIA in legislative planning and EU law transposition in the WB administrations, 2017-2019}

\section{Legislative planning and RIA}

Previous OECD/SIGMA assessments of the WB administrations have brought to light many challenges that countries of the region face in ensuring effective legislative planning and transposition of EU law. Government work programmes and legislative plans of the WB administrations are often found to be unrealistic. This means not only that implementation rates are low but that a high number of annually planned legislative measures are carried forward to the next year, creating significant backlogs. On average, it is estimated that nearly half (46 percent) of all planned legislative activities are not approved by the WB administrations within the planned annual deadlines (OECD/SIGMA 2017 Assessments). Moreover, a significant proportion of legislation approved in the region is adopted outside the formally agreed plans, undermining the credibility of the government legislative plans. Additionally, many laws are adopted in emergency procedures, avoiding the standard procedures for consultation, preparation, quality checks and oversight, which is a major issue in several WB administrations.

The quality of approved legislation presents significant challenges. A large proportion of approved laws in the region must be amended within a year of adoption (OECD/SIGMA, 2017 assessments). This, among other issues, suggests not only that the preparatory and analytical work in drafting legislation is insufficient, but that there is a lack of proper central guidance and oversight.

Meanwhile, weak government planning also contributes to inadequate preparatory work and analysis of individual legislative proposals. A lack of planning also affects resource allocation and planning for analytical and stakeholder engagement through RIA and public consultation. This is especially relevant for WB administrations, since the RIA models are contingent on the legislative planning process. In most 
administrations but Kosovo and partly also North Macedonia, substantive RIA work starts only after the measure is formally approved and included in the annual government legislative plan.

Initiation of RIA work after the adoption of the annual legislative plan creates several complications. By that stage, a political decision to regulate and draft legislation has often already been taken. This precludes some of the potential benefits of RIA, in terms of considering wider alternative policy options, including non-regulatory ones. Even in Kosovo, where RIA starts relatively early in the process and precedes the approval of the government's legislative plan, the analysis primarily focuses on the regulatory options. This is due to the fact that administration needs to justify and support government intervention by initiating a new law, so that the measure is approved and included in the annual legislative plan.

As already noted, there is concern that this approach can reduce officials' incentives to conduct proper and objective RIA analysis during the legal drafting phase. RIA analysis should be updated during this phase if it is to provide meaningful input in the legislative drafting process. In North Macedonia, RIA is initiated with the preparation of an RIA plan, which is expected to be completed in parallel with the preparation of the annual government work plan. This includes some basic initial assessment and the development of a timeline of preparation of RIA. In this respect, North Macedonia provides a good example of planning RIA work.

All WB administrations have been using regulations as a key policy instrument. The volume of legislative activity in the region was generally stable in 2017-2019 (Table 3.1). RIA systems have been functioning in line with the national rules and procedures set by the WB administrations, except in some levels of Bosnia and Herzegovina $(\mathrm{BiH})$, where certain elements of RIA have not yet been introduced. As of 2019, all the administrations had established basic processes and capacity for regular RIA in drafting a significant share of the government's legislative initiatives. The type and quality of RIA and underlying analyses, however, vary in quality.

Some administrations, like that of North Macedonia, experienced a significant increase in the number of laws approved in 2018 and 2019. This may reflect the many changes and reforms being introduced in the country at the time. Unusually, the number of laws approved in 2019 was significantly higher than initially planned for. By contrast, in Albania, BiH and Kosovo, the number of laws approved in 2019 was significantly lower than anticipated. These results highlight the challenges many WB administrations face in ensuring effective government legislative planning.

RIA reports are being used to support drafting and adoption of legislation in all WB administrations. BiH administrations, however, have not yet produced full, comprehensive RIAs; and most are basic or initial RIAs. Based on the number of RIAs produced during this period, North Macedonia is the clear leader in the region. It prepared almost 200 RIAs on various draft legislative initiatives in 2019 , which suggests that the system is instituted throughout the administration. 
Table 3.1. Legislative planning and RIA activities from 2017-2019

\begin{tabular}{|l|r|r|r|r|r|r|r|r|r|}
\hline & \multicolumn{3}{|c|}{$\mathbf{2 0 1 7}$} & \multicolumn{3}{|c|}{$\mathbf{2 0 1 8}$} & \multicolumn{3}{c|}{$\mathbf{2 0 1 9}$} \\
\hline & $\begin{array}{c}\text { Planned } \\
\text { laws }\end{array}$ & \multicolumn{1}{|c|}{$\begin{array}{c}\text { Approved } \\
\text { laws }\end{array}$} & $\begin{array}{c}\text { Number } \\
\text { of RIAs }\end{array}$ & $\begin{array}{c}\text { Planned } \\
\text { laws }\end{array}$ & $\begin{array}{l}\text { Approved } \\
\text { laws }\end{array}$ & $\begin{array}{l}\text { Number } \\
\text { of RIAs }\end{array}$ & $\begin{array}{l}\text { Planned } \\
\text { laws }\end{array}$ & $\begin{array}{l}\text { Approved } \\
\text { laws }\end{array}$ & $\begin{array}{c}\text { Number of } \\
\text { RIAs }\end{array}$ \\
\hline Albania & 103 & 41 & - & 76 & 29 & 9 & 75 & 31 & 42 \\
\hline BiH (State) & 48 & 13 & NA & 29 & 6 & NA & 44 & 2 & NA \\
\hline BiH (Federation) & 109 & 41 & 76 & 94 & 34 & 71 & 92 & 33 & 50 \\
\hline BiH (RS) & 179 & NA & 73 & 142 & NA & 84 & 95 & N/A & 139 \\
\hline BiH (BD) & 62 & 17 & - & 65 & 18 & 12 & 56 & 8 & 35 \\
\hline Kosovo & 154 & 57 & 18 & 128 & 84 & 39 & 80 & 11 & 12 \\
\hline Montenegro & 104 & 69 & 111 & 99 & 45 & 101 & 85 & 58 & 75 \\
\hline North Macedonia & 77 & 54 & 43 & 171 & 109 & 94 & 178 & 242 & 186 \\
\hline Serbia & 331 & 16 & 91 & 329 & 120 & 108 & 327 & 88 & 95 \\
\hline
\end{tabular}

Note: The number of RIAs includes those that were completed by ministries on draft laws during a calendar year, based on information available to the relevant RIA management units of each WB administration. It is not possible to report how many of the draft RIAs were actually linked with the approved laws in many administrations, since some approved laws were exempt from RIA and a number of RIAs were prepared in the previous year. For Albania, full implementation of RIA started in January 2019; 14 draft laws were exempt from RIA requirement in 2019. For $\mathrm{BiH}$ administrations, the number includes initial/basic RIAs. No official data on RIA was provided for the BiH State level. Information on approved laws at the BiH Republika Srpska (RS) was not available, and the Brčko District (BD) did not conduct any RIAs in 2017. For North Macedonia, the number of laws planned for 2017 is based on the government work plan for July-December 2017, when the new Government took office. The number of approved laws includes those that were subject to RIA. For Serbia, RIA numbers are based on the number of RIAs sent to the Public Policy Secretariat (PPS) for opinions. Data on planned and approved laws was provided by the General Secretariat of the Government of Serbia.

Source: SIGMA analysis, based on publicly available data, as well as information and data provided by the WB administrations.

WB administrations that have "two-tier" or "two-category" RIA systems (e.g. categories of initial/basic and full RIAs), such as the four levels of $\mathrm{BiH}$, have also recorded relatively high numbers of RIAs. However, in $\mathrm{BiH}$, there are very basic RIAs developed as part of the preparation of the annual legislative plans. Official information on the RIA numbers produced at the State level was not available.

\section{RIA quality check}

The central function of quality checks of draft RIA reports is institutionalised in most of the WB administrations. Evidence suggests that the relevant oversight is carried out on draft RIAs following the rules prescribed in national regulations. The RIA quality scrutiny function is not clearly established and performed at the BiH State level. Dedicated officials of the RIA oversight bodies are formally involved in the quality checks of RIA in most administrations, but the workload, quality and type of RIA scrutiny vary.

As noted in the previous chapter, the oversight function is performed as part of the broader role of management and support of RIA systems in all administrations. Officials of the relevant national RIA management and oversight bodies are also responsible for RIA quality checking in all administrations, except BiH State (Table 3.2). These officials often combine many other functions, in addition to RIA scrutiny. The analysis of data on the number of staff and the number of RIAs scrutinised can indicate the challenging workload of the oversight bodies of many administrations. The numbers of officials provided are only indicative, since many perform other functions too.

On average, based on the numbers in 2019 , North Macedonia has the highest number of final draft RIAs checked per official. On average, about 50 RIA reports were checked by each official in 2019 (see Table 3.2). Partly, this can be explained by the fact that North Macedonia adopted the highest number of legislative acts in 2019 (see Table 3.1), most of which required RIA. On the other hand, the oversight bodies of several other administrations of the WB region had a much lower number of RIAs to process in 2019. For example, each official of the Kosovo RIA oversight unit reviewed, on average, only one RIA 
report in 2019. While realising the limitations and weaknesses of such basic analysis, this indicates the potential pressures and risks facing many RIA oversight bodies in performing their important tasks.

Table 3.2. Staff resources allocated for quality check of draft RIA reports

\begin{tabular}{l|c|c|c}
\hline & $\begin{array}{c}\text { Number of staff formally } \\
\text { allocated for central RIA } \\
\text { quality check } \\
\text { (March 2020) }\end{array}$ & $\begin{array}{c}\text { Number of RIAs prepared on } \\
\text { draft laws } \\
(2019)\end{array}$ & $\begin{array}{c}\text { Indicative average number of } \\
\text { RIAs on laws reviewed by each } \\
\text { official of an oversight body }\end{array}$ \\
\hline Albania & 4 & 42 & 11 \\
\hline BiH (State) & - & NA & - \\
\hline BiH (Federation) & 4 & 50 & 13 \\
\hline BiH (RS) & 5 & 139 & 18 \\
\hline BiH (BD) & 2 & 35 & 1 \\
\hline Kosovo & 10 & 12 & 15 \\
\hline Montenegro & 5 & $75^{\star}$ & 52 \\
\hline North Macedonia & 3 & $157^{\star}$ & 11 \\
\hline Serbia & 9 & $95^{\star}$ & 18 \\
\hline
\end{tabular}

Note: The numbers of officials involved in the quality checks of RIAs are only indicative, since many perform other functions too, including review of RIAs prepared on secondary legislation and PIAs prepared on policy documents (Serbia). Data on staff numbers working on oversight of RIAs is based on information provided by the administration and is accurate as of March 2020. BiH (State) quality check on RIA is not fully established within the administration, and the number of RIA are not available.

* In Montenegro and Serbia, the total number of RIAs, including both primary and secondary legislation, was 385 and 154 respectively. In North Macedonia, 186 RIAs were prepared in 2019, but only 157 of those were submitted to the oversight body for opinion.

Source: SIGMA analysis, based on information provided by the WB administrations.

\section{Planning of EU transposition and RIA}

As with planning government legislative activities, WB administrations face many challenges in ensuring effective, realistic planning of the EU law transposition activities. An estimated one-third of all planned legislative measures related to EU transposition are carried forward to the next year in all the WB administrations (Table 3.3; 2017 OECD/SIGMA assessments), further indicating the weaknesses of the government planning systems.

\section{Table 3.3. Quality of government planning for EU law transposition}

\begin{tabular}{l|c|c}
\hline & $\begin{array}{c}\text { Alignment between government } \\
\text { legislative plan and EU integration } \\
\text { plans }\end{array}$ & $\begin{array}{c}\text { Annual planned El-related } \\
\text { commitments carried forward to the } \\
\text { next year }\end{array}$ \\
\hline $\begin{array}{l}\text { Average for the region } \\
\text { (based on simple average of individual country results) }\end{array}$ & $78 \%$ & $32 \%$ \\
\hline
\end{tabular}

Note: Based on individual country results of the assessment conducted by SIGMA using its assessment methodology, based on The Principles of Public Administration and related methodology (SIGMA, 2017).

Source: SIGMA analysis, based on individual country monitoring reports $(2017,2019)$, www.sigmaweb.org/publications/monitoring-reports.htm.

Additionally, WB administrations face difficulties in aligning different government planning documents and in policy co-ordination (2017 OECD/SIGMA assessments). Often, there is a mismatch between the annual 
legislative plans and plans for implementation of the El-related legislative commitments. Furthermore, reports on implementation of the existing transposition plans of most WB administrations are not made public. For example, 2019 reports on the implementation of their national plans for EU integration are published only in Montenegro, Kosovo and Serbia ${ }^{13}$. This limits the opportunity for the public and stakeholders to be involved in the monitoring of the overall EU integration and regulatory activities, making the process less transparent and accountable.

As noted in the previous chapter, EU transposition plans of the WB administrations are part of broader national plans of acquis alignment (NPAAs) and EU integration. These plans typically cover three main components: i) plans for preparation and adoption of the relevant national legislation for transposing the acquis; ii) an assessment of the capacity-building needs for legal transposition work, and, for ensuring implementation of new legislation (including, for example, estimates of additional resources needed for establishment of new institutions, hiring new civil servants, making investments in equipment and new installations); and iii) financial estimates of costs on the state budget, covering both transposition and implementation activities. Costing for implementation, however, does not include estimates of the wider impact and costs of new regulations arising from the EU transposition in general, such as additional costs for businesses, economy and citizens, which should be captured as part of RIA.

The review of individual plans and practice in the region suggests that costing is arguably the weakest aspect in NPAAs and national plans (when compared to the other two parts of the NPAAs, transposition and capacity building). The review of the latest NPAAs of the regional administrations shows that not all administrations provide cost estimates in their NPAAs. Additionally, when cost estimates are provided, it is not clear that they are prepared consistently, that they are based on a similar approach and methodology in all areas, and that the relevant ministries of finance check and verify them before including them in the plans. The costing of the NPAA of Albania, North Macedonia and Kosovo is publicly available. In North Macedonia, for the 2017-2019 period, the estimated cost for the state budget is expected to be EUR 2.1 billion. In the case of North Macedonia, almost all activities planned in the NPAA are covered by the budget. Activities that are not approved by the Ministry of Finance or planned in the mid-term budgetary perspective cannot be included in the NPAA. In the case of Kosovo, the administration estimated that the cost of implementation of the NPISAA in 2019 would be EUR 94.5 million. No estimates are provided for the cost of implementation of NPISAA activities for the remaining programming period (2020-2023). It should be noted that it is not possible to verify the reliability and accuracy of the estimates.

Serbia and Albania also perform costing of their planned EU integration activities, but the estimates are not publicly available. Montenegro and Bosnia Herzegovina (at all levels of government) do not provide cost estimates in their transposition plans. Montenegro performs costing on the level of negotiation positions using a methodology for costing of NPAA similar to that used by other WB countries.

In general, the transposition plans are regularly updated by all WB administrations, covering all acquis chapters of accession negotiations. The main challenge, however, is the implementation of the planned transposition activities, which is low across all administrations (Table 3.4). Relatively small administrations, such as Montenegro and North Macedonia, have recorded relatively higher rates of implementation of EU transposition measures, and arguably also have relatively more ambitious planning than their bigger neighbours (such as Serbia and Albania). This may reflect a level of realism in planning, but also each country's political situation and the stage of EU integration.

Low implementation rate of EU transposition cases can be partly explained by the limited amount of preparatory work, resources and analytical skills devoted to planning and costing, which can result in unrealistic and ambitious planning. A high implementation rate, however, does not necessarily correlate

13 In the case of Serbia, implementation reports for three quarters of 2019 are available. 
with a better quality of transposition. High rates may suggest that many EU laws were transposed without adequate preparation and analysis, potentially leading to poor implementation and enforcement.

Effective planning, development and approval of laws requires administrative capacity and resources. Thorough analysis of the wider risks and impacts can help administrations prioritise and plan legislative work more effectively. Analysis of regulatory changes and risks can also increase the chances of successful and full implementation. None of the WB administrations appears to have a systematic approach to using RIA or other analytical approaches to help prioritisation and preparation of their national EU transposition plans.

\section{Table 3.4. Implementation of EU legislative commitment arising from El in 2017-2019}

Draft laws and by-laws/regulations planned and approved by Western Balkan administrations as part of their respective NPAAs

\begin{tabular}{l|c|c|c|c|c|c|c|c|c}
\hline & \multicolumn{3}{|c|}{2017} & \multicolumn{3}{c|}{2018} & \multicolumn{3}{c}{2019} \\
\hline & Planned & Approved & $\%$ & Planned & Approved & $\%$ & Planned & Approved & $\%$ \\
\hline Albania & 80 & 15 & $19 \%$ & 106 & 29 & $27 \%$ & 131 & 82 & $62 \%$ \\
\hline BiH (State) & 30 & 4 & $13 \%$ & 18 & 1 & $6 \%$ & 83 & 10 & $12 \%$ \\
\hline $\begin{array}{l}\text { BiH } \\
\text { (Federation) }\end{array}$ & 54 & 26 & $48 \%$ & 38 & 10 & $26 \%$ & 42 & 13 & $31 \%$ \\
\hline BiH (RS) & 149 & 70 & $47 \%$ & 131 & 61 & $46 \%$ & 169 & 96 & $57 \%$ \\
\hline BiH (BD) & n.a. & n.a. & n.a. & n.a. & n.a. & n.a. & n.a. & n.a. & n.a. \\
\hline Kosovo & 34 & 7 & $20 \%$ & n.a. & n.a. & n.a. & 160 & 59 & $37 \%$ \\
\hline Montenegro & 363 & 262 & $72 \%$ & 364 & 260 & $71 \%$ & 222 & 146 & $66 \%$ \\
\hline $\begin{array}{l}\text { North } \\
\text { Macedonia }\end{array}$ & 91 & 82 & $90 \%$ & 116 & 100 & $86 \%$ & 114 & 72 & $63 \%$ \\
\hline Serbia & n.a. & n.a. & n.a. & 304 & 126 & $41 \%$ & 136 & 89 & $65 \%$ \\
\hline
\end{tabular}

n.a. $=$ not available.

Note: The figures include legislative and regulatory measures related to EU integration commitments.

$\mathrm{BiH}$ State level: Data on planned and approved legislative measures is based on the information provided in the relevant work plans and reports of the BiH Council of Ministers; data on 2017 and 2018 is for planned and approved laws, while data on 2019 also includes secondary legislation. Kosovo: 2017 figures are on legislative measures only. Data for 2019 are taken from the NPISAA report for 2019. Montenegro: Report on implementation of the Successful European Accession Programme (PPCG). Serbia: NPAA report for Q3-2019. For 2019, only aggregate data for the period 2018 and Q1-3 2019 are available in the NPAA report, indicating an aggregate result for 2018-Q1-3 2019 of $49 \%$ (215 acts adopted, of 440 planned). Serbia's final full annual report for 2019 was not available. The Albania figures were provided by the Ministry for Europe and Foreign Affairs.

Source: SIGMA analysis, based on information provided by the administrations and publicly available reports on El and transposition.

In terms of the volume of legislative and regulatory activities arising from El commitments, Montenegro and Serbia, which have been in formal negotiations with the EU for several years, adopted the highest number of legal acts in 2019 and ( 146 and $89^{14}$ respectively). The BiH Republika Srpska (RS) also shows a high rate of implementation of its planned EU transposition cases (96 measures, $57 \%$ of all planned measures for the year).

Review of the practice and implementation confirms that analytical input in prioritisation and preparation of the NPAAs is limited across all WB administrations. RIA does not appear to be used to help prioritisation and planning of EU transposition work in any of the administrations. It appears that EU IA reports prepared by the EC, which can be a useful source of analytical data and information for planning, costing and

14 The 2019 NPAA Report on Serbia covered only three-quarters of 2019. 
transposition, are not systematically and consistently used in development and revision of El planning either.

\section{Key conclusions}

All WB administrations faced various challenges and weaknesses in planning and implementing government legislative plans and EU transposition plans in 2017-2019. RIA is embedded in the system of legislative drafting and is systematically conducted by all WB administrations, including on EU transposition measures. EU transposition plans are regularly prepared and updated, but the implementation rate has been relatively low in many administrations. EU transposition plans of most administrations provide some estimates of costing as well as an assessment of capacity-building needs. Costing estimates are provided, but it is not always clear what the estimates cover, and the reliability and consistency of the figures reported in the plans is sometimes in question. The RIA process and methodology does not appear to be used in any of the WB administrations to inform prioritisation, preparation and updating of the annual EU transposition plans.

\subsection{Quality of RIA: review of the process and analysis}

\section{Introduction}

This section presents the main findings of the qualitative analysis of 50 sample RIA reports produced by the WB administrations in 2019 and 2020. Four to six RIA reports from each WB administration, together with the relevant legislative proposals, have been systematically analysed to assess the quality and consistency of analysis and the RIA process (see Annex 1 for the full list of RIA reports analysed from each administration).

The quality and consistency of implementation of RIA have been analysed by focusing on the following aspects in each individual RIA sample: the RIA preparatory process; presentation and clarity of the RIA reports; use of external experts in the RIA process; completeness of analysis covering all regulatory changes; consultation with stakeholders and the public; implementation of central quality control; use of EU impact assessments in the RIA samples dealing with EU transposition and publication of the final RIA reports.

The second section assesses the quality and comprehensiveness of analysis in individual RIA reports, focusing on the following key elements of a typical RIA: problem analysis and policy objectives; consideration of alternative options; options appraisal and analysis of the preferred (main) option; analysis of budget/fiscal impacts; quality of data and information; implementation and enforcement; and monitoring and evaluation ${ }^{15}$.

\subsubsection{Quality of preparatory process of individual RIA samples}

\section{RIA preparatory process}

The review of RIA samples confirms that the RIA work in most WB administrations effectively starts after the approval of the annual legislative work plan of the government. The only exception is Kosovo, where RIAs have to be prepared and approved for individual legislative measures to be included in the Government's annual legislative plan. In North Macedonia, the process also starts relatively early, since the ministries are required to do initial analysis and prepare RIA development plans that must be approved along with the annual legislative plans. RIA reports are being prepared, as required by internal regulations and government working procedures in most administrations. However, full implementation of RIA is still

\footnotetext{
15 The review of samples is based on the information provided in each individual RIA report. No other information has been used.
} 
lagging in $\mathrm{BiH}$ administrations, where only initial, basic RIAs are being prepared and development of comprehensive RIAs has not yet effectively started.

There is no evidence in any of the WB administrations that RIA reports are being reviewed and updated regularly, throughout different stages of the policy development cycle, as and when new evidence and data is collected, including through internal and external consultations.

In Kosovo, the RIA process starts relatively early. However, the approved RIA report is not updated during the legal drafting phase. The Government Co-ordination Secretariat (GCS), the quality-control body for RIA, does not formally assess the content of the law against the findings of the RIA analysis to inform the final decision on approval of the draft law by government. In $\mathrm{BiH}$ at all levels, initial or basic RIAs are chiefly prepared at the time of legislative planning, and they contain limited analysis of the impact and risks of policies.

Unfortunately, based on the information available on the preparatory process of sample RIA reports analysed as part of this study, it is not possible to provide estimates of the time and resources spent on RIA studies. With the exception of Kosovo, the RIA reports produced often lack basic information on the RIA preparatory process, timeline or stage of the policy development. Key information on the RIA development process and timeline is available in the RIA plans prepared in North Macedonia.

\section{Table 3.5. Consistency in following the requirements and standards of the RIA process and methodology}

\begin{tabular}{l|c|c|c}
\hline & Yes & No & $\begin{array}{c}\text { Not relevant / } \\
\text { not possible to confirm }\end{array}$ \\
\hline Consistency of using the standard RIA structure or template & 47 & 3 & \\
\hline Analysis is clearly structured and presented & 49 & 1 & 8 \\
\hline Were external experts involved in RIA preparation? & 12 & 30 & \\
\hline Discussion of the reliability of data and information used & 19 & 31 & \\
\hline RIA discussing public consultation/stakeholder engagement activities & 46 & 4 & \\
\hline $\begin{array}{l}\text { Evidence that the outcome of public consultation was used in } \\
\text { RIAs }\end{array}$ & 30 & 20 & \\
\hline Review of draft RIA by the quality control body & 44 & & \\
\hline Is the RIA report published/available on a website? & 35 & 15 & \\
\hline RIA covering all regulatory changes included in the proposed law & 45 & 5 & \\
\hline Is the RIA related to transposition of an EU law? & 16 & 34 & \\
\hline $\begin{array}{l}\text { For RIAs related to EU transposition, was there any reference to } \\
\text { the EU Impact Assessment report? }\end{array}$ & 1 & 15 & \\
\hline
\end{tabular}

Note: Based on the review of 50 individual RIA samples and related documents, such as the draft law, as provided by the WB administrations. No interviews or verification with officials were carried out. Text highlighted in bold indicates the weakest areas.

Source: SIGMA analysis, based on the review of 50 RIA samples.

\section{Clarity and presentation of RIA reports}

Presentation of the findings of the analysis was clear in most of the cases. The standard templates, structures and forms of RIA, as established by the national regulations and methodologies, have been followed in all samples from each administration, with a few exceptions. One was the Serbian RIA on the Draft Law on the Changes and Amendments to the Law on Fulfilment of Financial Obligations in Commercial Transactions. This did not follow the prescribed structure of presentation, as required by the RIA regulations. The report did not even follow an older version of the RIA report structure.

As discussed in the previous chapter, the Serbian and $\mathrm{BiH}$ administrations do not have a standardised RIA template, making it difficult to present the findings of the analysis in a clear, consistent and structured way. 
This is particularly an issue in complex RIAs that require long sections for the evidence base and analysis, which complicates presentation of the key findings and recommendations. In contrast, Albania and Kosovo use well-structured RIA templates. This facilitates a standardised approach to analysing aspects of the RIA process, while providing a basis for comprehensive analysis based on a set of prompts.

\section{Use of external expert support}

Most of the RIA reports included in the sample were produced without any external support. Only 12 out of the 50 RIA samples contain information indicating that external experts were involved during the RIA development process. At the same time, it should be noted that the quality of RIAs produced with external expert support was not significantly better.

Use of external experts in RIA preparation can help address shortages in skills and expertise to conduct complex analysis. It is noteworthy in this regard that other countries with even more developed systems may also use external experts when developing RIAs. But those often relate to the assessment of complex regulatory measures that require specialist input that is not available in the administration.

Review of the RIA samples suggests that when external experts are involved, they mostly work on legal drafting tasks, rather than on the RIA. Even if external experts are included, they may not achieve full, in-depth analysis of the impact of the proposal. Most external support for RIA is provided through technical assistance projects, which are not always equipped to help analyse complex regulatory proposals and their impact.

External expert input in RIA is welcome, but it is important that it not substitute for the standard tasks civil servants are expected to perform. Experts should be engaged to fill gaps in expertise and skills that cannot be performed by civil servants. The civil service has to keep control of the overall RIA process. One example of external expert involvement in RIA work was Montenegro's RIA on the Draft Law on Public Private Partnerships. This comparative analysis of international experiences and trends in the policy area developed various alternative options, which strengthened the RIA analysis.

\section{Comprehensiveness of analysis covering all regulatory measures considered}

Most of the RIA samples appeared to capture all regulatory measures considered in the draft laws, and were analysed as part of a single RIA structure and report. The coverage of most RIAs was comprehensive in that respect.

However, when a single piece of legislation includes many different policy measures and regulatory changes, it can be good practice to prepare an "overarching" or "umbrella" RIA to provide an overview of all the impacts of the legislative package. The practice of preparing "overarching" RIAs, followed by separate analyses of different regulatory measures included in the draft legislative proposal, has not yet been established in the Western Balkans.

In some policy areas, a regulatory change does not typically come into force with the adoption of the law, since the secondary legislation has yet to be adopted. This complicates the task of impact analysis. Full regulatory impact of a legislative initiative often depends on the options chosen in the drafting of the legal instrument. When secondary legislation is outside the scope of RIA, which is the case in Albania, Kosovo and North Macedonia, the risk is that significant impacts of a policy change are not properly considered and analysed in the RIA supporting the complete regulatory intervention. In this situation, it is recommended that the RIA on primary legislation summarise and present, in broad terms, the anticipated costs and benefits of the law, once the full legislative framework has been established with the necessary secondary legislation. Alternatively, a clear requirement or process for systematic analysis of secondary legislation should be introduced.

The review of RIA samples identified several such cases, as well as the risks that need to be carefully considered when deciding on the approach and scope of analysis. For example, Albania's RIA on the Draft 
Law on Financial Markets discusses other regulatory changes that are expected to be adopted to complete the regulatory framework. This includes adoption of a new Draft Law on Virtual Assets and several regulations. It is not clear, however, how those changes affect the impact analysis in this RIA. Furthermore, because Albania does not require RIA on secondary legislation, the additional impact introduced in the adoption of new regulations could potentially not be analysed at all. The final conclusion and findings in this RIA are thus incomplete. Similar examples and risks apply to many other RIA samples analysed.

Similarly, the North Macedonia's RIA on the Draft Law on Tobacco, Tobacco Products and Related Products stipulates that up to 20 pieces of secondary legislation will need to be adopted to allow for full implementation of the new legislation. These regulations are likely to create significant additional costs and burdens that are not considered or even mentioned in this RIA. Additionally, because RIA is not required on secondary legislation in North Macedonia, major regulatory impacts may not be analysed at all.

\section{Consultation with stakeholders and the public}

Nearly all RIA samples include references to public consultation and stakeholder engagement activities that were conducted for the development of the RIA and/or the related proposal. This shows that the RIA and public consultation processes are aligned and connected, at least in terms of procedures and process.

Most of the WB administrations, including Albania, Kosovo and Montenegro, have dedicated sections in their RIA templates for conducting public consultations. This is helpful in the presentation of public consultation findings and the outcomes for the decision-making process. In some WB administrations, such as Kosovo, Serbia and Montenegro, line ministries have separate procedural requirements to report on the outcome of public consultation on a separate form.

The information in the RIA reports often discusses the consultations held on the draft legislative initiatives, such as meetings, roundtable discussions or online consultations. RIA samples from Albania and BiH provided relatively less information about stakeholder consultations and discussions.

In general, the discussions of public consultation in the RIA samples concern the process, not the findings and outcome of discussions with stakeholders. For example, Montenegro's RIA on the Draft Company Law provides detailed information about the public consultation process, indicating that over 300 comments and suggestions were received. But it does not explain what those comments concerned, or whether they were incorporated in the final version of the draft law. The RIA report mentions only that the Draft Law was improved on the basis of the comments received, but does not explain how that change affected the analysis and data used in RIA.

Reporting on the results of public consultation in RIA documents is particularly useful for administrations that do not otherwise have strong systems of reporting on the outcome of public consultation and stakeholder engagement, such as Albania, BiH and Kosovo. Several good examples of analysis and presentation and use of the findings of public consultation emerged in the RIA reports. Serbia's RIA on the Draft Law on Marks provides a thorough analysis of both the process and outcome of public consultation, including various suggestions collected during consultations with comments on their potential impact. The RIA also explains clearly whether a specific suggestion was accepted, and how it affected the final design of the policy. Another good example of reporting on the outcome of public consultation was provided in the North Macedonia's Law on Lobbying. All suggestions received during public consultation were listed, with an explanation as to why certain recommendations from stakeholders were not considered in the policy design. Some of the reasons given invoked the additional, unnecessary administrative burdens likely to be created.

\section{Central quality control}

The function of quality checks of RIA reports at the final stage of the legislative drafting process is established formally in all administrations. Review of the sample RIA reports shows that the final scrutiny of RIAs is also performed in practice in most administrations. 
There appear to be some challenges with the implementation of the RIA quality scrutiny function within the $\mathrm{BiH}$ administrations. For example, based on the review of samples, it was not possible to confirm that all final draft RIA reports were checked by the relevant scrutiny body in the FBiH administration, indicating gaps in the exercise of this important function. At the BiH State level, the Ministry of Justice receives preliminary RIAs as part of the preparation of the annual legislative work plans of ministries, but no check is performed at the final stage, largely because the initial RIAs are not developed further during the drafting of law and because preparation of full RIAs has not yet been instituted.

In Montenegro, all the RIA samples had been reviewed by the quality scrutiny bodies, namely the Ministry of Finance. The focus of the scrutiny of RIA, however, was primarily on the soundness of the estimates for fiscal and business impact (including the impact on the business environment and small and medium-sized enterprises, or SMEs). This can be explained by the fact that the scrutiny body is based in the Ministry of Finance, which also establishes the scope of potential final oversight. The Ministry of Information Society and Administration (MISA) of North Macedonia and Serbia's Public Policy Secretariat (PPS) have also reviewed and issued opinions on the RIA samples, but the opinions focus primarily on the compliance and procedural aspects of the RIA process, and not the quality of analysis. However, the scrutiny body of North Macedonia has started producing negative opinions on some RIA reports from 2019, while the number of negative opinions issued by the PPS increased in the years covered by the report. There is a concern that the opinions issued by the MISA, as the RIA quality body, are not checked and considered by the relevant unit of the General Secretariat when preparing the final package for Government consideration and approval. In the case of Serbia, it appears that there has been increased scrutiny of assessment of impact on the business environment and SMEs.

In Albania, the RIA scrutiny body issues informal opinion/feedback on RIA. It is not current practice to issue a formal opinion in the current RIA regulations. This is probably explained by the institutional set-up of the RIA scrutiny body, which is based in a directorate of the Prime Minister's Office (PMO) that checks the final package submitted by the ministries for approval.

In Kosovo, because the RIA is prepared and approved early in the process, the quality check is also performed early in the process. No checks are carried out in the final stage, after the law is drafted, to ensure that the RIA document and the analysis included in it are still relevant.

The review of RIA samples and the opinions issued on their quality shows that the quality scrutiny bodies often focus not on the quality of analysis and content of RIAs, but on procedural and compliance issues. One example, in Montenegro, is the Opinion on the RIA on the Draft Law on Changes and Amendments to the Law on Copyright and Related Rights. The Ministry of Finance, the centralised RIA scrutiny body, does not raise any questions about why the analysis does not include a qualitative assessment or discussion of the potential impact on businesses.

\section{Use of EU impact assessments}

As noted previously, the RIA methodology and regulations applied in the WB administrations formally require that the same standards and rigorous analysis are applied both on domestic and on EU-originating proposals. Of the RIA samples reviewed for this study, 16 out of 50 concerned legislative proposals to transpose the acquis into domestic legislation. Only one of the 16 , however, referred to the impact assessment on the original EU law developed by the European Commission (EC). The Concept Document on Competition from Kosovo includes a reference to the outcomes of the assessment of the impact of the competition policy at the EU level, as well as to the specific EC assessment report.

This underlines the general unfamiliarity in the WB region with external sources of data and analysis that can be used to prepare and analyse EU legal harmonisation and transposition. Given the increasing demands on all WB administrations to transpose and implement the acquis, this practical shortcoming affects not just the quality of RIA but the acquis transposition itself. Despite the high-level political 
commitment and the pressure to transpose the acquis, administrations in the region do not appear to find much value in analysing fully EU-originated legislation and its potential impact.

RIAs on draft legislation that are intended to harmonise the national legislation with the acquis often fail to provide full information on the policy and regulatory change that is being introduced or the results they aim to achieve. Instead, the objective of the proposal is presented as harmonising the law with the acquis. For example, the North Macedonia's RIA on the Draft Law on Changes and Amendments to the Law on Customs Tariffs lists legal harmonisation with the EU law as the objective of the proposal but does not explain specifically what changes will be introduced as a result of the regulatory change. The Montenegro RIA on the Draft Law on Public-Private Partnership, on the other hand, discusses the policy problem under consideration and explains clearly how the proposal will help harmonise the national legislation with EU law $^{\mathrm{xxx}}$

Finally, none of the RIA samples on transposition cases refer to or use data on the experience of a current EU Member State in transposing the relevant EU directive or regulation into domestic legislation. All EU Member States have their own internal procedures and methodologies of ex ante assessment of new regulatory proposals arising from the EU. Their experience and approach to transposition could be helpful for WB administrations. The experience of Croatia and Slovenia in transposing EU directives and regulations is likely to be relevant and useful for WB administrations. One such example is Montenegro's RIA on the Draft Law on Public-Private Partnership. It appeared to provide a regional experience to addressing the problem, but it focused more on the policy approach than the experience of transposition.

\section{Publication of the final RIA reports}

As noted in the previous chapter, all WB6 administrations make the final RIA reports available online, with the exception of $\mathrm{BiH}$. This was confirmed by the review of the sample RIA reports and of the national administrations' websites. The approach to publication, however, differs.

In Serbia, RIAs are published by the PPS, the centralised RIA oversight body. The RIA is published after opinion on the quality of RIA is issued, together with other materials included in the draft legal package received from the law's proponents. In North Macedonia, RIA reports are published in the government's electronic registry of regulations (ENER). In Albania and Montenegro, RIAs are published on the Parliament websites after the legislative packages are submitted by the Government. Montenegro publishes RIA reports on the Government website.

\section{Key conclusions}

Review of RIA samples confirms that the process of RIA is now embedded in the WB administrations' policy development and decision making. Standard RIA reports and templates are consistently used, but the approach varies across the region. The RIA reports are not reviewed and updated at the different stages of the policy development cycle. External experts are consulted during preparation of RIA, but there is no significant difference in the quality of analysis of those RIA reports. Quality checks are conducted in practice, but different approaches are used, and it is not clear what impact the scrutiny has on the quality of the final RIA reports. It appears that in most administrations, even if a negative opinion is issued by the quality-control body, the RIAs are not revised before final approval of the legislative proposal. The focus of the scrutiny is on procedural issues, and only limited checks are made on the quality of the analysis and data. In Kosovo, checks on the quality of RIA are made in the early stages, and the scope of analysis may not no longer be fully relevant for the final draft law. In Montenegro, the scrutiny of RIAs by the Ministry of Finance is more focused on the fiscal and business impact. Most administrations publish RIA reports. EU and Member State IA reports are not systematically used by any of the administrations to prepare RIA reports on transposition cases. Information on public consultation and stakeholder engagement is included in RIA reports, but they mainly discuss the process of public consultation, with little information on the outcome and its use in the RIA. Many administrations do not assess the full impact of new legislation that 
will be supported by secondary legislation, given that there is no ex ante impact assessment of secondary legislation.

\subsubsection{Quality of analysis in RIA samples}

All WB administrations set very high standards for RIA analysis. In practice, however, conducting high-quality analysis of impacts of regulatory changes is demanding and requires time and resources. As noted in the previous chapter, performing high-level analysis may not be justified for all regulatory proposals, given that the analysis should be proportionate to the benefits expected from conducting RIA. Review of the RIA samples shows that in all administrations, the quality of analysis is below the expected standards set by the relevant methodologies and regulations.

\section{Problem analysis and policy objectives}

In most of the RIA samples reviewed, the analysis of the problem was found to be adequately covered and presented. In general, the quality of this section of RIA appears to be of relatively better quality than others. The policy objectives of the regulatory proposals considered in the RIA are also adequately covered in most of the RIAs reviewed.

A few good examples of problem analysis can be noted. For example, the RIA on the Draft Law on Changes and Amendments to the Law on Enforcement and Security prepared by the Serbian administration contained a detailed discussion of the problem under consideration and the supporting data. Another good problem analysis and definition was provided in the Albanian RIA on the Draft Law on Changes and Amendments to the Law on Aquaculture. In analysing the policy problem, the latest available data on the current situation and problem were identified and used. On the other hand, the sample RIA on Draft Law on Financial Markets Based on Distributed Registry Technology in Albania only discusses the context of the policy and the importance and size of the problems globally, and does not explain the problem the policy aims to address. The RIA on the Law on Private-Public Partnership prepared by Montenegro's Ministry of Finance presents a clear discussion of the problem under consideration. Among BiH administrations, RIA samples produced by the RS provide better description and analysis of policy problem. The RIA prepared by the BiH State level on the Draft Law on Changes and Amendments to the Excise Tax Law is a good example of adequate analysis of problem and policy objectives. In general, this is one of the few comprehensive RIAs prepared at the State level so far. The quality of RIA is good, with significant input from external experts.

All RIA samples from the BiH RS and Serbian administrations discuss and present policy objectives appropriately. The BiH RS RIA samples present both general and specific objectives of the relevant draft laws. For example, the BiH RS RIA on the Draft Law on Changes and Amendments to the Law on Internal Payment Transaction presents an adequately formulated general objective, as well as several specific objectives, the majority of which were measurable. Some of the Serbian RIA samples included indicators to be used to assess progress toward the set objectives. For example, Serbia's RIA on the Draft Law on Changes and Amendments to the Law on Enforcement and Security provides adequately defined policy objectives. Furthermore, it also suggests several indicators to measure the progress towards achieving the policy objectives. 
Table 3.6. Quality of analysis and discussion of selected sections of RIA (all administrations)

The weakest areas observed in the most RIA samples are highlighted in the first column.

\begin{tabular}{|c|c|c|c|c|c|}
\hline & $\begin{array}{c}\text { Comprehensive } \\
\text { [Yes] }\end{array}$ & Moderate & Minimal & $\begin{array}{l}\text { Not provided } \\
\quad[\mathrm{No}]\end{array}$ & $\begin{array}{c}\text { Not } \\
\text { applicable/not } \\
\text { relevant }\end{array}$ \\
\hline Discussion of the problem under consideration & 20 & 24 & 6 & 0 & \\
\hline Definition of policy objectives & 35 & 15 & 0 & 0 & \\
\hline $\begin{array}{l}\text { Consideration of at least one alternative option, } \\
\text { in addition to the preferred and "Do nothing" } \\
\text { options }\end{array}$ & 38 & & & 12 & \\
\hline $\begin{array}{l}\text { Discussion/justification for selecting the } \\
\text { preferred option is provided }\end{array}$ & 30 & 18 & 2 & 0 & \\
\hline Discussion of key affected groups & 18 & 22 & 7 & 3 & \\
\hline Quantification of the impact & 11 & 4 & 7 & 28 & \\
\hline $\begin{array}{l}\text { Monetisation of some costs of preferred } \\
\text { option }\end{array}$ & 11 & 4 & 1 & 34 & \\
\hline $\begin{array}{l}\text { Quality of fiscal/budgetary impact assessment } \\
\text { provided }^{*}\end{array}$ & 14 & 3 & 13 & 3 & \\
\hline $\begin{array}{l}\text { Use of at least one appraisal technique, } \\
\text { CBA, CEA or Multi-Criteria Analysis (MCA) }\end{array}$ & $\begin{array}{c}2 \\
(\mathrm{MCA})\end{array}$ & & & 48 & \\
\hline Analysis of economic impact & 6 & 19 & 13 & 9 & 3 \\
\hline $\begin{array}{l}\text { Analysis of impact on business, in particular } \\
\text { SMEs }\end{array}$ & 4 & 19 & 8 & 11 & 8 \\
\hline $\begin{array}{l}\text { Coverage of administrative burdens and } \\
\text { costs to businesses }\end{array}$ & 4 & 13 & 9 & 14 & 10 \\
\hline Analysis of social impact & 5 & 15 & 18 & 9 & 3 \\
\hline Analysis of environmental impact & 1 & 2 & 5 & 5 & 37 \\
\hline $\begin{array}{l}\text { Specific impact covered (e.g. gender, youth, } \\
\text { distributional, regional impact) }\end{array}$ & 3 & 7 & 1 & 2 & 37 \\
\hline $\begin{array}{l}\text { Discussion of implementation and enforcement } \\
\text { arrangements }\end{array}$ & 18 & 12 & 16 & 4 & \\
\hline $\begin{array}{l}\text { Discussion of potential implementation } \\
\text { risks }\end{array}$ & 1 & 6 & 19 & 24 & \\
\hline $\begin{array}{l}\text { Discussion of future evaluation and } \\
\text { post-implementation plans }\end{array}$ & 2 & 8 & 13 & 27 & \\
\hline
\end{tabular}

* Fourteen stated there will be no impact; 3 provided in FIA.

Note: Based on the review of 50 individual RIA samples and related documents, such as the draft law, as provided by the WB administrations. No interviews or verification with officials were conducted. A qualitative review of the information and data provided in each individual RIA report has been carried out. Each question or part of the RIA analysis has been categorised into four groups, based on the quality of the information and data presented: comprehensive, moderate, minimal and not provided. The weakest areas are highlighted in bold text.

Source: SIGMA analysis.

\section{Consideration of alternative options}

Analysis of RIA samples primarily focused on the preferred option. But most of the RIA samples reviewed (38 out of 50 ) considered at least one additional alternative option, in addition to the preferred and "Do nothing" options.

Of the regional administrations, Albania, North Macedonia and Serbia appear to have a more effective approach to considering alternative policy options. Most of their RIA samples discuss at least one alternative option, in addition to the preferred and "Do nothing" options. The alternative options, however, are typically not analysed in as much detail as the administration's preferred option. It is thus not possible to confirm that the preferred option is delivering the best outcome for the country. 
One good example from North Macedonia is the RIA on the Draft Law on Lobbying. Montenegro RIA samples also contained good examples of RIA that considered alternative options. The RIA on the Draft Law on the Life Partnership of the Same-Sex Couples, for example, discusses several alternatives, as well as the preferred option.

Kosovo has a good practice of systematically considering improving implementation and enforcement in the current regulatory regime as a possible solution to each problem. This is often presented and considered in RIA as an alternative option to the main regulatory choice. This systematic approach to consideration of challenges related to implementation can help strengthen the rationale for intervention through a new regulatory change. It is also important, however, to explore a wider range of options, and not only those related to enforcement.

Quite a few of the RIA samples could have considered alternative, non-regulatory options, but they did not. The BIH RS RIA on the Draft Law on Fire Protection, for example, cites as one of the main causes of the problem a lack of knowledge of the importance of fire protection measures. However, it does not consider alternative measures for strengthening capacity and raising awareness which, based on the information provided, are also a valid response for addressing the problem. Similarly, the BIH RS RIA on the Draft Law on Protection of Mental Health says that increasing the availability and quality of the existing mental health services by regulatory measures is one of the goals of the proposed policy. It does not consider any non-regulatory measures that could further the goal of protecting mental health.

\section{Options appraisal and quality of analysis of the preferred (main) option}

The quality of the analysis of policy impact, including the use of options appraisal techniques such as cost-benefit analysis (CBA), cost-effectiveness analysis (CEA) and multi-criteria analysis (MCA) is arguably the weakest aspect of RIA in the WB administrations. Even basic qualitative discussions and comparison of alternative options are not being systematically carried out in the region to support the selection of the preferred option. Most sample RIA reports provided only basic qualitative analysis of the impact of the preferred option. Limited quantification and monetisation is provided. Monetisation of impacts, particularly those of anticipated benefits, is not even attempted in most of the RIA samples.

Systematic comparison of different alternative options, at least in qualitative terms, is critical for a good RIA outcome. Of the 50 RIA samples from different WB administrations, only two RIAs attempted to analyse and compare the impact of different proposals based on an MCA approach to appraising alternative options. No RIA sample attempted to apply CBA or CEA. Both of the RIAs were prepared in Albania: the RIA on the Draft Law on Forests and RIA on the Draft Law on Changes and Amendments to the Law on Food. However, even in these cases, it appeared that the criteria used and values assigned were not clearly justified and presented. A few RIA samples provided a clear comparison of alternative options based on a simple, qualitative assessment of the impact. For example, the RIA on the Law on Lobbying of North Macedonia attempted to provide a brief analysis of the impact of both regulatory and non-regulatory options.

The quality of analysis in RIA samples varied significantly, but many similarities emerge in terms of their challenges and weaknesses. Overall, Albania and Kosovo RIA samples appear to provide relatively better analysis of impacts of the main policy options than the RIAs of other administrations. On the other hand, the quality of analysis of all RIA samples from the $\mathrm{BiH}$ administrations and Montenegro might be considered less than optimal. One Montenegrin RIA, however, on the Draft Law on Life Partnership of Same-Sex Couples provided a detailed qualitative discussion of the impact of the preferred option. The quality of RIA reports is mixed for North Macedonia and Serbia, particularly the analysis of the preferred option, both producing RIAs with strengths and weaknesses in the analysis.

For example, the BiH State level's RIA on the Draft Law on Changes and Amendments to the Law on Appointment Procedures in BIH State Institutions and its RIA on the Draft Law on the Courts do not adequately discuss the likely impact of the proposal, even though the regulatory changes being considered are likely to have a significant impact on the public sector and on citizens. Target groups of potentially 
affected stakeholders are not identified in these RIAs, and no quantification is provided. Analysis of impacts of the RIA on the Law on Amending the Customs Tariffs prepared by North Macedonia can also be considered below standard, because the RIA considers changes in the regulations and VAT rates, but includes no discussion of the potential impact of the proposal on any sector or group. The RIA report says no additional financial cost is likely to arise from the proposal. This appears to refer to the additional costs only in the state budget and is questionable, given that the changes concern tariff and tax administration. Potential costs for businesses as a result of this impact are not acknowledged at all. Similarly, the RIA on the Draft Company Law of Montenegro appears to have significant impact on businesses and public. But the RIA does not give a full analysis of the relevant impact on different stakeholders. One good example is Serbia's RIA on the Draft Law on Changes and Amendments to the Law on Enforcement and Security. This properly identified its impact and provides solid analysis to back it up. All potential impacts appear to have been identified and analysed in detail, including economic and social impacts, the impact on businesses and possible administrative burdens. The impact was monetised and the analysis properly identified the stakeholders involved.

As for quantification and monetisation of identified impact, a few RIA samples could have made more effort to provide stronger quantification and monetisation of the anticipated impact. The BiH State level RIA on the Draft Law on Right to Trial in a Reasonable Period, for example, provided quantification of the number of the trial files processed, with some other data, but failed to estimate the cost of the anticipated impact, to offer a clear overall assessment of the likely costs and benefits. Albania's RIA on the Draft Law on Changes and Amendments to the Law on Aquaculture provides quantification but does not take the next step to try to monetise costs.

Some RIA samples failed to identify and discuss social, environmental or gender impact, although it is clear from the respective draft laws that the suggested measures would have such an impact. Serbia's Draft Law on Changes and Amendments of the Law on Waters, for example, considers some measures that will clearly impact the environment. The accompanying RIA, however, neither identifies this nor gives any details about it. North Macedonia's RIA Draft Law on Tobacco, Tobacco Products and Related Products states that there will be no impacts on society and the environment from the proposed regulatory measures.

\section{Analysis of budget/fiscal impact}

Almost all the RIA samples include a short section discussing the expected impact of the preferred option on the state budget. Impact on the state budget is more likely to be discussed than the impact on business, for example. Throughout the region, reporting of fiscal impacts needs to be more systematic and integrated into the RIA to report clearly the total estimates costs and benefits for the state budget.

Review of the RIA samples suggests that reporting on the budgetary impact is more systematic only in Albania and Kosovo. Serbia and BiH do not consistently include fiscal impact estimates in the RIA reports, since they are provided in a different analysis and on a form that covers budgetary impact only (FIA). This can create confusion and limit a comprehensive assessment of the impact of policy options. It is not clear how the total costs of a proposal are summarised for final political decision making if the cost to the state budget is reported in a separate document.

Three out of five Kosovo RIA samples reviewed provide budget impact assessment of all the considered options. One good example is Kosovo's RIA report on the Concept Document in the Field of Competition. This provides a thorough analysis of the impact on the state budget of all the considered options: the preferred option, for preparing a new Law on Protection of Competition, and an alternative, non-regulatory option on developing professional capacity and skills in the national Competition Agency.

Another good example of RIA that includes a thorough fiscal assessment is the BiH State level's RIA on the Draft Law on the Changes and Amendments to the Law on Excise Tax. This is one of the few comprehensive RIA reports prepared by the WB administrations. As it is the first comprehensive RIA performed in the $\mathrm{BiH}$ State level, it benefited from substantial support from external experts. 


\section{Implementation and enforcement}

Implementation and enforcement provisions of the proposed regulatory option are covered in the majority of RIA samples, with the exception of RIAs produced by the BiH administrations. The same applies to the identification of institutions responsible for implementation, monitoring and enforcement.

The most detailed elaboration of implementation measures is provided in Kosovo RIA samples. One good example is the Kosovo RIA on the Concept Document in the Field of Competition. Generally speaking, however, discussions of implementation in Kosovo's RIA samples were chiefly in the context of improving current practice without changing the regulatory framework.

Of the sample RIA reports, the North Macedonia's RIA on Lobbying is a good example of a discussion of implementation and enforcement measures, detailing implementation and enforcement measures of both regulatory and non-regulatory options. Meanwhile, North Macedonia's RIA on the Draft Law on Changes and Amending the Law on Customs Tariffs does not contain information about the institutions responsible for implementation, monitoring and enforcement, nor any measures in this regard.

None of the administrations fully discuss risks associated with implementation and enforcement. Such issues were mentioned in two Albanian RIA samples, and in one RIA sample from each of BiH RS, Kosovo, Montenegro, North Macedonia and Serbia. The Serbian RIA on the Draft Law on Changes and Amendments to the Law on Enforcement and Security offers a good discussion of the risks of implementation.

\section{Monitoring and evaluation aspects}

The systems and methodologies on impact assessment in the Western Balkans generally acknowledge the importance of ensuring a full policy cycle and the assessment of results after implementation, in order to inform future policy debates. This is a challenging task, however, even in countries with better-developed RIA systems. Most of the RIA samples from the WB administrations do not, in practice, include an adequate discussion of monitoring arrangements, ex post implementation review plans or future evaluation approaches. This highlights the general lack of policy evaluation in the WB region, which is much weaker than ex ante impact assessment. The problem appears to be worse in the RIA systems and approaches of the $\mathrm{BiH}$ administrations.

In terms of good practice of discussing the evaluation and monitoring aspects of policy, the sample RIA on the Draft Law on Changes and Amendments to the Law on Enforcement and Security in Serbia could be mentioned. It offers a useful presentation of an approach for monitoring and post-implementation evaluation measures and indicators. The RIA clearly sets out which institution is responsible for monitoring and evaluation and which indicators will be used. North Macedonia's RIA on the Draft Law on Lobbying is a good example of a comprehensive discussion on when and how the post-implementation review will be conducted.

Albanian RIA samples consistently provide discussions of certain aspects of monitoring, post implementation and evaluation arrangements. These do not, however, always provide a full explanation of how it will be performed in practice. For example, the RIA on the Law on Financial Markets confirms that the monitoring will be carried out by the Financial Supervision Agency and the National Agency for Information Society, but does not explain which indicators and aspects of the new regulatory regime will be monitored and how and when it will start.

\section{Quality of data and information}

It is important for accurate and reliable data be used in the RIA analysis, and for open and honest discussion about gaps in the final conclusions of the analysis. The review of sample RIAs suggests that this aspect is not being consistently considered in RIA in the WB region. Several good examples and practices should however be noted. 
In general, the RIA samples from Kosovo provided relatively better discussion about the reliability of data and information used in the analysis. For example, the Concept Document on the Application for Jobs by Members of Non-Majority Communities Holding Diplomas Issued by Parallel Educational Institutions Providing Instruction in Serbian Language in Kosovo includes detailed data on the number of universities, schools and students. This is critical for analysing the policy and impacts, helping to grasp the magnitude of the problem. This RIA also explained some of the challenges of data collection and usage, as well as the limitations of the available data.

Another good example of the use of data to identify and address a problem is Montenegro's RIA on the Draft Law on the Life Partnership of the Same-Sex Couples, which estimates the lesbian, gay, bisexual, transgender and intersex (LGBTI) population and the annual number of expected same-sex life partnerships.

\section{Key conclusions}

Review of RIA samples shows that the quality of RIAs produced by WB administrations is below the standards and levels set in the relevant methodologies and formal rules. The required procedural steps of RIA appear to have been followed in all administrations, and RIAs are being systematically produced by the system, but the quality of analysis provided in RIAs varies. Significant quality variations are apparent both between and within administrations, and also in the different components of an RIA. Based on the sample review, Albania, Kosovo and Serbia appear to provide relatively better-quality analysis in their RIAs. Some examples of good RIAs are also produced by other administrations. The overall quality and depth of analysis, the involvement of stakeholders in the RIA process and the presentation of findings still lag below the official standards in all WB administrations. Identification of real alternative options and their systematic appraisal within the RIA analysis is not systematically carried out in any administration. Most often, the preferred option is justified based on qualitative discussion of impacts, but those do not always cover all possible impacts. Quantification of impacts on key stakeholders has been done in a few cases, but impacts are rarely monetised. 


\section{Chapter 4. Policy recommendations}

This chapter provides several policy recommendations to help the administrations of the Western Balkans (WB) to improve and strengthen their ex ante systems of impact assessment and achieve more informed and evidence-based EU legal harmonisation.

\section{Improving the RIA systems and implementation}

Strengthen the regulatory and methodological frameworks, streamline the existing systems and processes and provide continued support to Regulatory Impact Assessment (RIA) from senior political leadership, to ensure consistent and full implementation of RIA in all ministries.

- All WB administrations need to ensure full, consistent implementation of RIA rules and methodologies, focusing on both the process as well as the quality of individual RIAs, ensuring full and consistent analysis of all type of impacts, including impacts on gender.

- All WB administrations should provide a stronger political and senior management support to ensure more consistent, full implementation of RIA rules and standards and to increase the standards and demand better analysis and conclusions in individual RIA reports.

- All WB administrations should consider expanding the available methodologies and guidance materials, to provide more detailed, practical guidance and examples to line ministries on different steps and aspects of RIA analysis. The formal requirements for analysis that have been established need to be supplemented by more detailed explanations and practical examples on the use of analytical techniques. Exemplary RIAs should be proactively shared. RIA guidance documents in administrations that have used RIA for several years, including North Macedonia and $\mathrm{BiH} \mathrm{RS}$, need to consider updating the relevant guidance document to incorporate the experience from recent years, during which practical RIA has been in use. This would provide additional guidance in some of the more problematic areas.

- All WB administrations need to consider initiating the RIA process earlier in the policy-making cycle, e.g. by embedding formalised requirements for basic analysis in the early stages of the policy development process, before a decision to intervene through a regulatory measure is made. This can help with the policy debate on effective government intervention, in particular at the time when ministries are developing strategic reform programmes (e.g. sectoral strategies). Early initiation of RIA work can provide more time for analysis, help identify alternative, non-regulatory options and allow proper assessment of complex regulatory proposals to inform final government decision making.

- All WB administrations should ensure that RIA is seen as a continuing process and that the RIA report is regularly updated and enhanced at key stages in the preparatory and approval process. 
- $\quad$ All BiH administrations need to fully implement all RIA requirements and start systematically producing comprehensive RIAs on the most significant regulatory proposals, as envisaged in their regulations. BiH State-level administration should complete the regulatory framework with amendments to the Rules of Procedure of the Council of Ministers. This will enable full RIA implementation, establish a clear RIA process and clarify and confirm the roles and responsibilities of various institutions involved in RIA management, support and quality control, to avoid overlaps and gaps.

- Kosovo needs to consider changing its internal processes and rules to align the RIA process with the legislative drafting and decision-making process. In particular, the administration should ensure that RIAs are strengthened and developed in internal and external consultations and most importantly, during, the legal drafting, ensure that the final decision on the proposal is based on the best and most recent data and relevant analysis.

Ensure that the scope of RIA and standards of analysis for different types of RIAs are clear and established within the regulatory and methodological frameworks of the national administrations, and that ex ante analysis of relatively more significant regulatory proposals is prioritised and receives more resources and time for in-depth analysis.

- Many of the WB administrations would benefit from reviewing the scope and model of RIA, considering the available resources, workload and limitations and constraints related to the lack of analytical skills in ministries. They need to ensure that the most significant regulatory proposals receive more resources throughout the process, from initial analysis to the final quality check by the relevant scrutiny body.

- Albania, all BiH administrations, Kosovo, Montenegro and North Macedonia should consider introducing clear and practical criteria and thresholds for identifying the most significant regulatory proposals early in the policy-making process to use it for more optimal planning and allocation of resources.

- Serbia would benefit from reviewing the effectiveness of its formal thresholds and the existing filtering mechanism that allows categorisation of regulatory measures into "basic" and "full" RIAs, to assess whether the current approach is indeed working and the principle of proportional analysis works in practice.

- All WB administrations would benefit from clarifying the process used to exclude certain regulatory proposals from RIA analysis, to ensure the criteria are clear and consistently applied and do not provide unjustifiable blanket exceptions to large policy areas that may benefit from the RIA process. Decisions to exclude certain legislative proposals from RIA requirement should be transparent and clear. $\mathbf{B i H}$ administrations might wish to consider excluding draft laws on state budget from the RIA requirement as other preparatory and analytical processes are used for it.

- All WB administrations should regularly review and improve the templates used to report the analysis, findings and conclusions of individual RIA studies. The core findings and recommendations should be clearly presented on the template with an executive summary, in a standardised structure. The template should require a summary of the key findings, including the main impacts and monetised costs and benefits, shown separately from the main body of the analysis. This will facilitate final review by senior management and ministers.

- Albania, Kosovo, North Macedonia should plan to expand the scope of RIA to require systematic, proportional analysis of regulations proposed through secondary legislation. 
Ensure RIA methodology and process are aligned with other processes and tools used in the preparation of new policy proposals and inter-ministerial consultation.

- All WB administrations would benefit from reviewing their national methodologies for RIA, to make sure they are consistent with other methodologies and tools used to prepare planning and strategic documents. For example, the methodology for estimation of costs in the public sector should be consistent with the methodological guidance issued by the ministries of finance for estimating the cost to the budget. Annual and multi-annual cost and revenue projections for a specific new policy presented in RIA must be consistent with the financial allocations provided for that area in the budget and in the medium-term expenditure framework.

- All WB administrations should ensure that total societal costs and benefits of the proposal are clearly described, summarised and presented in the RIA report, regardless of whether separate statements are used to report budgetary impact assessments (e.g. fiscal or budgetary impact assessment forms). This will ensure that all impacts related to the proposals, including any impact on the state budget, are considered and assessed systematically as part of a single document.

- All WB administrations should make additional efforts to integrate RIA fully in the policy-making process. Very often RIA is an add-on task completed at the end of the process.

Strengthen the organisation of internal ministerial work on RIA within and between line ministries; ensure effective central support and management of the RIA process, and support regular programmes for capacity building.

- All WB administrations need to strengthen internal capacity and working arrangements for organising RIA work and co-operation within and between line ministries, including sharing information, specialist knowledge and data. RIA should be actively used to facilitate policy co-ordination and inter-ministerial consultation, to better understand the full impact of the policy.

- All WB administrations should increase their internal capacity for supporting the development of RIAs, either through RIA support units or designated ministry officials. These units or officials should become a source of specialist information and methodological advice for conducting analysis in the department and serve as contact points for the central RIA management bodies for regular monitoring and reporting on RIA implementation.

- Albania, BiH State, FBiH and BiH BD administrations, Kosovo and Serbia should consider introducing formal requirements for ministers, deputy ministers or senior ministry officials to review and sign off on the final draft RIA report, to confirm the accuracy and robustness of the analysis and data before it is submitted to the Government.

- Central RIA management units in all WB administrations should offer pro-active guidance and support on procedural and methodological aspects of individual RIAs.

\section{Ensure continuous training and capacity development in ministries}

- All WB administrations should ensure that regular training on policy making and RIA be made available to ministry officials as part of the standard training curriculum for civil servants. All civil servants involved in policy design and development should undergo regular training on RIA. 
- All WB administrations need to ensure that the training provided meets actual training needs. The content of training programmes should be designed and updated based on regular analysis of the main weaknesses in the quality of RIAs.

- All WB administrations should establish formal or informal networks or groups of RIA practitioners to encourage the exchange of information, knowledge and expertise and enhance co-operation between line ministries.

- All WB administrations should consider enhancing their capacity for conducting analytical studies and complex analysis for RIA. For example, they might consider establishing a community of practice or a professional network of experts in the civil service, made up of analysts and economists working on RIAs, to encourage the sharing of knowledge and expertise. Special targeted training courses and specialist resources can be provided for these groups, to enhance their knowledge and skills on more technical and analytical topics, such as the application of cost-benefit analysis and other appraisal techniques, RIA methodology and specialist guidance.

Strengthen the mandate and capacity of RIA oversight and quality-control bodies and the methodology for the final quality check

- $\quad$ All WB administrations should ensure that the oversight bodies that check the quality of draft RIA reports have adequate resources. They should also have the ability to conduct checks both on compliance with RIA procedures and the content and quality of analysis and conclusions presented in the draft RIA reports, before they are submitted to government for final approval. Opinions on individual RIAs should also provide concrete recommendations and practical suggestions for further improvement.

- The centre of government $(\mathrm{CoG})$ institutions responsible for checking the final package of draft legislative proposals and supporting documents (e.g. the general secretariats) in all WB administrations should consistently check the final RIA report and the opinion issued by the quality-control body, to ensure that the final version addresses the major concerns and recommendations.

- All WB administrations should develop or enhance their methodologies and processes for quality oversight, to ensure that all draft RIA reports are reviewed consistently, based on a set of objective standards and criteria. A risk-based system of final scrutiny of RIA could be set up. This would allow internal resources of the oversight body to focus on measures that are novel or contentious and those expected to have the greatest impact and/or to be of less than optimal quality.

- Albania should consider strengthening the mandate of the RIA oversight body and formalise the scrutiny process by issuing formal opinions on the quality of draft RIA reports. This would replace the current practice of providing informal feedback only.

- The relevant administrations in $\mathrm{BiH}$, particularly those at the BiH State level and $\mathrm{FBiH}$, should clarify the process and criteria for regular, consistent checks on the final draft RIA reports by the relevant CoG oversight body and establish the procedures in practice.

Ensure accountability of the RIA process through openness, transparency and systematic publication of RIA reports on a central government website

- All WB administrations should ensure that draft and final RIA reports and the opinions issued by the quality-control body are systematically published at key stages of policy development, e.g. that RIA reports are published for public consultation along with the draft legal act that they accompany. RIA reports should be updated and finalised after the enactment stage, to reflect on any changes in policy that take place at the parliament. 
- All WB administrations should consider developing a central government website to publish final RIAs and provide access to the relevant methodologies and guidance documents. The website can also provide full information about the government "Better Regulation" policy and other related programmes (e.g. regulatory management, simplification programmes).

- Kosovo, North Macedonia and BiH (for all RIAs) should ensure that the final RIA reports and related documents are officially submitted to the Parliament as part of the package of documents supporting the draft legislative proposal. Parliamentarians should have full access to the underlying analysis supporting legislative proposals of government.

- All WB administrations need to consider promoting the use of RIA in parliaments, to increase the quality of draft legislative initiatives of individual members and proposals for substantial amendments to draft laws developed by the government. The parliamentary rules of procedure should stipulate that bills initiated by individual members of parliament should comply with requirements for impact assessment, similar to those applied by the executive when preparing draft laws.

Ensure regular monitoring, review and evaluation of RIA systems and practices and initiate changes and improvements as part of a central government reform programme or strategy

- All WB administrations should introduce regular monitoring and reporting on the effectiveness of their RIA system. This should be based on a set of indicators to help assess the consistency and quality of RIAs and their overall impact on the quality of legislation (e.g. the number and share of RIAs produced, compared to the total volume of draft legislation; number and share of positive and negative opinions by different ministries; key challenges related to the quality of RIAs). Administrations should ensure that regular reports on RIA systems are published, on at least an annual basis.

- All WB administrations need to ensure effective co-ordination of RIA reforms with other changes and reforms initiated in the policy-making system and public administration. This particularly relates to adjustments in the national systems of policy planning, fiscal impact analysis and financial planning, public consultation, ex post evaluation and service delivery, simplification and reduction of administrative burdens.

- Building on the existing RIA systems, the WB administrations should consider developing a holistic programme or approach to regulatory policy management, better regulation and simplification of administrative procedures. RIA systems and methodology should be used to set up mechanisms to reduce the administrative burden and the cost of new regulatory proposals, and to help administrations develop and run separate programmes aimed at regulatory simplification and reducing administrative burdens.

- All WB administrations should make plans for strengthening their capacity for monitoring and ex post review and evaluation of policies. These efforts should be fully aligned with the existing processes and practices of ex ante impact analysis and will complete the policy cycle. 


\section{Improving the quality of the EU legal harmonisation}

\section{Enhance national regulations and methodologies for EU integration planning, requiring consistent use of analysis and evidence at all phases of EU law harmonisation.}

- $\quad$ All WB administrations should use their RIA systems and methodologies and internal capacity better, to inform the preparation, prioritisation, planning and implementation of EU legal harmonisation. Administrations should introduce changes in existing procedures to identify and analyse the most significant new regulatory changes arising from EU legal harmonisation commitments early in the process. Analysis should be conducted using the existing RIA methodology and processes. Initiating RIA early on can help gather valuable information and analytical evidence for realistic planning and sequencing of EU transposition work, leading to better implementation and enforcement.

- All WB administrations should ensure that EU transposition plans are fully aligned with implementation capacity and with other government planning documents, such as annual legislative plans and fiscal plans.

- The relevant regulations and methodologies on RIA in all WB administrations should provide full guidance on the specifics for analysing the impact and risks of legal measures to harmonise domestic legislation with the acquis. The methodologies and processes used to develop and regularly update the national plans for EU law transposition should also acknowledge the existing requirements and standards for ex ante assessment of new regulatory proposals and provide additional guidance to ministries to make sure they are taken into account in preparing their legislative transposition plans.

- All WB administrations should enhance their guidance on the process of EU transposition planning, particularly on costing. The existing methodologies on preparation of the National Plans for Adoption of the Acquis (NPAA) should be expanded to provide clear guidance on costing individual measures and the use of RIA methodology to identify and analyse the most significant regulations early in the process. The guidance should differentiate the cost estimates of preparation and the adoption of legal instruments from the wider costs and impact of new policies and regulations, including on business and economy. RIA methodologies can be used to provide systematic assessment of the impact at an early stage in the process. Stronger central checks are needed to verify the estimates of the costs of transposition measures provided by ministries.

- Albania and North Macedonia, as countries starting formal negotiations on different chapters, should consider strengthening the existing EU co-ordination and planning mechanisms and guidance and ensure systematic use of RIA to inform the preparation of negotiation positions, and future negotiations, focusing on the most complex regulatory areas first. Serbia and Montenegro should also consider using RIA to inform their negotiations with the EU on individual regulatory proposals and for possible revision of their original negotiation positions on various regulatory areas covered by the acquis.

- The relevant EU co-ordination and planning structures in all WB administrations should systematically check the existence of initial draft RIA reports to assess the quality and level of preparedness for transposition and implementation of the most complex regulations. This can help minimise the risks of weak or unrealistic transposition planning or partial implementation and enforcement at later stages.

- RIA central management and support units, as well as institutions responsible for EU legal harmonisation in all WB administrations, should promote the use of impact assessments (IAs) prepared by the EC and the EU Member States on the Directives and regulations being transposed, as important background documents. 
These IAs are a valuable source of additional information and guidance that can help convey the scope and magnitude of potential regulatory impacts during EU transposition and implementation.

- All WB administrations should ensure that existing rules and quality standards of lawmaking and policy analysis actively contribute to the high-level national goal of EU integration. The political leadership should encourage the culture of the public administration to appreciate the benefits of application and use of RIA and other analytical tools in lawmaking.

- All WB administrations will benefit from developing a set of core principles for preparing and planning EU legal harmonisation, to achieve better outcomes. These principles might include commitments to:

- avoid "gold-plating" (going beyond the minimum EU requirements) to minimise unnecessary burdens and costs on the national economy;

- consider fully all possible impacts and risks of EU law transposition when preparing the relevant national legislation;

- consider carefully the timing and alternative options of transposition (where possible) to ensure that domestic businesses are not put at a disadvantage in the EU market unnecessarily early in the integration process.

- identify the best legal drafting and transposition techniques for each individual case, including direct "copy-out", which can minimise the risks of "gold plating".

- develop mechanisms of regular review, monitoring and evaluation of new regulations after adoption to ensure full implementation and enforcement; and where relevant and possible, consider using "sunset" clauses for automatic expiry of regulations. 


\section{Annex A. List of individual RIA reports analysed}

As part of the study, 50 sample RIA reports and supporting documents were analysed to inform the preparation of Chapter 3. The analysis included four to six RIA samples from each administration prepared in 2019 and 2020.

Table 1. Full list of individual RIA reports analysed

\begin{tabular}{|c|c|c|c|c|}
\hline & Administration & Year & Lead ministry & $\begin{array}{c}\text { Is it a new law or amendments } \\
\text { to an existing law? }\end{array}$ \\
\hline $\begin{array}{l}\text { RIA on the Draft Law on Changes and } \\
\text { Amendments to the Law on Aquaculture }\end{array}$ & Albania & 2019 & $\begin{array}{l}\text { Ministry of Agriculture and } \\
\text { Rural Development }\end{array}$ & Amendments \\
\hline $\begin{array}{l}\text { RIA on the Draft Law on Changes and } \\
\text { Amendments to the Law on Foreign } \\
\text { Citizens }\end{array}$ & Albania & 2019 & $\begin{array}{l}\text { Ministry of Interior/ } \\
\text { Ministry of Finance and } \\
\text { Economy; Ministry for Europe } \\
\text { and Foreign Affairs }\end{array}$ & Amendments \\
\hline RIA on the Draft Law on Forests & Albania & 2019 & $\begin{array}{l}\text { Ministry of Tourism and } \\
\text { Environment }\end{array}$ & New law \\
\hline $\begin{array}{l}\text { RIA on the Draft Law on Changes and } \\
\text { Amendments to the Law on Food }\end{array}$ & Albania & 2019 & $\begin{array}{l}\text { Ministry of Agriculture and } \\
\text { Rural Development }\end{array}$ & Amendments \\
\hline $\begin{array}{l}\text { RIA on the Draft Law on the Treatment } \\
\text { with Transitional payment for Seniority of } \\
\text { Service of the Employees of the State } \\
\text { Police, the Republic Guard and the } \\
\text { Service for Internal Affairs and } \\
\text { Complaints in the Ministry of Interior }\end{array}$ & Albania & 2019 & Ministry of Internal Affairs & New law \\
\hline $\begin{array}{l}\text { RIA on Draft Law on Financial Markets } \\
\text { Based on Distributed Ledger } \\
\text { Technology }\end{array}$ & Albania & 2019 & $\begin{array}{l}\text { Ministry of Finance and } \\
\text { Economy }\end{array}$ & New law \\
\hline $\begin{array}{l}\text { RIA on the Draft Law Changes and } \\
\text { Amendments to the Excise Law }\end{array}$ & BiH State & 2018 & Indirect Taxation Authority & Amendments \\
\hline $\begin{array}{l}\text { RIA on the Draft Law on Changes and } \\
\text { Amendments to the Law on Appointment } \\
\text { Procedures in BIH Institutions }\end{array}$ & BiH State & 2019 & Ministry of Justice & Amendments \\
\hline $\begin{array}{l}\text { RIA on the Draft Law on the Courts of } \\
\text { BiH }\end{array}$ & BiH State & 2019 & Ministry of Justice & New law \\
\hline $\begin{array}{l}\text { RIA on the Draft Law on Changes and } \\
\text { Amendments to the Law on Free Access } \\
\text { to Information }\end{array}$ & BiH State & 2019 & Ministry of Justice & Amendments \\
\hline $\begin{array}{l}\text { RIA on the Draft Law on Management of } \\
\text { Property Acquired by Criminal Act }\end{array}$ & BiH State & 2019 & Ministry of Justice & New law \\
\hline $\begin{array}{l}\text { RIA on the Draft Law on Air Protection } \\
\text { Explanatory Note }\end{array}$ & $\mathrm{FBiH}$ & 2019 & $\begin{array}{c}\text { Ministry of Environment and } \\
\text { Tourism }\end{array}$ & New law \\
\hline $\begin{array}{l}\text { RIA on the Draft Law on Single Register } \\
\text { on Taxes and Fees }\end{array}$ & $\mathrm{FBiH}$ & 2019 & Ministry of Finance & New law \\
\hline RIA on the Draft Interest Rate Law & $\mathrm{FBiH}$ & 2019 & Ministry of Finance & New law \\
\hline $\begin{array}{l}\text { RIA on the Draft Law on Changes and } \\
\text { Amendments to the Corporate Tax Law }\end{array}$ & $\mathrm{FBiH}$ & 2020 & Ministry of Finance & Amendments \\
\hline $\begin{array}{l}\text { RIA on Legislation on Strategic Planning } \\
\text { and Management of Development in the } \\
\text { RS }\end{array}$ & $\mathrm{BiH}$ RS & 2020 & $\begin{array}{l}\text { Ministry of Economy and } \\
\text { Entrepreneurship }\end{array}$ & New law \\
\hline
\end{tabular}




\begin{tabular}{|c|c|c|c|c|}
\hline & Administration & Year & Lead ministry & $\begin{array}{c}\text { Is it a new law or amendments } \\
\text { to an existing law? }\end{array}$ \\
\hline RIA on the Draft Law on Fire Protection & $\mathrm{BiH}$ RS & 2019 & Ministry of the Interior & New law \\
\hline $\begin{array}{l}\text { RIA on the Draft Law Changes and } \\
\text { Amendments to the Law on Internal } \\
\text { Payment Transaction }\end{array}$ & $\mathrm{BiH}$ RS & 2019 & Ministry of Finance & Amendments \\
\hline $\begin{array}{l}\text { RIA on the Draft Law on Liquidation } \\
\text { Procedure }\end{array}$ & $\mathrm{BiH}$ RS & 2019 & Ministry of Justice & New law \\
\hline $\begin{array}{l}\text { RIA on the Draft Law Changes and } \\
\text { Amendments to the Law on Protection } \\
\text { and Treatment of Children }\end{array}$ & $\mathrm{BiH}$ RS & 2019 & Ministry of Justice & Amendments \\
\hline $\begin{array}{l}\text { RIA on the Draft Law on Protection of } \\
\text { Mental Health }\end{array}$ & $\mathrm{BiH}$ RS & 2019 & $\begin{array}{l}\text { Ministry of Health and Social } \\
\text { Welfare }\end{array}$ & New law \\
\hline RIA on the Draft Law on the Budget & $\mathrm{BiH} \mathrm{BD}$ & 2019 & Finance Directorate & New \\
\hline $\begin{array}{l}\text { RIA on the Draft Law Changes and } \\
\text { Amendments to the Law on Police }\end{array}$ & $\mathrm{BiH} \mathrm{BD}$ & 2019 & Brčko District Police & Amendments \\
\hline $\begin{array}{l}\text { RIA on the Draft Law on Changes } \\
\text { Amendments to the Law on Social } \\
\text { Protection }\end{array}$ & $\mathrm{BiH} \mathrm{BD}$ & 2019 & $\begin{array}{l}\text { Department of Health and } \\
\text { Other Services }\end{array}$ & Amendments \\
\hline $\begin{array}{l}\text { RIA on the Draft Law Changes and } \\
\text { Amendments to the Law on Catering } \\
\text { Activity }\end{array}$ & $\mathrm{BiH} \mathrm{BD}$ & 2019 & $\begin{array}{l}\text { Department for Economic } \\
\text { Development, Sports and } \\
\text { Culture }\end{array}$ & Amendments \\
\hline $\begin{array}{l}\text { RIA on the Draft Law on Takeovers of } \\
\text { Joint Stock Companies }\end{array}$ & $\mathrm{BiH} \mathrm{BD}$ & 2018 & $\begin{array}{l}\text { Securities Commission of the } \\
\text { Brčko District of BiH }\end{array}$ & New law \\
\hline RIA on the Draft Law on E-Government & Montenegro & 2019 & $\begin{array}{l}\text { Ministry of Public } \\
\text { Administration }\end{array}$ & New law \\
\hline $\begin{array}{l}\text { RIA on the Draft Law Changes and } \\
\text { Amendments to the Law on Copyright } \\
\text { and Related Rights }\end{array}$ & Montenegro & 2019 & Ministry of Economy & Amendments \\
\hline $\begin{array}{l}\text { RIA on the Draft Law Public Private } \\
\text { Partnership }\end{array}$ & Montenegro & 2019 & Ministry of Finance & New law \\
\hline $\begin{array}{l}\text { RIA on the Draft Law on Ionising } \\
\text { Radiation Protection, Radiation and } \\
\text { Nuclear Safety and Security }\end{array}$ & Montenegro & 2019 & $\begin{array}{l}\text { Ministry of Sustainable } \\
\text { Development and Tourism }\end{array}$ & New law \\
\hline RIA on the Draft Company Law & Montenegro & 2019 & Ministry of Economy & New law \\
\hline $\begin{array}{l}\text { RIA on the Draft Law on Life Partnership } \\
\text { of Same-Sex Couples }\end{array}$ & Montenegro & 2018 & $\begin{array}{l}\text { Ministry of Human and } \\
\text { Minority Rights }\end{array}$ & New Law \\
\hline $\begin{array}{l}\text { RIA on the Draft Law on Social } \\
\text { Protection }\end{array}$ & $\begin{array}{c}\text { North } \\
\text { Macedonia }\end{array}$ & 2018 & $\begin{array}{l}\text { Ministry of Labour and Social } \\
\text { Policy }\end{array}$ & New law \\
\hline RIA on the Draft Law on Lobbying & $\begin{array}{c}\text { North } \\
\text { Macedonia }\end{array}$ & 2019 & Ministry of Justice & New Law \\
\hline $\begin{array}{l}\text { RIA on the Draft Law Changes and } \\
\text { Amending to the Law on Trade } \\
\text { Companies }\end{array}$ & $\begin{array}{c}\text { North } \\
\text { Macedonia }\end{array}$ & 2019 & Ministry of Economy & Amendments \\
\hline $\begin{array}{l}\text { RIA on the Draft Law on Free Access to } \\
\text { Information of Public Importance }\end{array}$ & $\begin{array}{c}\text { North } \\
\text { Macedonia }\end{array}$ & 2018 & Ministry of Justice & New law \\
\hline $\begin{array}{l}\text { RIA on the Draft Law on Tobacco, } \\
\text { Tobacco Products and Related Products }\end{array}$ & $\begin{array}{c}\text { North } \\
\text { Macedonia }\end{array}$ & 2018 & $\begin{array}{l}\text { Ministry of Agriculture, } \\
\text { Forestry and Water Economy }\end{array}$ & New Law \\
\hline $\begin{array}{l}\text { RIA on the Draft Law on Changes and } \\
\text { Amending the Laws on Customs Tariffs }\end{array}$ & $\begin{array}{c}\text { North } \\
\text { Macedonia }\end{array}$ & 2018 & Ministry of Finance & Amendments \\
\hline $\begin{array}{l}\text { Concept Document (CD) for application } \\
\text { for jobs by members of non-majority of } \\
\text { communities holding diplomas issued by } \\
\text { parallel educational institutions providing } \\
\text { instruction in the Serbian language in the } \\
\text { Republic of Kosovo }\end{array}$ & Kosovo & 2019 & $\begin{array}{l}\text { Ministry of Education, Science } \\
\text { and Technology }\end{array}$ & Concept Document \\
\hline CD for the Kosovo Accreditation Agency & Kosovo & 2019 & $\begin{array}{l}\text { Ministry of Education, Science } \\
\text { and Technology }\end{array}$ & Concept Document \\
\hline
\end{tabular}




\begin{tabular}{l|c|c|c|c}
\hline KD on Administration of Condominiums & Kosovo & 2018 & $\begin{array}{c}\text { Lead ministry } \\
\text { Ministry of Environment and } \\
\text { Spatial Planning }\end{array}$ & $\begin{array}{c}\text { Is it a new law or amendments } \\
\text { to an existing law? }\end{array}$ \\
\hline $\begin{array}{l}\text { CD on Information Systems and } \\
\text { Networks Security Measures }\end{array}$ & Kosovo & 2019 & Ministry of Economy & Concept Document \\
\hline CD on Competition & Kosovo & 2019 & Ministry of Trade and Industry & Concept Document \\
\hline $\begin{array}{l}\text { RIA on the Draft Law on Changes and } \\
\text { Amendments to the Law on Enforcement } \\
\text { and Security }\end{array}$ & Serbia & 2019 & Ministry of Justice & Amendments \\
\hline $\begin{array}{l}\text { RIA on the Draft Law on Changes and } \\
\text { Amendments of the Law on Fulfilment of } \\
\text { Financial Obligations in Commercial } \\
\text { Transactions }\end{array}$ & Serbia & 2019 & Ministry of Finance & Amendments \\
\hline $\begin{array}{l}\text { RIA on the Draft Law on Marks } \\
\text { RIA on the Draft Law on Metrology }\end{array}$ & Serbia & 2019 & $\begin{array}{c}\text { Ministry of Education, Science } \\
\text { and Technological } \\
\text { Development }\end{array}$ & New law \\
\hline $\begin{array}{l}\text { RIA on the Draft law on Changes and } \\
\text { Amendments of the Law on Planning } \\
\text { and Construction }\end{array}$ & Serbia & 2019 & $\begin{array}{c}\text { Ministry of Construction, } \\
\text { Transport and Infrastructure }\end{array}$ & Amendments \\
\hline $\begin{array}{l}\text { RIA on the Draft law on Changes and } \\
\text { Amendments of the Law on Waters }\end{array}$ & Serbia & 2019 & $\begin{array}{l}\text { Ministry of Agriculture, } \\
\text { Forestry and Water } \\
\text { Management }\end{array}$ & Amendments \\
\hline
\end{tabular}




\section{The SIGMA Programme}

SIGMA (Support for Improvement in Governance and Management) is a joint initiative of the OECD and the European Union (EU), principally financed by the EU. SIGMA has been working with partner countries on strengthening public governance systems and public administration capacities since 1992.

In partnership with the European Commission (EC) Directorate-General for Neighbourhood and Enlargement Negotiations (DG NEAR), we currently work with:

- Albania, Bosnia and Herzegovina, Kosovo*, Montenegro, North Macedonia, Serbia and Turkey as EU candidate countries and potential candidates; and

- Algeria, Armenia, Azerbaijan, Belarus, Egypt, Georgia, Jordan, Lebanon, Moldova, Morocco, Palestinian Authority ${ }^{1}$, Tunisia and Ukraine as EU Neighbourhood countries.

SIGMA provides assistance in six key areas:

1. Strategic framework of public administration reform

2. Policy development and co-ordination

3. Public service and human resource management

4. Accountability

5. Service delivery

6. Public financial management, public procurement and external audit.

SIGMA reviews and gives feedback on:

- Governance systems and institutions

- Legal frameworks

- Reform strategies and action plans

- Progress in reform implementation.

SIGMA provides:

- Advice on the design and prioritisation of reforms

- Methodologies and tools to support implementation

- Recommendations for improving laws and administrative arrangements

- Opportunities to share good practice from a wide range of countries, including regional events

- Policy papers and multi-country comparative studies.

For further information on SIGMA, consult our website:

www.sigmaweb.org

\section{() OECD 2021}

As SIGMA is part of the OECD, the same conditions of use apply to its publications: http://www.oecd.org/termsandconditions.

This designation is without prejudice to positions on status, and is in line with United Nations Security Council Resolution 1244/99 and the Advisory Opinion of the International Court of Justice on Kosovo's declaration of independence.

1 Footnote by the European External Action Service and the European Commission: this designation shall not be construed as recognition of a State of Palestine and is without prejudice to the individual positions of the European Union Member States on this issue. 


\section{Notes}

' OECD (2020), Regulatory Impact Assessment, OECD Best Practice Principles for Regulatory Policy, OECD Publishing, Paris, https://doi.org/10.1787/7a9638cb-en.

ii Ibidem.

iii OECD 2020, Regulatory Policy and the COVID-19 Crisis, OECD, viewed 25 January 2021, https://www.oecd.org/regreform/regulatory-policy/reg-covid-19-activities.htm.

iv OECD (2019), Better Regulation Practices across the European Union, OECD Publishing, Paris, https://doi.org/10.1787/9789264311732-en.

v Official Journal of the European Union (2012), Consolidated version of the Treaty on

European Union C326/1, 26 October 2012, https://eur-lex.europa.eu/legalcontent/EN/TXT/?uri=CELEX\%3A12012M004.

vi European Union: Council of the European Union, Presidency Conclusions Copenhagen, 2122 June 1993, 180/1/93, https://www.consilium.europa.eu/media/21225/72921.pdf.

vii European Union: Council of the European Union, Presidency Conclusions Madrid, 15-16 December 1995, 12/95, https://www.europarl.europa.eu/summits/mad1 en.htm.

viii Ibidem.

ix Albania (2018), The Rules of Procedure of the Council of Ministers of Albania (Amendments).

× $\mathrm{BiH}$ (2017), The Uniform Rules for Legislative Drafting.

${ }^{x i} \mathrm{FBiH}$ (2014), Decree on Regulatory Impact Assessment Procedure (Official Gazette of FBiH, $55 / 2014)$.

xii BiH RS (2019), The Rules of Procedure of Government; Decision on Implementing Regulatory Impact Assessment in the Legislative Drafting Procedure (Official Gazette of RS, No. 21/19).

xiii Kosovo (2012), The Rules of Procedure, Part IV.

xiv Montenegro (2012), The Rules of Procedure of the Government, Articles 33 and 40.

xv North Macedonia (2013), Government Rules of Procedure (Amendments adopted on 1 May 2015, in particular Articles 8, 20, 66, 67 and 68). 
xvi Serbia (2018), Law on the Planning System of Serbia (Official Gazette, No. 30/2018); RoP of Government (Official Gazette, No. 61/2006 - clean, 69/2008, 88/2009, 33/2010, 69/2010, 20/2011, 37/2011, 30/2013, 76/2014 and 2/2019); Decree on the Methodology of Public Policy Management, Impact Assessment of Public Policies and Legislation, and the Content of Individual Public Policy Documents (Official Gazette, No. 8/2019).

xvii OECD (2018), "Case Studies of RegWatchEurope regulatory oversight bodies and of the European Union Regulatory Scrutiny Board", OECD, Paris https://www.oecd.org/gov/regulatorypolicy/regulatory-oversight-bodies-2018.htm.

xviii Directorate for European Integration Sarajevo (2020) Smjernice za usklađivanje propisa Bosne i Hercegovine s pravnom tečevinom Evropske unije, Oxygen, Sarajevo

https://www.dei.gov.ba/uploads/documents/smjernice-za-uskladivanje-propisa-bih-s-pravnomtecevinom-evropske-unije 1606812865.pdf.

xix Kosovo (2015), Administrative Instruction (GRK) No.03/2015 on Budget Impact Assessment For New Government Initiatives https://gzk.rks-gov.net/ActDetail.aspx?ActlD=10099.

xx North Macedonia (2006), Procedural Manual for Approximation of Legislation and Guidelines for Revisions of the NPAA (revised in 2014).

${ }^{x \times i} \mathrm{BiH}$ State, Brief guidelines for conducting RIA in the process of EU integration.

xxii BiH RS, Methodological Guidance for Conducting RIA.

xxiii Kosovo (2018), Guidelines and Manual for Developing Concept Documents, Tool 15; Kosovo (2014), Practical Guidelines for Legal Approximation of the Legislation of the Republic of Kosovo with the Legislation of the European Union.

xxiv North Macedonia, Manual for Conducting RIA and Manual for transposition of the EU acquis.

xxv Serbia, Manual for Conducting RIA, Instruction for Conducting RIA.

xxvi Kosovo, Guidelines and manual for developing Concept Documents, Tool 15.

xxvii Kosovo, Regulation on the Rules of Procedure of the Government of the Republic of Kosovo No. 09/2011 (Articles 7, 35 and 36).

xxviii Kosovo, GIZ (2014) Practical Guidelines for Legal Approximation of the Legislation of the Republic of Kosovo with the Legislation of the European Union, http://meiks.net/repository/docs/practical guidelines for legal aproximation.pdf.

xxix Montenegro (2009), Information on introducing the statement on the compatibility of Montenegrin legislation with the corresponding legislation of the European Union with the conformity table.

xxx Directive 2014/23/ EU of the European Parliament and of the Council, 26 February 2014 https://eur-lex.europa.eu/legal-content/EN/TXT/?uri=celex:32014L0023. 